\title{
sPeuplierungı als merkantilistisches Instrument: Privilegierung von Einwanderern und staatlich gelenkte Ansiedlungen
}

\section{Merkantilismus und Kameralismus in Deutschland}

Die Perzeption von Migration durch Fürsten und Staaten war stets mitgeprägt von sich verändernden Diskursen. Ob Migranten als unerwünscht abgelehnt oder als Bereicherung willkommen geheißen wurden, hing nicht zuletzt auch von der Selbstwahrnehmung des aufnehmenden Staates, seinen politischen Zielsetzungen und den grundlegenden Konzeptionen und Vorstellungen von einer funktionierenden Gesellschaft ab. Im Deutschland des 17. und 18. Jahrhunderts erwiesen sich insbesondere die wirtschaftspolitischen Leitvorstellungen, die man trotz ihrer Diversität unter den Begriffen `Merkantilismus` oder ১Kameralismus`zusammenfassen kann, als ausgesprochen förderlich für eine staatliche Migrationspolitik. Zwar lösten die wirtschaftspolitischen Maximen nicht übergangslos und vollständig die Konzepte konfessioneller Homogenität ab, wie die zahlreichen konfessionspolitischen Repressionsmaßnahmen und Ausweisungen bis ins 19. Jahrhundert hinein deutlich machen, doch bildeten sie in vielen Fällen ein Gegengewicht und eine Möglichkeit der Überwindung konfessioneller Einheitsideale.

Die Begriffe >Merkantilismus` und `Kameralismus` stehen für eine Vielzahl durchaus unterschiedlicher Theorien und Rezepte in der praktischen Wirtschaftspolitik und Staatsführung, wie sie in der zweiten Hälfte des 17. Jahrhunderts vorherrschend wurden. ${ }^{1}$ Ähnlich wie beim eng damit zusammenhängenden Begriff des >Absolutismus` handelt es sich beim `Merkantilismus` um eine Negativprägung, die aus der Rückschau erfolgte, und zwar durch den schottischen Philosophen und Vordenker des Liberalismus Adam Smith (>An Inquiry into the Nature and Causes of

\footnotetext{
1 Dazu einführend z.B. Rainer Gömmel, Die Entwicklung der Wirtschaft im Zeitalter des Merkantilismus 1620-1800, München 1998; Friedrich-Wilhelm Henning, Handbuch der Wirtschafts- und Sozialgeschichte Deutschlands, 3 Bde., Paderborn 1991-2003, hier Bd. 1, S. 756-783; Fritz Blaich, Die Epoche des Merkantilismus, Wiesbaden 1973; Hans-Werner Holub, Eine Einführung in die Geschichte des ökonomischen Denkens, 4 Bde., Münster/Wien 2005-2007, hier Bd. 2; Thomas Sokoll, Kameralismus, in: Friedrich Jäger (Hg.), Enzyklopädie der Neuzeit, Bd. 6, Stuttgart 2007, Sp. 290-299; sowie die Beiträge bei Moritz Isenmann (Hg.), Merkantilismus. Wiederaufnahme einer Debatte, Stuttgart 2014. Grundlegend immer noch Eli F. Heckscher, Der Merkantilismus, 2 Bde., Jena 1932.
} 
the Wealth of Nations`, 1776). ${ }^{2}$ Und ähnlich wie beim Absolutismusbegriff folgte in Deutschland eine positive Umbildung, insbesondere durch Gustav von Schmoller. ${ }^{3}$ Dennoch ist dem Merkantilismus in der neueren Forschung bislang eine mit dem >Absolutismus` vergleichbare Dekonstruktion erspart geblieben.

Vereinfacht dargestellt bezeichnet >Merkantilismus` eine zumeist auf Handel und Gewerbe ausgerichtete Wirtschaftsauffassung, die von der prinzipiellen Begrenztheit der monetären und natürlichen Ressourcen ausging und somit bemüht war, Geld und Rohstoffe möglichst im Land zu halten und auf Kosten der konkurrierenden Mächte zu vermehren. Exportiert werden sollten vor allem Fertigprodukte, die im Gegenzug Geld beziehungsweise Edelmetall ins Land brachten. Der Merkantilismus war dabei ganz deutlich staatswirtschaftlich geprägt, das heißt sein Ziel lag vornehmlich in der Mobilisierung aller Ressourcen für Staatszwecke - eine Tendenz, die durch die Aufklärung noch verstärkt wurde. ${ }^{4}$ Für die deutschen Territorien nach dem Dreißigjährigen Krieg hat sich der Begriff >Kameralismus` eingebürgert, der sich von der landesherrlichen Kammer herleitet. ১Kameralismus` verweist auf ein ganzes Bündel von Maßnahmen der >guten Policey`, zu denen neben Aspekten der Staatsverwaltung insbesondere auch die Steuerpolitik, die umfassende (zumeist stark dirigistische) Förderung von Handel und Gewerbe, der Landesausbau sowie

2 Jüngste Ausgabe: Adam Smith, An Inquiry into the Nature and Causes of the Wealth of Nations, hg.v. Jonathan B. Wight, Petersfield 2007. Zur Begriffsbildung durch Smith z.B. Blaich, Epoche, S. 3; Henning, Handbuch, Bd. 1, S. 758; und mit Hinweis auf den Einfluß der französischen Physiokraten Isenmann, Einleitung, in: ders. (Hg.), Merkantilismus, S. 9-17, hier S. 9f.

3 Gustav von Schmoller, Das Merkantilsystem in seiner historischen Bedeutung: städtische, territoriale und staatliche Wirtschaftspolitik, in: ders., Umrisse und Untersuchungen zur Verfassungs-, Verwaltungs- und Wirtschaftsgeschichte, besonders des preußischen Staates im 17. und 18. Jahrhundert, Leipzig 1898, Ndr. Hildesheim/New York 1974, S. 1-60. Zur Auseinandersetzung mit dem Merkantilismus auch Blaich, Epoche, S. 4; Erhard Dittrich, Die deutschen und österreichischen Kameralisten, Darmstadt 1974, S. 1-24; und zum Vergleich mit dem Absolutismusbegriff Thomas Simon, Merkantilismus und Kameralismus. Zur Tragfähigkeit des Merkantilismusbegriffs und seiner Abgrenzung zum deutschen `Kameralismus`, in: Isenmann (Hg.), Merkantilismus, S. 65-82, hier S. 65.

4 Ganz deutlich etwa bei Philipp Wilhelm von Hörnigk (1640-1714); vgl. dazu Kurt Zielenziger, Die alten deutschen Kameralisten. Ein Beitrag zur Geschichte der Nationalökonomie und zum Problem des Merkantilismus, Jena 1914, Ndr. Frankfurt a.M. 1966, S. 278-294; Dittrich, Kameralisten, S. 6668; Heinz-Joachim Brauleke, Leben und Werk des Kameralisten Philipp Wilhelm von Hörnigk. Versuch einer wissenschaftlichen Biographie, Frankfurt a.M. 1978, hier besonders S. 98-104. Zusammenfassend Henning, Handbuch, Bd. 1, S. 757f. und 765f.; Hermann Kellenbenz, Deutsche Wirtschaftsgeschichte, 2 Bde., München 1977-1981, hier Bd. 1, S. 311f.; Gömmel, Entwicklung, S. 4450; Johannes Kunisch, Absolutismus. Europäische Geschichte vom Westfälischen Frieden bis zur Krise des Ancien Régime, 2. Aufl. Göttingen 1999, S. 100; sowie Karsten Müller-Scheeßel, Jürgen Findorff und die kurhannoversche Moorkolonisation im 18. Jahrhundert, Hildesheim 1975, S. 1f.; Martin Fuhrmann, Volksvermehrung als Staatsaufgabe? Bevölkerungs- und Ehepolitik in der deutschen politischen und ökonomischen Theorie des 18. und 19. Jahrhunderts, Paderborn 2002, S. 24f.; Blaich, Epoche, S. 170-178. 
die Bevölkerungspolitik gehörten. ${ }^{5}$ Wirtschaft wurde damit im 17. Jahrhundert erstmals konsequent als ein Faktor der Politik wahrgenommen. Im wirtschaftlichen Sinne folgten die Kameralisten dabei den Prinzipien des Merkantilismus. ${ }^{6}$

Eine zentrale Rolle innerhalb der kameralistischen Staats- und Wirtschaftstheorien kam bis zum Erscheinen von Thomas Robert Malthus' >Essay on the Principle of Population` (1798) der Maxime von der Bevölkerungsvermehrung zu, denn von ihr versprachen sich die Obrigkeiten eine Erhöhung der Produktion und des Konsums, was die Hebung des allgemeinen Wohlstands und damit auch der Steuerleistung zur Folge haben sollte. ${ }^{7}$ Auch der Mensch wurde somit zur Ressource, die staatlicher Planung unterworfen wurde. Bei der Entwicklung kameralistischer Auffassungen, in denen Wirtschaft vor allem als Teil der Politik behandelt wurde, kam der Rezeption italienischer Staatsräsondiskurse eine zentrale Bedeutung zu. Daneben war das Werk Jean Bodins, das die Nützlichkeit einer hohen Bevölkerungszahl betonte und später in der Praxis des französischen >Colbertinismus eine wichtige Rolle spielte, von großem Gewicht auch für die deutsche Diskussion. ${ }^{8}$ In Anlehnung an diese Vorgänger, aber zugleich deutlich über diese hinausgehend lehrte besonders die deutsche politische Theorie seit dem frühen 17. Jahrhundert den Zusammenhang zwischen dem Bevölkerungsreichtum eines Landes und dessen Wohlstand. Nach Denkern wie Jakob Bornitz (1560-1625) und Hermann Latherus (1583-1640) ${ }^{9}$ war es insbesondere Veit Ludwig von Seckendorff (1626-1692), der die Entwicklung popu-

5 Blaich, Epoche, S. 16-18; Dittrich, Kameralisten, S. 30-34; Kellenbenz, Wirtschaftsgeschichte Bd. 1, S. 297; Gömmel, Entwicklung, S. 42; Henning, Handbuch, Bd. 1, S. 763f.; Fuhrmann, Volksvermehrung, S. 24f.; Sokoll, Kameralismus, Sp. 294-298; Simon, Merkantilismus. Auf staatlichen Dirigismus zielen die meisten der kameralistischen Theoretiker ab; sehr deutlich etwa Wilhelm von Schröder (1640-1688); vgl. Dittrich, Kameralisten, S. 63-66.

6 Anton Tautscher, Geschichte der deutschen Finanzwissenschaft bis zum Ausgang des 18. Jahrhunderts, in: Wilhelm Gerloff/Fritz Neumark (Hg.), Handbuch der Finanzwissenschaft, Bd. 1, 2. Aufl. Tübingen 1952, S. 384-415, hier S. 387f.; Dittrich, Kameralismus, S. 32f.

7 Vgl. Fuhrmann, Volksvermehrung, S. 23; Gömmel, Entwicklung, S. 44f.; Henning, Handbuch, Bd. 1, S. 775; Sokoll, Kameralismus, Sp. 295; Márta Fata, Migration im kameralistischen Staat Josephs II. Theorie und Praxis der Ansiedlungspolitik in Ungarn, Siebenbürgen, Galizien und der Bukowina von 1768 bis 1790, Münster 2014, S. 21-29.

8 Zu Bodin z.B. Dittrich, Kameralisten, S. 38f.; Holub, Einführung, Bd. 2, S. 150-153. Zum Merkantilismus Colberts Pierre Deyon, Le mercantilisme, Paris 1969, S. 22-30; Holub, Einführung, Bd. 2, S. 154-159. Zur Bedeutung des italienischen Staatsräsondiskurses und seiner Rezeption in Deutschland vgl. Justus Nipperdey, Ansätze zur Ökonomisierung in der Politiktheorie des frühen 17. Jahrhunderts, in: Hubertus Busche (Hg.), Departure for Modern Europe. A Handbook of Early Modern Philosophy (1400-1700), Hamburg 2011, S. 105-116; ders., Bevölkerungstheorie und Konfessionsmigration in der Frühen Neuzeit, in: Europäische Geschichte Online (EGO), hg.v. Institut für Europäische Geschichte, Mainz 2010, URL: http://www.ieg-ego.eu/nipperdeyj-2010-de (Zugriff 13.9.2012); ders., Die Erfindung der Bevölkerungspolitik. Staat, politische Theorie und Population in der Frühen Neuzeit, Göttingen 2012.

9 Vgl. zu diesen Nipperdey, Ansätze. 
lationistischer Ideen in Deutschland vorantrieb. In seinem Werk >Teutscher Fürsten Statı, das 1656 in Frankfurt am Main erstmals erschien und zahlreiche Neuauflagen bis weit ins 18. Jahrhundert hinein erlebte, wies Seckendorff darauf hin, dass »auff der Menge wohlgenehrter Leute der grösseste Schatz des Landes besteht «. ${ }^{10}$ Ähnliche Gedanken finden sich auch bei Hermann Conring (1606-1681), Johann Joachim Becher (1635-1682), Theodor Ludwig Lau (1670-1740), Johann Heinrich Gottlob von Justi (1711-1771) oder Joachim Georg Darjes (1714-1791), um nur einige zu nennen. ${ }^{11}$ Neusiedler und Kolonisten zu gewinnen, wurde als Mittel zur Verbesserung der wirtschaftlichen Verhältnisse wie auch der Staatseinnahmen daher von einigen Kameralisten explizit empfohlen. Generell wurde zu diesem Zweck auch religiöse Toleranz gefordert, zumal Vorbilder wie die Niederlande als Beispiele dafür angeführt wurden, dass ein Staat, in dem verschiedene Konfessionen geduldet wurden, $\mathrm{zu}$ wirtschaftlicher Blüte gelangen konnte. ${ }^{12} \mathrm{Zu}$ den Empfehlungen gehörte auch, Einwanderer mittels besonderer Privilegien anzulocken. ${ }^{13}$ Privilegien sind eine in

10 Veit Ludwig von Seckendorff, Teutscher Fürsten Stat, Frankfurt a.M. 1656 (zahlreiche weitere Auflagen), hier zitiert nach Stefi Jersch-Wenzel, Juden und `Franzosen` in der Wirtschaft des Raumes Berlin/Brandenburg zur Zeit des Merkantilismus, Berlin 1978, S. 42. Vgl. zur Rolle Seckendorffs in der Entwicklung populationistischer Überlegungen auch Dittrich, Kameralisten, S. 71; Zielenziger, Kameralisten, S. 345, 361f.; Hans-Christof Kraus, Kriegsfolgenbewältigung und `Peuplierung im Denken deutscher Kameralisten des 17. und 18. Jahrhunderts, in: Matthias Asche/Michael Herrmann/Ulricke Ludwig/Anton Schindling (Hg.), Krieg, Militär und Migration in der Frühen Neuzeit, Berlin 2008, S. 265-279; Nipperdey, Erfindung, S. 282-294. Zu Seckendorff insgesamt Michael Stolleis, Veit Ludwig von Seckendorff, in: ders. (Hg.), Staatsdenker in der Frühen Neuzeit, München 1995, S. 148-171.

$11 \mathrm{Zu}$ diesen und weiteren Zielenziger, Kameralisten, S. 111-413; Jutta Brückner, Staatswissenschaften, Kameralismus und Naturrecht. Ein Beitrag zur Geschichte der Politischen Wissenschaft im Deutschland des späten 17. und frühen 18. Jahrhunderts, München 1977, S. 43-51 und 60-91; Dittrich, Kameralisten, passim; Holub, Einführung, Bd. 2, S. 201-249; Kraus, Kriegsfolgenbewältigung; und speziell zu Becher: Herbert Hassinger, Johann Joachim Becher 1635-1682. Ein Beitrag zur Geschichte des Merkantilismus, Wien 1951. Eine ganz ähnliche Auffassung findet sich bei Johann H.G. von Justi, Gesammelte Politische und Finanz-Schriften, Kopenhagen/Leipzig 1761, wiedergegeben bei Fuhrmann, Volksvermehrung, S. 28. Lau befürwortete zwecks Bevölkerungsvermehrung sogar die Polygamie; vgl. Dittrich, Kameralisten, S. 74.

12 Vgl. hierzu insbesondere Erich Hassinger, Wirtschaftliche Motive und Argumente für religiöse Duldsamkeit im 16. und 17. Jahrhundert, in: Archiv für Reformationsgeschichte, 49. 1958, S. 225245; ders., Religiöse Toleranz im 16. Jahrhundert. Motive - Argumente - Formen der Verwirklichung, Basel/Stuttgart 1966; Nipperdey, Bevölkerungstheorie. Diese Argumentation wurde im Zusammenhang mit größeren Verfolgungswellen auch in der Publizistik vorgebracht; vgl. am Beispiel der Hugenottenverfolgung in Frankreich Ulrich Niggemann, Die Hugenottenverfolgung in der zeitgenössischen deutschen Publizistik (1681-1690), in: Francia. Forschungen zur westeuropäischen Geschichte, 32. 2005, Bd. 2, S. 59-108, hier S. $88 f$.

13 Hierzu besonders Martin Preetz, Die deutschen Hugenotten-Kolonien. Ein Experiment des Merkantilismus, Diss. Jena 1930, S. 8-10; Jersch-Wenzel, Juden, S. 41f.; Fuhrmann, Volksvermehrung, S. 44-49; Kraus, Kriegsfolgenbewältigung. 
der Vormoderne durchaus typische Erscheinung, die keineswegs auf die hier zu betrachtende Epoche zwischen Westfälischem Frieden und den Umbrüchen der Napoleonischen Zeit zu beschränken ist. Es handelte sich beim Privileg um ein vom Landesherrn erteiltes sius singulare`, ein individuelles Einzelrecht im Gegensatz zum allgemein geltenden Recht. Privilegien stellten also Ausnahmen vom geltenden Recht dar, besaßen jedoch gleichzeitig selbst Gesetzeskraft. Typischerweise erschien das - oft auch unter den Bezeichnungen >Freiheiten`, >Concessions` oder >Begnadigung firmierende - Privileg in Form einer Privilegienurkunde. ${ }^{14}$

Die Lehren der entstehenden Kameralwissenschaften drangen in der zweiten Hälfte des 17. Jahrhunderts verstärkt in das konkrete Regierungshandeln ein. Dies ist zumindest teilweise darauf zurückzuführen, dass nun vermehrt Räte mit universitärer Ausbildung die Schlüsselpositionen in den Regierungsgremien einnahmen. Diese zumeist juristisch ausgebildeten Politiker waren in der Regel auch mit den neuen Lehren der Ökonomie vertraut, vor allem aber waren sie es gewohnt, Situationen rational $\mathrm{zu}$ analysieren und planend einzugreifen. ${ }^{15}$ Die erheblichen Zerstörungen und Menschenverluste, zu denen der Dreißigjährige Krieg in zahlreichen Regionen des Heiligen Römischen Reichs geführt hatte, verstärkten in vielen deutschen Staaten den Druck, durch planvolles Handeln den Wiederaufbau voranzutreiben und die Bevölkerungsverluste auszugleichen. ${ }^{16}$ Zugleich stiegen in den Jahrzehnten nach 1648 die Ausgaben der Fürsten um ein Vielfaches, da zahlreiche

14 Zur Definition Heinz Mohnhaupt, Privatrecht in Privilegien, in: Vorträge zur Geschichte des Privatrechts in Europa, Frankfurt a.M. 1981, S. 58-75, hier S. 59f.; ders., Untersuchungen zum Privileg und Kodifikation im 18. und 19. Jahrhundert, in: Ius Commune, 4. 1972, S. 71-121, hier S. 74-83; ders., Privileg, neuzeitlich, in: Handwörterbuch zur deutschen Rechtsgeschichte, Bd. 3, Berlin 1984, Sp. 2005-2011; sowie Barbara Dölemeyer, Die Aufnahmeprivilegien für Hugenotten im europäischen Refuge, in: dies./Heinz Mohnhaupt (Hg.), Das Privileg im europäischen Vergleich, Frankfurt a.M. 1997, S. 303-328, hier S. 305. Für das Mittelalter auch Hermann Krause, Privileg, mittelalterlich, in: Handwörterbuch zur deutschen Rechtsgeschichte, Bd. 3, Berlin 1984, Sp. 1999-2005.

15 Schon für das 16. Jahrhundert: Maximilian Lanzinner, Konfessionelles Zeitalter 1555-1618, in: ders./Gerhard Schormann, Konfessionelles Zeitalter/Dreißigjähriger Krieg, Stuttgart 2004, S. 3-203, hier S. 81-83.

16 Vgl. zu den Bevölkerungsverlusten in der Folge des Dreißigjährigen Krieges Günther Franz, Der Dreißigjährige Krieg und das deutsche Volk. Untersuchungen zur Bevölkerungs- und Agrargeschichte, 4. Aufl. Stuttgart/New York 1979 (Erstauflage 1939), S. 5-63. Die von Franz ermittelten Angaben hinsichtlich der demographischen Situation nach dem Krieg wurden von neueren Arbeiten im Wesentlichen bestätigt; vgl. Christian Pfister, Bevölkerungsgeschichte und historische Demographie 1500-1800, München 1994, S. 14-18; Paul Münch, Das Jahrhundert des Zwiespalts. Deutsche Geschichte 1600-1700, Stuttgart 1999, S. 36-39; Heinz Schilling, Höfe und Allianzen. Deutschland 1648-1763, Berlin 1989, S. 71f.; und zu Brandenburg: Matthias Asche, Neusiedler im verheerten Land. Kriegsfolgenbewältigung, Migrationssteuerung und Konfessionspolitik im Zeichen des Landeswiederaufbaus. Die Mark Brandenburg nach den Kriegen des 17. Jahrhunderts, Münster 2006, S. 40-54. Zur kameralistischen Politik zusammenfassend auch Johannes Burkhardt, Vollendung und Neuorientierung des frühmodernen Reiches 1648-1763, Stuttgart 2006, S. 172-188. 
Territorien nun - nach den Erfahrungen des Krieges - darangingen, ein stehendes Heer und eine effektivere Staatsverwaltung aufzubauen. ${ }^{17}$ Der im Westfälischen Frieden hinzu gewonnene Handlungsspielraum zumindest der größeren Territorien des Reichs schuf zudem - der Logik der Zeit entsprechend - ein verstärktes Repräsentationsbedürfnis, das sich in einer Vergrößerung der Hofhaltung, in zahlreichen Bauprojekten und prunkvollen Festlichkeiten niederschlug. ${ }^{18}$ Mit dieser Entwicklung, die keineswegs, wie manchmal noch zu lesen ist, persönlicher >Verschwendungssucht` der Fürsten geschuldet ist, sondern den zeittypischen Formen der Visualisierung von Herrschaft, entstand zugleich ein erhöhter Finanzbedarf, der sich nur durch ein optimiertes Steueraufkommen und damit durch einen allgemeinen Wohlstand im Land decken ließ. Patriarchalische Fürsorge für die Untertanen verband sich so - durchaus in Übereinstimmung mit den Lehren Bechers und Schröders - mit der Suche nach immer neuen Finanzquellen und dem Streben nach einer möglichst umfassenden Ressourcenabschöpfung. ${ }^{19}$

Obwohl zahlreiche deutsche Territorien bevölkerungspolitische Akzente setzten, hat die Forschung sich stets am intensivsten mit der Kolonisationspolitik Brandenburg-Preußens befasst. Sicher entspricht dies zumindest teilweise der tatsächlichen Vorreiterrolle des Kurfürstentums seit der Mitte des 17. Jahrhunderts. Nimmt man den ebenfalls gut erforschten deutschen Südwesten hinzu, so wird deutlich, dass der Fokus der Forschung offenbar auf den Regionen lag, in denen Migration aufgrund der Zerstörungen durch den Dreißigjährigen Krieg zu einem Massenphänomen wurde. Dies wird sich auch in der vorliegenden Darstellung widerspiegeln.

\section{2 `Peuplierung` nach dem Dreißigjährigen Krieg}

Nach den verheerenden Zerstörungen und Bevölkerungsverlusten durch den Dreißigjährigen Krieg und die mit ihm verbundenen Hungersnöte und Seuchenzüge setzte vielerorts eine demographisch-kompensatorische Migration ein, das heißt eine Wanderungsbewegung aus den kriegsverschonten Gebieten mit Bevölkerungs-

17 Vgl. z.B. Johannes Kunisch, Absolutismus. Europäische Geschichte vom Westfälischen Frieden bis zur Krise des Ancien Régime, 2. Aufl. Göttingen 1999, S. 98; Heinz Duchhardt, Europa am Vorabend der Moderne 1650-1800, Stuttgart 2003, S. 56-62.

18 Vgl. z.B. Johannes Kunisch, Funktion und Ausbau der kurfürstlich-königlichen Residenzen in Brandenburg-Preußen im Zeitalter des Absolutismus, in: Peter-Michael Hahn/Kristina Hübener/ Julius H. Schoeps (Hg.), Potsdam. Märkische Kleinstadt - europäische Residenz. Reminiszenzen einer eintausendjährigen Geschichte, Berlin 1995, S. 61-83, hier S. 61-69.

$19 \mathrm{Zu}$ Becher und Schröder vgl. Dittrich, Kameralisten, S. 64; und Brückner, Staatswissenschaften, S. 48. Allgemein dazu: Hans-Joachim Röpke, Die Wachstumstheorie der deutschen Merkantilisten, Diss. Marburg 1971, S. $80 \mathrm{f}$. 
überschuss in die stark vom Krieg betroffenen Regionen. ${ }^{20}$ Meist gingen diesen kleineren, oft aus dem Nahbereich kommenden Wanderungsbewegungen keine systematischen Anwerbungen voraus. Dennoch ist davon auszugehen, dass die von Bevölkerungsverlusten betroffenen Staaten solchen Einwanderern Vergünstigungen boten, um ihre Ansiedlung zu erleichtern. In Brandenburg-Preußen etwa spielten Kolonisten aus den weniger verwüsteten Gebieten Holsteins, Lüneburgs, Braunschweigs und Mecklenburgs eine wichtige Rolle beim Wiederaufbau. ${ }^{21}$ Im Süden Deutschlands waren es hingegen vielfach Neusiedler aus den Alpenländern. ${ }^{22}$

Dabei darf freilich nicht übersehen werden, dass in vielen bereits stark entvölkerten Gebieten aufgrund der akuten Not die Abwanderung weiter anhielt und auch manche Neuansiedlungen nicht von Dauer waren. ${ }^{23}$ In vielen Fällen versuchten Landesherren, diese kontinuierliche Abwanderung durch Abwerbungsverbote und ähnliche Maßnahmen zu unterbinden und zugleich den Zuzug zu forcieren, indem sie verschiedene Anreize für die Niederlassung boten. Dies gilt für den Zuzug neuer Bevölkerungsgruppen allgemein sowie speziell für bestimmte Städte oder Landstriche, deren Wachstum gezielt gefördert werden sollte. In der vom Dreißigjährigen Krieg stark getroffenen Kurpfalz erließ Kurfürst Karl Ludwig beispielsweise bereits im Mai 1650 ein Edikt, das potenzielle Zuzügler aufforderte, sich in der Pfalz nieder-

20 Dazu die - freilich in vielen Punkten aufgrund ihrer an nationalsozialistischer Ideologie angelehnten Grundtendenz problematische - Arbeit von Franz, Krieg, S. 64-103; sowie Matthias Asche, Krieg, Militär und Migration in der Frühen Neuzeit. Einleitende Beobachtungen zum Verhältnis von horizontaler und vertikaler Mobilität in der kriegsgeprägten Gesellschaft Alteuropas im 17. Jahrhundert, in: Asche/Herrmann/Ludwig/Schindling (Hg.), Krieg, S.11-36, und Jochen Oltmer, Migration, Krieg und Militär in der Frühen und Späten Neuzeit, in: ebd., S. 37-55. Außerdem der Beitrag von Matthias Asche in diesem Band.

21 Franz, Krieg, S. 98-100; außerdem Asche, Neusiedler, S. 157-165, 185-194.

22 Vgl. generell dazu Franz, Krieg, S. 64-103; sowie Matthias Asche, Schweizer Protestanten aus ländlichen Regionen im Elsaß, in Südwestdeutschland und in Brandenburg-Preußen seit der Mitte des 17. Jahrhunderts, in: Klaus J. Bade/Pieter C. Emmer/Leo Lucassen/Jochen Oltmer (Hg.), Enzyklopädie Migration in Europa. Vom 17. Jahrhundert bis zur Gegenwart, Paderborn 2007, S. 969-973, hier S. 969-971; und Eberhard Fritz, Kriegsbedingte Migration als Forschungsproblem. Zur Einwanderung aus Österreich und der Schweiz nach Südwestdeutschland im späten 17. und frühen 18. Jahrhundert, in: Asche/Herrmann/Ludwig/Schindling (Hg.), Krieg, S. 241-249.

23 Vgl. Franz, Krieg, passim. Zur fortgesetzten Auswanderung etwa aus der Kurpfalz Volker Sellin, Die Finanzpolitik Karl Ludwigs von der Pfalz. Staatswirtschaft und Wiederaufbau nach dem Dreißigjährigen Krieg, Stuttgart 1978, S. 100f. Zu den mäßigen Erfolgen der frühen Siedlungsversuche in Brandenburg Asche, Neusiedler, S. 263-265, 273f.; Werner Grieshammer, Studien zur Geschichte der Réfugiés in Brandenburg-Preußen bis 1713, Berlin 1935, S. 27; Eckart Birnstiel/Andreas Reinke, Hugenotten in Berlin, in: Stefi Jersch-Wenzel/Barbara John (Hg.), Von Zuwanderern zu Einheimischen. Hugenotten, Juden, Böhmen, Polen in Berlin, Berlin 1990, S. 16-152, hier S. 39. Vgl. auch Ernst Opgenoorth, Friedrich Wilhelm. Der große Kurfürst von Brandenburg. Eine politische Biographie, 2 Bde., Göttingen 1971-1978, hier Bd. 1, S. 174f., und Walter Kuhn, Geschichte der deutschen Ostsiedlung in der Neuzeit, 2 Bde., Köln/Graz 1955-1957, hier Bd. 2, S. $101 f$. 
zulassen. ${ }^{24}$ Auch Kurbrandenburg - sicher eines der am stärksten kriegsverheerten Gebiete im Reich - bemühte sich mit solchen Einwandererprivilegien um die Wiederbesiedlung, wobei in den Edikten der 1660er Jahre zunächst vor allem der Wiederaufbau der Städte im Mittelpunkt stand. ${ }^{25}$ Meist handelte es sich um eine Folge mehrfach wiederholter Edikte, im Zuge derer bisweilen auch die ursprünglichen Angebote verbessert wurden. ${ }^{26}$ Allgemein üblich waren - wie sich auch in der Folgezeit immer wieder zeigte - eine Anzahl von Steuerfreijahren sowie die kostenlose Bereitstellung von Baumaterial durch die Landesherrschaft. ${ }^{27}$ Auch Rückkehrer wurden in diesem Zusammenhang angesprochen und die Restitution ihrer Güter geregelt. ${ }^{28}$ Obwohl die Forschung sich hinsichtlich einer aktiven Bevölkerungspolitik meist auf protestantische Territorialstaaten beschränkt hat, sind durchaus auch Beispiele einer planmäßigen Wiederbesiedlung aus katholischen Territorien bekannt. So erließ der Kurfürst und Erzbischof von Mainz, Johann Philipp von Schönborn, bereits im Oktober 1648 ein Edikt, das niederlassungswilligen Neusiedlern im Kurerzstift Privilegien und Freiheiten versprach und das während des Krieges geflüchtete Landeskinder zur Rückkehr aufforderte. ${ }^{29}$ Entsprechende Maßnahmen wurden unter der Ägide Schönborns auch im Fürstbistum Würzburg ergriffen. ${ }^{30}$

24 Vgl. Gerhard Biskup, Die landesfürstlichen Versuche zum wirtschaftlichen Wiederaufbau der Kurpfalz nach dem 30jährigen Kriege 1648-1674. Ein Beitrag zur Wirtschaftsgeschichte der Pfalz, Diss. Frankfurt a.M. 1930, S. 12; Sellin, Finanzpolitik, S. 104f., und zum Gesamtzusammenhang ebd., S. 97-115. Zur Herkunft der Einwanderer auch Franz, Krieg, S. 65-68. Zu den Bevölkerungsverlusten der Kurpfalz im Dreißigjährigen Krieg ganz knapp Sellin, Finanzpolitik, S. 98f.; Joachim Heinz, »Bleibe im Lande, und nähre dich redlich!« Zur Geschichte der pfälzischen Auswanderung vom Ende des 17. bis zum Ausgang des 19. Jahrhunderts, Kaiserslautern 1989, S. 20; ausführlich zum Oberamt Lautern: Ernst Christmann, Dörferuntergang und -wiederaufbau im Oberamt Lautern während des 17. Jahrhunderts, Otterbach/Kaiserslautern 1960.

25 Edikt Kf. Friedrich Wilhelms, Cölln a.d. Spree, 19. Januar 1661, abgedruckt bei Christian O. Mylius, Corpus Constitutionum Marchicarum, 6 Bde., Berlin/Halle 1737-1755, hier Bd. 5/1, Sp. 367-368. Weitere Edikte aus den Jahren 1667 und 1669 ebd., Sp. 367-370, 369-370, 369-372. Vgl. zu diesen Maßnahmen auch Jersch-Wenzel, Juden, S. 31f.; Opgenoorth, Friedrich Wilhelm, Bd. 2, S. 54; Meta Kohnke, Das Edikt von Potsdam. Zu seiner Entstehung, Verbreitung und Überlieferung, in: Jahrbuch für Geschichte des Feudalismus, 9. 1985, S. 241-275, hier S. 249; Birnstiel/Reinke, Hugenotten, S. 39.

26 So auch in der Kurpfalz; vgl. Biskup, Versuche, S. 13; Sellin, Finanzpolitik, S. 104f.; und allgemein zur Bevölkerungspolitik der Kurpfalz Albrecht Ernst, Die reformierte Kirche der Kurpfalz nach dem Dreißigjährigen Krieg (1649-1685), Stuttgart 1996, S. 23.

27 Vgl. für die Kurpfalz Biskup, Versuche, S. 12f.; Sellin, Finanzpolitik, S. 107f. Zu Kurbrandenburg vgl. Jersch-Wenzel, Juden, S. 31f.; Opgenoorth, Friedrich Wilhelm, Bd. 2, S. 54; Kohnke, Edikt, S. 249.

28 Biskup, Versuche, S. 13-15; Sellin, Finanzpolitik, S. 104-106.

29 Vgl. dazu Georg Mentz, Johann Philipp von Schönborn, Kurfürst von Mainz, Bischof von Würzburg und Worms 1605-1673, 2 Bde., Jena 1896-1899, hier Bd. 2, 145 f.

30 Ebd., 146f. Daß der Fokus der Forschung stark auf protestantische Migrantengruppen gerichtet ist, hat sicher auch damit zu tun, daß katholische Einwanderer keine eigenständigen Kirchenge- 
Neben solchen allgemeinen Einwanderungsaufforderungen bemühte sich vor allem der Kurfürst von Brandenburg auch direkt um die Anwerbung besonders erwünschter Gruppen. Seit 1646 wurden mit Hilfe niederländischer Siedler ländliche Kolonien angelegt und wüst gefallene Dörfer wiederbesiedelt. Insbesondere im havelländischen Kreis sowie ab 1649 und 1652 in den Ämtern Zehdenick, Liebenwalde, Fehrbellin, Chorin, Tangermünde und Gramzow entstanden auf diese Weise Niederlassungen. ${ }^{31}$ Auch für die Neumark und Preußen wurden Siedler aus den Niederlanden angeworben. ${ }^{32}$ Diese Kolonisten erhielten anstelle allgemeiner Privilegien zumeist spezielle Ansiedlungskontrakte, die freilich ganz ähnliche Zusagen enthielten wie die Privilegienedikte. Die Niederländer erhielten Steuerfreijahre, die persönliche Freiheit und die Freiheit von Frondiensten. Sie konnten einen eigenen Richter für die Niedergerichtsbarkeit bestellen und eigene niederländisch-reformierte Pfarrer berufen. Vermutlich durften sie ihre Kirchengemeinden sogar nach ihrer gewohnten presbyterial-synodalen Kirchenverfassung verwalten. ${ }^{33}$ Während auf diese Weise bis zum Beginn der 1680er Jahre die meisten Bauernstellen in der Prignitz wiederbesetzt werden konnten, hat Matthias Asche in seiner umfassenden Untersuchung zeigen können, dass durch erneute Kriegsereignisse in der Uckermark und im Land Ruppin die Ansätze mehrfach wieder zunichte gemacht wurden, sodass hier erst mit der Hugenotten- und Schweizerkolonisation ab 1685 die Mehrzahl der ländlichen Stellen wieder besetzt wurde. ${ }^{34}$

Auch der Wiederaufbau zerstörter und stark entvölkerter Städte zog sich oft über Jahrzehnte hin und war vielerorts noch zum Zeitpunkt der Hugenotteneinwanderung ab 1685 nicht abgeschlossen. Ein Beispiel dafür ist Magdeburg, das 1631

meinden als Träger einer Exulantenidentität herausbildeten; vgl. dazu Bettina Braun, Katholische Konfessionsmigration im Europa der Frühen Neuzeit - Stand und Perspektiven der Forschung, in: Henning P. Jürgens/Thomas Weller (Hg.), Religion und Mobilität. Zum Verhältnis von raumbezogener Mobilität und religiöser Identitätsbildung im frühneuzeitlichen Europa, Göttingen 2010, S. 75112.

31 Dazu bereits Max Beheim-Schwarzbach, Hohenzollernsche Colonisation, Leipzig 1874, S. 36-39; Kuhn, Ostsiedlung, S. 101f.; Grieshammer, Studien, S. 19-28; Franz, Krieg, S. 100; Opgenoorth, Friedrich Wilhelm, Bd. 1, S. 173-176. Eine kurze Zusammenfassung der jüngeren Forschung bieten Birnstiel/Reinke, Hugenotten, S. 39f.; Wolfgang Neugebauer, Zentralprovinz des Absolutismus. Brandenburg im 17. und 18. Jahrhundert, Berlin 2001, S. 68; Dagmar Freist, Südniederländische calvinistische Flüchtlinge in Europa seit der Frühen Neuzeit, in: Bade/Emmer/Lucassen/Oltmer (Hg.), Enzyklopädie Migration, S. 1019-1029, hier S. 1023. Umfassend und auf dem neuesten Forschungsstand Asche, Neusiedler, S. 261-285, 431-434.

32 Hinweise bei Opgenoorth, Friedrich Wilhelm, Bd. 1, S. 173; Franz, Krieg, S. 100; Asche, Neusiedler, S. 264.

33 Grieshammer, Studien, S. 23-27; Asche, Neusiedler, S. 431-434.

34 Vgl. dazu Asche, Neusiedler, S. 173-175, 195-205 und 290-302; Lieselott Enders, Die Uckermark. Geschichte einer kurmärkischen Landschaft vom 12. bis zum 18. Jahrhundert, Weimar 1992, S. 374380 . 
durch die Truppen Tillys verwüstet worden war. ${ }^{35}$ Noch 1722 wurden in der Stadt 76 wüste Stellen gezählt, und auch die Bevölkerung, die vor dem Krieg 35.000 zählte, hatte 1681 erst wieder einen Stand von 8.000 erreicht. ${ }^{36}$ Schwer getroffen waren auch Berlin und andere kurbrandenburgische Städte. Die Einwanderungsedikte seit 1661 versprachen daher insbesondere Einwanderern in die Städte spezielle Vergünstigungen.

Ähnliches lässt sich über das kurpfälzische Mannheim sagen. Nach der vollständigen Zerstörung der Stadt im Dreißigjährigen Krieg erließ der aus dem Exil zurückgekehrte Kurfürst Karl Ludwig zunächst einen allgemeinen Aufruf, sich in Mannheim anzusiedeln. Sowohl in den kurbrandenburgischen Edikten als auch in den 1652 für Mannheim erlassenen Privilegien finden sich die üblichen Elemente: Zollfreie Einfuhr von mitgebrachten Gütern, Freiheit von der Leibeigenschaft, Steuerfreijahre, Zunftfreiheit für Handwerker und Manufakturisten oder kostenloser Eintritt in die Zünfte, Einquartierungsfreiheit, öffentliche Ausübung der reformierten Konfession (im Falle Mannheims sogar die volle Religionsfreiheit). Hinzu kamen kostenlose Grundstücke und Lieferung von Baumaterialien. ${ }^{37}$ Außerdem bemühte sich der Pfälzer Kurfürst um die Einwanderung wohlhabender Juden aus Spanien und Portugal, denen er eine günstige Konzession erteilte. ${ }^{38}$ Im September 1660 erlangten auch deutsche Juden eine Ansiedlungskonzession. ${ }^{39}$ Sie erhielten zwölf Jahre Freiheit vom üblichen Juden-Schutzgeld, durften einen Rabbi, einen Vorsänger und einen Schulmeister einstellen sowie Handel und Gewerbe betreiben. Dafür waren sie verpflichtet, nach Ablauf der Freijahre ein Schutzgeld zu bezahlen sowie innerhalb des ersten Jahres ihrer Ansiedlung ein Haus nach vorgegebenem Muster

35 Dazu Helmut Asmus, 1200 Jahre Magdeburg, 2 Bde., Halberstadt 2002, hier Bd. 1, S. 543-561; Mathias Tullner, Das Trauma Magdeburg - Die Elbestadt im Dreißigjährigen Krieg, in: Matthias Puhle (Hg.), »... gantz verheeret!« Magdeburg und der Dreißigjährige Krieg, 2. Aufl. Halle 1998, S. 13-24, hier S. 20f.; Michael Kaiser, Die `Magdeburgische Hochzeit` (1631). Gewaltphänomene im Dreißigjährigen Krieg, in: Eva Labouvie (Hg.), Leben in der Stadt. Eine Kultur- und Geschlechtergeschichte Magdeburgs, Köln 2004, S. 195-213.

36 Vgl. Henri Tollin, Geschichte der französischen Colonie zu Magdeburg, 3 Bde., hier Bd. 2, S. 256; und Ulrich Niggemann, Immigrationspolitik zwischen Konflikt und Konsens. Die Hugenottenansiedlung in Deutschland und England (1681-1697), Köln 2008, S. 155 mit Anm. 185.

37 Druck des brandenburgischen Ansiedlungsedikts von 1661: Mylius, Corpus Constitutionum Marchicarum, Bd. 5/1, Sp. 367-368. Vgl. dazu Jersch-Wenzel, Juden, S. 31f.; Opgenoorth, Friedrich Wilhelm, Bd. 2, S. 54; Kohnke, Edikt, S. 249; Birnstiel/Reinke, Hugenotten, S. 39. Druck der Mannheimer Privilegien: Henri Tollin, Urkunden zur Geschichte hugenottischer Gemeinden in Deutschland: Mannheimer Urkunden, Magdeburg 1898, S. 1-23. Vgl. ders., Geschichte, Bd. 1, S. 245-249; Johannes Fischer, Die Pfälzer Kolonie zu Magdeburg. Zum Andenken an ihre vor 250 Jahren erfolgte Begründung, Magdeburg 1939, S. 9; Ernst, Kirche, S. 62; Helmut Friedmann, Alt-Mannheim im Wandel seiner Physiognomie, Struktur und Funktionen (1606-1965), Bad Godesberg 1968, S. 166. 38 Vgl. dazu Karl Otto Watzinger, Geschichte der Juden in Mannheim 1650-1945, Stuttgart 1984, S. 13.

39 Ebd., S. 13-15. 
zu erbauen. ${ }^{40}$ Nachdem Mannheim 1689 abermals zerstört worden war, kehrten nach der Erneuerung der Konzession 1698 aufgrund der relativ günstigen Privilegien viele der vor dem Krieg geflüchteten Juden in die Stadt zurück. ${ }^{41}$

Noch bei der Ansiedlung von >Glaubensflüchtlingen` gegen Ende des 17. Jahrhunderts spielte der Aspekt des Wiederaufbaus der Städte eine zentrale Rolle. Dies gilt im 17. Jahrhundert in besonderer Weise für die bekannteste städtische Einwanderergruppe, die - freilich intern genauer zu differenzierenden - Hugenotten..$^{42}$ Ein Blick auf die bekannten Privilegien für diese Einwanderer zeigt bereits deutlich, dass städtische Ansiedlungen bevorzugt wurden und dass ein großer Teil der Vergünstigungen und Zugeständnisse gewerbetreibenden Hugenotten in den Städten galt. Insbesondere der Aufbau verfallener Häuser beziehungsweise die Neubebauung leerer Hausstellen wurde durch kostenloses Baumaterial und Zuschüsse gefördert. ${ }^{43}$ Zugleich wurde der Druck auf die Besitzer verfallener Häuser und unbebauter

40 Privilegientext abgedruckt ebd., S. 13f.

41 Ebd., S. 16-19.

42 >Hugenotten wird in der neueren Forschung eher als Sammelbegriff für verschiedene Gruppen französisch-sprechender Protestanten gebraucht; vgl. Wilhelm Beuleke, Studien zum Refuge in Deutschland und zur Ursprungsheimat seiner Mitglieder, Obersickte 1966, S. 41-43; Johannes E. Bischoff, Hugenotten und Hugenotten-Nachkommen als städtische Minderheiten, in: Bernhard Kirchgässner/Fritz Reuter (Hg.), Städtische Randgruppen und Minderheiten, Sigmaringen 1986, S. 115-128, hier S. 116f.; ders., Getrennte Begriffsverwendung, Hugenotten, Hugenotten-Nachkommen, desgleichen Exulanten, Emigranten, Refugiés, Franzosen, erleichtern auch die shugenottischer Familien- und Bevölkerungs-Forschung, in: Der Deutsche Hugenott, 53. 1989, S. 71-80, hier S. 72f.; Asche, Neusiedler, S. 501-504; und Eberhard Gresch, Die Hugenotten. Geschichte, Glaube und Wirkung, 2. Aufl. Leipzig 2005, S. 29.

43 Zum gewerbeorientierten Zuschnitt der Privilegien vgl. Niggemann, Immigrationspolitik, S. 287f.; ders., Die altständische Antwort auf die soziale Herausforderung Migration: Privilegien als Mittel staatlicher Einwanderungspolitik im Europa der Frühen Neuzeit, in: Joachim Bahlcke/Rainer Leng/Peter Scholz (Hg.), Migration als soziale Herausforderung. Historische Formen solidarischen Handelns von der Antike bis zum 20. Jahrhundert, Stuttgart 2011, S. 183-200, hier S. 195f. Bei den vorgeschlagenen Ansiedlungsorten handelte es sich fast immer um Städte; so etwa Potsdamer Edikt (Art. 3), 29. Oktober 1685, abgedruckt bei Ernst Mengin (Bearb.), Das Recht der französischreformierten Kirche in Preußen. Urkundliche Denkschrift, Berlin 1929, S. 186-196, hier S. 188f.; und „Concessions et privilèges« Lgf. Karls, Kassel, 12. Dezember 1685 (Art. 4), abgedruckt bei Dieter Mempel (Bearb.), Gewissensfreiheit und Wirtschaftspolitik. Hugenotten- und Waldenserprivilegien 1681-1699, Trier 1986, S. 52. Vgl. darüber hinaus die zahlreichen Regelungen für den Aufbau oder die Instandsetzung von Häusern: Potsdamer Edikt Kf. Friedrich Wilhelms (Art. 5f.), 29. Oktober 1685, abgedruckt bei Mengin (Bearb.), Recht, S. 190f.; Edikt Lgf. Karls (Art. 5), Kassel, 12. Dezember 1685, abgedruckt bei Mempel (Bearb.), Gewissensfreiheit, S. 52. Einen Sonderfall stellt das zur Ansiedlung der Hugenotten in Hameln ausgestellte Privilegienedikt Hg. Ernst Augusts, Hannover, 1. August 1690, dar, abgedruckt bei Thomas Klingebiel (Bearb.), Die Hugenotten in den welfischen Landen. Eine Privilegiensammlung, Bad Karlshafen 1994, S. 62-87. Vgl. auch das Privilegienedikt für die `Pfälzer` in Magdeburg: Edikt Kf. Friedrichs III., Gröningen, 25. Mai 1689, gedruckt bei Mylius, Corpus Constitutionum Marchicarum Bd. 6 (Anhang), Sp. 66-72. 
Grundstücke erhöht. Als mit der Einwanderung von Hugenotten, >Pfälzern` und anderen die Möglichkeit $\mathrm{zu}$ bestehen schien, die Aufbauarbeit wesentlich $\mathrm{zu}$ beschleunigen, wurden für einige Städte >Baureglements` durch den Landesherrn erlassen, die die Besitzer zwingen sollten, ihre Grundstücke zu bebauen oder Häuser instand zu setzen. Ansonsten drohte die Enteignung. ${ }^{44}$ Die Beispiele Magdeburg, Hameln und Kassel zeigen allerdings, dass es zumeist bei der Drohung blieb, auch weil die Einwanderer häufig selbst nicht in der Lage waren, die Grundstücke zügig zu bebauen. ${ }^{45}$

Insgesamt lässt sich also feststellen, dass es in den deutschen Territorien nach dem Dreißigjährigen Krieg neben der ungelenkten demographisch-kompensatorischen Migration intensive Bemühungen um eine aktive Bevölkerungspolitik gab. Dabei richteten sich die politischen Maßnahmen einerseits auf die Ressource Mensch selbst, andererseits und eng damit zusammenhängend auf die Wiederbesetzung wüstgefallener Haus- und Hofstellen in den Städten und auf dem Land. Anreize in Form von Privilegien oder speziellen Ansiedlungskontrakten sowie gezielte Anwerbungsmaßnahmen sollten Neusiedler ins Land locken. Die stark kriegszerstörten Territorien der Kurpfalz und Kurbrandenburgs nahmen in den Jahrzehnten nach dem Dreißigjährigen Krieg eine gewisse Vorreiterrolle ein.

\section{Ansiedlung von >Glaubensflüchtlingens als merkantilistische Bevölkerungspolitik}

Von einer planmäßigen und großangelegten Einwanderungspolitik kann in den meisten deutschen Territorien sicher erst im Kontext der Anwerbung von >Glaubensflüchtlingen` die Rede sein. ${ }^{46}$ Insbesondere im äußersten Westen des Reichs hatte es

44 Z.B. „Verordnung daß in Cassel die wüsten Wohnhäusser abgeändert und die ledigen Baustätten nach einem Modell bebauet werden sollen«, erlassen von Lgf. Karl, Kassel, 1. November 1687, abgedruckt in Sammlung fürstlich-hessischer Landesordnungen, Bd. 3, S. 321f. Ähnliches Edikt für Hameln durch Hg. Ernst August, Hannover, 10. September 1696, abgedruckt bei Klingebiel (Bearb.), Hugenotten, S. 88-90. Zu diesem und einem frühen Edikt der Regierung in Hannover auch ders., Weserfranzosen. Studien zur Geschichte der Hugenottengemeinschaft in Hameln 1690-1757, Göttingen 1992, S. 102, 105f. Zu den Edikten Kf. Friedrichs III. und Kg. Friedrich Wilhelms I. für Magdeburg vgl. Tollin, Geschichte, Bd. 2, 302f.; und ders., Hugenottische Topographie von Magdeburg, in: Geschichtsblätter für Stadt und Land Magdeburg, 28. 1893, S. 100-140, hier S. 108f.

45 Vgl. dazu Niggemann, Immigrationspolitik, S. 215-217. Vgl. zu Hameln auch Klingebiel, Weserfranzosen, S. 102f.

46 Generell zum Problem der >Konfessionsmigration` Ulrich Niggemann, Glaubensflucht als Migrationstyp? Charakteristika konfessionsbedingter Migration in der Frühen Neuzeit, in: Historisches Jahrbuch 135. 2015, S. 46-68; und der Beitrag von Alexander Schunka in diesem Band. Als Überblick vgl. z.B. Heinz Schilling, Die niederländischen Exulanten des 16. Jahrhunderts. Ein Beitrag zum 
freilich schon frühzeitig Versuche gegeben, Menschen, die aufgrund ihrer vom Mehrheitsbekenntnis abweichenden religiösen Auffassungen ihre Heimat verlassen wollten, aufzunehmen und gezielt anzusiedeln. Im 16. Jahrhundert waren es zunächst Städte wie Emden, Wesel, Aachen, Frankfurt am Main und Straßburg, die unter unterschiedlichen Bedingungen - Flüchtlinge aus den Niederlanden und Frankreich aufnahmen und sich dabei auch wirtschaftliche Vorteile erhofften. ${ }^{47}$ In der Kurpfalz entstanden auf diesem Wege für flämische und wallonische Einwanderer auch ländliche Kolonien, so zum Beispiel die Orte Frankenthal und Schönau (1562). ${ }^{48}$ Auch Landgraf Moritz von Hessen-Kassel erließ 1604 erstmals ein Edikt, das evangelischen Einwanderern die Ansiedlung in den Städten seines Territoriums erleichtern sollte. ${ }^{49}$ In Kursachsen wurden seit der Schlacht am Weißen Berg (1620)

Typus der frühneuzeitlichen Konfessionsmigrantion, in: Geschichte in Wissenschaft und Unterricht, 43. 1992, S. 67-78, hier S. 68f.; Arno Herzig, Der Zwang zum wahren Glauben. Rekatholisierung vom 16. bis zum 18. Jahrhundert, Göttingen 2000, S. 153-160; Thomas Klingebiel, Migration im frühneuzeitlichen Europa. Anmerkungen und Überlegungen zur Typologiediskussion, in: Comparativ. Leipziger Beiträge zur Universalgeschichte und vergleichenden Gesellschaftsforschung, 7. 1997, S. 23-38; Alexander Schunka, Glaubensflucht als Migrationsoption. Konfessionell motivierte Migrationen in der Frühen Neuzeit, in: Geschichte in Wissenschaft und Unterricht, 56. 2005, S. 547-564, hier S. 550-552; Leslie Page Moch, Moving Europeans. Migration in Western Europe since 1650, Bloomington/Indianapolis 1992, S. 27f.; Andrew Pettegree, Protestant Migration during the Early Modern Period, in: Simonetta Cavaciocchi (Hg.), Le Migrazioni in Europa secc. XIII-XVIII, Florenz 1994, S. 441-458.

47 Vgl. Heinz Schilling, Niederländische Exulanten im 16. Jahrhundert. Ihre Stellung im Sozialgefüge und im religiösen Leben deutscher und englischer Städte, Gütersloh 1972; ders., Exulanten (1992), S. 67-78. Knapper zur Einwanderung von Niederländern nach Westdeutschland Heinz Duchhardt, Glaubensflüchtlinge und Entwicklungshelfer. Niederländer, Hugenotten, Waldenser, Salzburger, in: Klaus J. Bade (Hg.), Deutsche im Ausland - Fremde in Deutschland. Migration in Geschichte und Gegenwart, München 1992, S. 278-287, hier S. 279-281; Thomas Klingebiel, Vorreiter der Freiheit oder Opfer der Modernisierung? Zur konfessionell bedingten Migration im frühneuzeitlichen Europa, in: Christoph Friederich (Hg.), 300 Jahre Hugenottenstadt Erlangen. Vom Nutzen der Toleranz, Nürnberg 1986, S. 21-28, hier S. 24; Rainer Postel, Asyl und Emigration in der Frühen Neuzeit, in: Hans-Wilhelm Eckhardt/Klaus Richter (Hg.), Bewahren und Berichten. Festschrift H.D. Loose, Hamburg 1997, S. 201-224, hier S. 203; und Freist, Flüchtlinge, S. 1021f.

48 Vgl. mit Hinweisen auf die ältere Literatur Asche, Neusiedler, S. 439f.; Dominique GuillemenotEhrmantraut, L'Immigration des Huguenots dans le Palatinat entre 1649 et 1685, in: Guido Braun/Susanne Lachenicht (Hg.), Hugenotten und deutsche Territorialstaaten. Immigrationspolitik und Integrationsprozesse, München 2007, S. 17-34, hier S. 17-19; Dominique Ehrmantraut/Michael Martin, Das Protokollbuch der französisch-reformierten Gemeinde zu Frankenthal 1658-1689, Speyer 2009, S. 253f.; und Freist, Flüchtlinge, S. 1023.

49 Edikt Lgf. Moritz', o.O., 24. Mai 1604, abgedruckt in Sammlung fürstlich-hessischer LandesOrdnungen, Bd. 1, Kassel 1767, S. 494f. Vgl. dazu auch Franz-Anton Kadell, Die Hugenotten in Hessen-Kassel, Darmstadt/Marburg 1980, S. 293f.; und Fritz Wolff, Die erste französische Gemeinde in Kassel (1615), in: Karl-Hermann Wegner (Hg.), 300 Jahre Hugenotten in Hessen. Herkunft und Flucht, Aufnahme und Assimilation, Wirkung und Ausstrahlung, Kassel 1985, S. 61-83, hier S. 65f. 
und der daraufhin einsetzenden Rekatholisierung Böhmens Tausende von böhmischen Protestanten aufgenommen, ohne dass hier freilich eine umfassende staatliche Lenkung zu erkennen ist. Vielmehr versuchte die kurfürstliche Regierung aus politischen Gründen, zu großes Aufsehen zu vermeiden. Meist wandten sich einzelne Auswanderer oder kleinere Gruppen mit Bittschriften (Suppliken) an den Landesherrn und baten um die Erlaubnis zur Niederlassung. ${ }^{50}$

Eine wirklich planmäßige Ansiedlung setzte erst nach dem Dreißigjährigen Krieg allmählich ein. In der Kurpfalz stand dabei in der ersten Zeit die Wiederherstellung der alten Fremdengemeinden im Zentrum der Bemühungen. Dabei verlagerte sich der Schwerpunkt der Kolonien allerdings auf das rechte Rheinufer, das vor französischen Übergriffen sicherer schien. ${ }^{51}$ Seit den 1660er Jahren begann dann jedoch allmählich die Einwanderung französischer Hugenotten, mit denen meist individuelle Ansiedlungskontrakte geschlossen wurden. Nach der Ansiedlung einiger Familien aus der Picardie in Iggelbach folgten die wichtigeren Koloniegründungen in Billigheim und Mörlheim 1664 und 1665.52 Aus Sicht dieser Einwanderer sprach für eine Niederlassung in der Pfalz sicher einerseits die Nähe zur Heimat, andererseits aber auch die Tatsache, dass hier früher bereits Fremdenkolonien bestanden hatten und die Pfalz als reformiertes Aufnahmeland bekannt war. Trotz der Vorzüge der Pfalz kamen in dieser Zeit die ersten Hugenotten auch nach Kurbrandenburg. ${ }^{53}$ Hier bildete jedoch erst das 1671 durch Kurfürst Friedrich Wilhelm erfolg-

50 Vgl. zur Auswanderung böhmischer Protestanten Georg Loesche, Die böhmischen Exulanten in Sachsen. Ein Beitrag zur Geschichte des dreißigjährigen Krieges und der Gegenreformation auf archivalischer Grundlage, Wien 1923; Eduard Winter, Die tschechische und slowakische Emigration in Deutschland im 17. und 18. Jahrhundert. Beiträge zur Geschichte der hussitischen Tradition, Berlin 1955, S. 9-50. Zur Aufnahme in Sachsen Wulf Wäntig, Kursächsische Exulantenaufnahme im 17. Jahrhundert. Zwischen zentraler Dresdner Politik und lebensweltlicher Bindung lokaler Machtträger an der sächsisch-böhmischen Grenze, in: Neues Archiv für Sächsische Geschichte, 74/75. 2003/2004, S. 133-174, hier S. 137-147; Alexander Schunka, Gäste, die bleiben. Zuwanderer in Kursachsen und der Oberlausitz im 17. und 18. Jahrhundert, Hamburg 2006, S. 53-65 und 103f.; ders., Böhmische Exulanten in Sachsen seit dem 17. Jahrhundert, in: Bade/Emmer/Lucassen/Oltmer (Hg.), Enzyklopädie Migration, S. 410-413; und speziell zur Aufnahme in Dresden Frank Metasch, Exulanten in Dresden. Einwanderung und Integration von Glaubensflüchtlingen im 17. und 18. Jahrhundert, Leipzig 2011.

51 Asche, Neusiedler, S. 440; Guillemenot-Ehrmantraut, Immigration, S. 27-33.

52 Vgl. Biskup, Versuche, S. 15; Guillemenot-Ehrmantraut, Immigration, S. 25f.; und Ehrmantraut/Martin, Protokollbuch, S. 255-268.

$53 \mathrm{Vgl}$. zu dieser frühen Hugenotteneinwanderung nach Brandenburg, die als planmäßige Ansiedlung zunächst auf dem Gut des Freiherrn von Schwerin bei Altlandsberg begann, Jean P. Erman/ Pierre Chr. F. Reclam, Mémoires pour servir à l'histoire des réfugiés françois dans les états du Roi, 9 Bde., Berlin 1782-1799, hier Bd. 1, S. 57f. und S. 349-356; Eduard Muret, Geschichte der Französischen Kolonie in Brandenburg-Preußen, unter besonderer Berücksichtigung der Berliner Gemeinde, Berlin 1885, S. 5f.; Karl Manoury, Die Geschichte der französischen Kirche in Berlin. Hugenottenkirche 1672-1955, Berlin 1955, S. 1f.; Opgenoorth, Friedrich Wilhelm, Bd. 2, S. 303; Eckart Birnstiel, Die 
te Aufnahmeangebot für fünfzig aus Wien und Niederösterreich vertriebene jüdische Familien einen eigentlichen Auftakt für die Aufnahme religiös Verfolgter. ${ }^{54}$

Gelegenheit für eine massenhafte Anwerbung von Einwanderern bot sich dann mit dem großen Exodus der Hugenotten, der im Zuge des verschärften konfessionspolitischen Vorgehens der französischen Regierung seit 1681 und insbesondere nach der Aufhebung des Edikts von Nantes im Oktober 1685 stattfand. ${ }^{55}$ Gerade bei den Hugenotten zeigt sich, wie wenig sich eine Migrationstypologie bewährt hat, die zwischen >freiwilliger` beziehungsweise >marktbedingter`, >erzwungener` sowie sstaatlich gelenkter Wanderung unterscheidet. ${ }^{56}$ Diese Migrationstypen bilden hier wie in anderen Fällen keine distinkten Kategorien, sondern verschiedene, komplementäre Facetten eines Vorgangs, weil die Unterscheidung nach sfreiwilliger und serzwungener Migration eher die Auswanderung, sstaatlich gelenkte Migration jedoch eher die Einwanderung betrifft. Marktbedingungen hingegen spielen sowohl bei der Auswanderung als auch bei der Einwanderung fast immer eine Rolle. ${ }^{57}$

Nachdem in England bereits 1681 mit der >Hampton Court Proclamation` eine Einladung an übersiedlungswillige Protestanten vom Kontinent ergangen war und verschiedene niederländische Städte und Provinzen Privilegienangebote veröffentlicht hatten ${ }^{58}$, entschied sich im Heiligen Römischen Reich zuerst Kurfürst Karl II.

Hugenotten in Berlin. Eine Gemeinde auf der Suche nach ihrer Kirche, in: Rudolf von Thadden/Michelle Magdelaine (Hg.), Die Hugenotten 1685-1985, München 1985, S. 115-126, hier S. 115f.; und Niggemann, Immigrationspolitik, S. 57f.

54 Zusammenfassend zur Ausweisung der Juden aus Wien und Niederösterreich Jersch-Wenzel, Juden, S. 26f.; Brigitte Scheiger, Juden in Berlin, in: Jersch-Wenzel/John (Hg.), Von Zuwanderern zu Einheimischen, S. 153-488, hier S. 168-171; und Selma Stern, Der preußische Staat und die Juden, 4 Bde., Tübingen 1962-1975, hier Bd. 1/1, S. 10f. Zur Aufnahme in Brandenburg Scheiger, Juden, S. 158 und 164-168; Jersch-Wenzel, Juden, S. 27; dies., Gemeinde, S. 14; Opgenoorth, Friedrich Wilhelm, Bd. 2, S. 304f.; Asche, Neusiedler, S. 96-98; Stern, Staat Bd. 1/1.

55 Vgl. hierzu im Überblick Ulrich Niggemann, Hugenotten, Köln/Weimar/Wien 2011, S. 23-30; sowie den Beitrag von Alexander Schunka in diesem Band.

56 Diese Typologie wird insbesondere von Thomas Klingebiel vertreten; vgl. Klingebiel, Migration. 57 Im Falle der Hugenotten weist auch Klingebiel auf diesen Umstand hin, doch ist dies eben nicht die Ausnahme, sondern der Regelfall; Klingebiel, Migration, S. 36.

58 Die am 28. Juli 1681 im >Privy Council beschlossene, jedoch erst im September 1681 gedruckte Proklamation ist ediert z.B. bei Mempel (Bearb.), Gewissensfreiheit, S. 32-34. Zur Hugenottenaufnahme in England vgl. Fernand de Schickler, Les Églises du Refuge en Angleterre, 3 Bde., Paris 1892, hier Bd. 2, S. 270-359; William Cunningham, Alien Immigrants to England, 2. Aufl. London/New York 1962, S. 223-249; A.P. Hands/Irene Scouloudi, French Protestant Refugees Relieved Through the Threadneedle Church, London 1681-1687, London 1971, S. 1-18; Robin D. Gwynn, Huguenot Heritage. The History and Contribution of the Huguenots in Britain, 2. Aufl. Brighton 2001, S. 44-51, 71-73, 166-182; Bernard Cottret, The Huguenots in England. Immigration and Settlement c. 1550-1700, Cambridge 1991, S. 185-190; Barbara Dölemeyer, Die Hugenotten, Stuttgart 2006, S. 63-69; und Niggemann, Immigrationspolitik, S. 71-73 und 96-98. Zu den niederländischen Aufnahmeedikten vgl. Hans Bots, Le Refuge dans les Provinces-Unies, in: Eckart Birnstiel/Chrystel 
von der Pfalz für ein Aufnahmeedikt, die `Friedrichsfelder Capitulation`von 1682, die freilich aus Sorge vor der Reaktion Frankreichs nicht publiziert wurde und die sich zudem nur auf eine konkrete Gruppe von Einwanderern für einen bestimmten Ort - nämlich Friedrichsfeld - bezog. ${ }^{59}$ Auch Herzog Georg Wilhelm von Braunschweig-Lüneburg-Celle ließ bereits im August 1684 ein Einladungsedikt ergehen ${ }^{60}$, doch die Mehrzahl der gezielt an die Hugenotten gerichteten und mit unterschiedlichen Privilegien ausgestatteten Texte wurde erst nach der Aufhebung des Edikts von Nantes erlassen. Beispiele hierfür sind das `Potsdamer Edikt $<$ Kurfürst Friedrich Wilhelms von Brandenburg ${ }^{61}$, die >Droits et privilèges` Markgraf Christian Ernsts von Brandenburg-Bayreuth ${ }^{62}$, das Novemberedikt Herzog Ernst Augusts von Hannover ${ }^{63}$, die >Concessions et privilèges` Landgraf Karls von Hessen-Kassel ${ }^{64}$ oder die beiden Privilegienedikte Markgraf Johann Friedrichs von Brandenburg-Ansbach. ${ }^{65}$

Bernat (Hg.), La Diaspora des Huguenots. Les réfugiés protestants de France et leur dispersion dans le monde (XVIe-XVIIIe siécles), Paris 2001, S. 63-74; Hans Bots u.a. (Hg.), Vlucht naar de Vrijheid. De Hugenoten en de Nederlanden, Amsterdam 1985, S. 68-70; und Willem Frijhoff, Uncertain Brotherhood. The Huguenots in the Dutch Republic, in: Bertrand van Ruymbeke/Randy J. Sparks (Hg.), Memory and Identity. The Huguenots in France and the Atlantic Diaspora, Columbia 2003, S. 128171, hier S. 143-151. Überblick über die englischen und niederländischen Erlasse auch bei Niggemann, Hugenotten, S. 51-53.

59 Erlass Kf. Karls II., Heidelberg, 10. Oktober 1682, abgedruckt bei Mempel (Bearb.), Gewissensfreiheit, S. 57-60. Vgl. dazu Ernst, Kirche, S. 336; Asche, Neusiedler, S. 441f.; Guillemenot-Ehrmantraut, Immigration, 26f.

60 Privilegienedikt Hg. Georg Wilhelms, Celle, 9. August 1684, abgedruckt bei Klingebiel (Bearb.), Hugenotten, S. 47-52.

61 Edikt Kf. Friedrich Wilhelms, Potsdam, 29. Oktober 1685, abgedruckt z.B. bei Mengin (Bearb.), Recht, S. 186-196. Vgl. zum Edikt und seiner Entstehung z.B. Grieshammer, Studien, S. 32f.; und vor allem Kohnke, Edikt; dies., Zur Vorgeschichte, Entstehung und Bedeutung des Edikts von Potsdam, in: Ingrid Mittenzwei (Hg.), Hugenotten in Brandenburg-Preußen, Berlin (Ost) 1987, S. $13-26$.

62 Edikt Mgf. Christian Ernsts, Bayreuth, 27. November 1685, abgedruckt bei Georg Schanz, Zur Geschichte der Colonisation und Industrie in Franken, Erlangen 1884 (Abt. 2: Urkundliche Beilagen), S. 6-8. Vgl. dazu auch August Ebrard, Christian Ernst von Brandenburg-Baireuth. Die Aufnahme reformirter Flüchtlingsgemeinden in ein lutherisches Land 1686-1712, Gütersloh 1885, S. 21; Karl Hintermeier, Selbstverwaltungsaufgaben und Rechtsstellung der Franzosen im Rahmen der Erlanger Hugenotten-Kolonisation von 1686 bis 1708, in: Erlanger Bausteine zur fränkischen Heimatforschung, 34. 1986, S. 37-162, hier S. 53-60; Ulrich Niggemann, Die Hugenotten in Brandenburg-Bayreuth. Immigrationspolitik als `kommunikativer Prozeßく, in: Braun/Lachenicht (Hg.), Hugenotten, S. 107-124, hier S. 110-116; Niggemann, Immigrationspolitik, S. 81-88.

63 Edikt Hg. Ernst Augusts, Hannover, 21. November 1685, abgedruckt bei Klingebiel (Bearb.), Hugenotten, S. 53-55.

64 Edikt Lgf. Karls, Kassel, 12. Dezember 1685, abgedruckt bei Mempel (Bearb.), Gewissensfreiheit, S. 51-56.

65 »Privilèges ecclésiastiques accordez aux François reformés« Mgf. Johann Friedrichs, Ansbach, 4. Januar 1686, und »Privilèges temporels accordez aux François reformés« Mgf. Johann Friedrichs, Ansbach, 1. Februar 1686, vgl. Schanz, Geschichte (Abt. 2), S. 294; und ders., Geschichte, S. 263-265. 
Schätzungsweise 38.000 bis 40.000 Hugenotten kamen in die aufnehmenden Territorien des Heiligen Römischen Reichs Deutscher Nation. ${ }^{66} 16.000$ bis 20.000 von ihnen wanderten in der Regierungszeit der Kurfürsten Friedrich Wilhelm und Friedrich III./I. nach Brandenburg-Preußen ein. ${ }^{67}$ Hessen-Kassel nahm etwa 3.500 bis 4.000 >Réfugiés` auf ${ }^{68}$, die übrigen verteilten sich auf die fränkischen Markgraftümer Brandenburg-Bayreuth und Brandenburg-Ansbach, auf die welfischen Herzogtümer, auf Reichsstädte wie Frankfurt am Main, Hamburg und Nürnberg sowie auf eine ganze Reihe kleinerer Fürstentümer, die zumeist ebenfalls spezielle Aufnahme- und Privilegienedikte erließen. ${ }^{69} \mathrm{Zu}$ beachten ist freilich, dass ein Großteil der Hugenotten nicht nach Deutschland ging, sondern vor allem in die Niederlande und nach England, wo sie oft bessere wirtschaftliche Startbedingungen vorfanden und zudem bereits in größerem Umfang Exilgemeinden vorhanden waren. ${ }^{70}$

Vorausgegangen waren bereits Einzelzugeständnisse; vgl. Wolfgang Dippert, Hugenottenansiedlung und die Geschichte der Schwabacher Reformierten Gemeinde, in: Hartmut Heller/Gerhard Schröttel (Hg.), Glaubensflüchtlinge und Glaubensfremde in Franken, Würzburg 1987, S. 139-153, hier S. $139 f$.

66 Vgl. Beuleke, Studien, S. 4; ders., Die Hugenotten in Niedersachsen, Hildesheim 1960, S. 16; Myriam Yardeni, Le Refuge protestant, Paris 1985, S. 77; Dölemeyer, Aufnahmeprivilegien, S. 303 und 327; Gresch, Hugenotten, S. 83. Von geringeren Zahlen gehen Samuel Mours, Les églises réformées en France, Paris/Straßburg 1958, S. 176; und Warren C. Scoville, The Persecution of Huguenots and French Economic Development 1680-1720, Berkeley/Los Angeles 1960, S. 352, aus.

67 Vgl. v.a. Jürgen Wilke, Die französische Kolonie in Berlin, in: Helga Schultz (Hg.), Berlin 16501800. Sozialgeschichte einer Residenz, 2. Aufl. Berlin 1992, S. 353-430, hier S. 358f. Außerdem dazu Helmut Erbe, Die Hugenotten in Deutschland, Essen 1937, S. 39; Jersch-Wenzel, Juden, S. 70; François David, Les colonies des réfugiés protestants français en Brandebourg-Prusse (1685-1809). Institutions, géographie et évolution de leur peuplement, in: Bulletin de la Société de l'Histoire du Protestantisme en France, 140. 1994, S. 111-142, hier S. 124f.; ders., Les colonies françaises en Brandebourg-Prusse. Une étude statistique de leur population, in: Manuela Böhm/Jens Häseler/Robert Violet (Hg.), Hugenotten zwischen Migration und Integration. Neue Forschungen zum Refuge in Berlin und Brandenburg, Berlin 2005, S. 69-93, hier S. 80-84; Dölemeyer, Aufnahmeprivilegien, S. 327; Gresch, Hugenotten, S. 92.

68 Zahlenangaben bei Erbe, Hugenotten, S. 39; Rudolf Schmidmann, Die Kolonien der Réfugiés in Hessen-Kassel und ihre wirtschaftliche Entwicklung im 17. und 18. Jahrhundert, Diss. Marburg 1929, S. 18-20; Beuleke, Hugenotten, S. 16; Yardeni, Refuge protestant, S. 77; Jochen Desel, Aspekte zur Ansiedlung der Hugenotten und Waldenser in Hessen-Kassel, in: Wegner (Hg.), Hugenotten, S. 95108, hier S. 96; Dölemeyer, Aufnahmeprivilegien, S. 327; Gresch, Hugenotten, S. 111.

69 Vgl. Beuleke, Hugenotten, S. 16; Dölemeyer, Aufnahmeprivilegien, S. 327; dies., Hugenotten, S. 98-160; Gresch, Hugenotten, S. 89-131; Asche, Neusiedler, S. 455; und zusammenfassend ders., Hugenotten in Europa seit dem 16. Jahrhundert, in: Bade/Emmer/Lucassen/Oltmer (Hg.), Enzyklopädie Migration, S. 635-643.

$70 \mathrm{Zu}$ den Zahlenverhältnissen Scoville, Persecution, S. 324; Gwynn, Heritage, S. 31; Dölemeyer, Aufnahmeprivilegien, S. 303, 327. Zu den bereits bestehenden Fremdengemeinden in London Cottret, Huguenots, 8-21; Gwynn, Heritage, S. 33-44; Cunningham, Immigrants, S. 149-157. 
Eng mit dem Hugenottenstrom verbunden waren die Wanderungen der Waldenser und der >Pfälzer`, die zuweilen auch als »Hugenotten im weiteren Sinne« bezeichnet werden. ${ }^{71}$ Diese teils vor religiöser Verfolgung, teils vor kriegerischen Auseinandersetzungen fliehenden Personen wurden häufig zusammen mit den Hugenotten privilegiert und angesiedelt, in einigen Fällen bildeten sie jedoch eigenständige Gemeinschaften, wie etwa die >Pfälzer`-Kolonie in Magdeburg, die mit dem sogenannten Gröninger Privileg vom 25. Mai 1689 geschlossen aus Mannheim angeworben wurde. ${ }^{72}$ Gerade im Hinblick auf die zweite Waldenserwanderung ab $1698^{73}$ wurden auch Territorien aktiv, die sich nach der Aufhebung des Edikts von Nantes an der Anwerbung von Hugenotten nicht beteiligt hatten, so etwa das Herzogtum Württemberg oder die Landgrafschaft Hessen-Darmstadt, in denen nun vor allem ländliche Ansiedlungen entstanden. ${ }^{74}$ Dabei ist jedoch zu unterscheiden zwischen den französischen Waldensern, die rechtlich wie die Hugenotten als Flüchtlinge behandelt wurden, und den savoyischen Waldensern, die vom Herzog ausgewiesen worden waren. ${ }^{75}$ Letztere konnten, ohne einen Affront $\mathrm{zu}$ riskieren, durch offizielle, staatenübergreifenden Hilfsmaßnahmen unterstützt werden. Die Koordination übernahm der niederländische Flüchtlingskommissar Pieter Valkenier, der mit den aufnahmewilligen Landesherren die Privilegien für die Waldenser aushan-

71 Zur Begrifflichkeit Beuleke, Studien, S. 41-43; Bischoff, Hugenotten, S. 116f.; ders., Begriffsverwendung, S. $72 f$.

72 Edikt Kf. Friedrichs III., Gröningen, 25. Mai 1689, gedruckt bei Mylius, Corpus Constitutionum Marchicarum, Bd. 6 (Anhang), Sp. 66-72. Vgl. dazu auch Ernst Thiele, Zur Übersiedlung der französischen Gemeinde Mannheims nach Magdeburg, in: Geschichtsblätter für Stadt und Land Magdeburg, 39. 1904, S. 143-157; Ralph Meyer, Geschichte der Deutsch-Reformierten Gemeinde in Magdeburg von den Anfängen bis auf die Gegenwart, 2 Bde., Magdeburg 1914, hier Bd. 1, S. 59-61; Fischer, Pfälzer Kolonie, S. 17-19; Dieter Elsner, Pfälzer in Magdeburg. »Fremde, bessere Wesen« in der Stadt? Von Mannheim nach Magdeburg, in: Labouvie (Hg.), Leben, S. 57-76, hier S. 58-60.

73 Zum Verbot der Waldenserkirche und den mehrfachen Vertreibungen aus dem savoyischen Piemont sowie zur Verfolgung der französischen Waldenser vgl. Alexander Schunka in diesem Band.

74 Vgl. Gresch, Hugenotten, S. 85, 89-91, 113f.; Dölemeyer, Hugenotten, S. 107-112, 144f.; Harald Schätz, Die Aufnahmeprivilegien für Waldenser und Hugenotten im Herzogtum Württemberg. Eine rechtsgeschichtliche Studie zum deutschen Refuge, Stuttgart 2010; Matthias Asche, Hugenotten und Waldenser in Württemberg. Immigration - Privilegien - Kirchenwesen - Identität - Integration. Ein Vergleich, in: Blätter für württembergische Kirchengeschichte, 110. 2010, S. 81-135.

75 Zur Unterscheidung Theo Kiefner (Bearb.), Die Privilegien der nach Deutschland gekommenen Waldenser, Stuttgart 1990, S. 32, 40-42; Matthias Asche, Waldenser in Mitteleuropa seit der Frühen Neuzeit, in: Bade/Emmer/Lucassen/Oltmer (Hg.), Enzyklopädie Migration, S. 1087-1090; ders., Glaubensflüchtlinge und Kulturtransfer. Perspektiven für die Forschung aus der Sicht der sozialhistorischen Migrations- und der vergleichenden Minderheitenforschung, in: Michael North (Hg.), Kultureller Austausch. Bilanz und Perspektiven der Frühneuzeitforschung, Köln 2009, S. 89-114, hier S. 92-94. 
delte. ${ }^{76}$ Überhaupt handelte es sich bei diesen größeren Gruppen seitens der aufnehmenden Staaten zumeist um mehr oder weniger umfassend organisierte Vorgänge, im Zuge derer für Transportmittel und erste Unterbringung gesorgt wurde. Oft wurden sie durch landesweite Kollektenausschreibungen - in einigen Fällen auch durch Gelder aus dem Ausland - unterstützt. $^{77}$

Obwohl auch die Salzburger Protestanten, die 1731/32 ihre Heimat verließen, rechtlich keine Flüchtlinge, sondern Vertriebene waren, sind die planmäßigen Anwerbungsvorgänge doch mit denen der Hugenottenwanderung vergleichbar. Menschen aus dem Fürstbistum Salzburg hatten schon Jahrzehnte zuvor immer wieder in kleineren Gruppen ihre Heimat verlassen, so etwa Bergbauern aus dem heute zu Osttirol gehörenden Defereggental oder Bergknappen aus Dürrnberg. Dadurch waren bereits Netzwerke entstanden, die insbesondere in die oberdeutschen Reichsstädte reichten. ${ }^{78}$ Als sich dann die Protestanten aus dem Pongau und Pinzgau an das Corpus Evangelicorum in Regensburg wandten ${ }^{79}$, entstand jedoch eine neue Situation. Insbesondere Preußen wurde nun aktiv. Bereits im Sommer 1731 wurde der preußische Gesandte am Regensburger Reichstag angewiesen, die Möglichkeit einer Aufnahme der Salzburger im Königreich zu sondieren, was gegenüber Verhandlungen um einen Verbleib der Betroffenen in ihrer Heimat offenkundig Priori-

76 Dazu Barbara Dölemeyer, >Tractat` oder Begnadigung? Vertragselemente in Exulantenprivilegien, in: Jean-François Kervégan/Heinz Mohnhaupt (Hg.), Gesellschaftliche Freiheit und vertragliche Bindung in Rechtsgeschichte und Philosophie, Frankfurt a.M. 1999, S. 144-164, S. 156-163; dies, Hugenotten, S. 35-37; dies., Privileg oder Vertrag? Valkeniers Verhandlungen mit den deutschen Fürsten, in: Albert de Lange/Gerhard Schwinge (Hg.), Pieter Valkenier und das Schicksal der Waldenser um 1700, Heidelberg 2004, S. 159-174.

77 Vgl. zur Einwanderungsorganisation sowie zu den Kollekten am Beispiel der Hugenotten mit weiteren Literaturhinweisen Niggemann, Immigrationspolitik, S. 118-128, 147-170. Zu den Kollekten im Zusammenhang mit der Waldenseransiedlung auch Dölemeyer, Pieter Valkenier, S. 167f.

78 Vgl. den Beitrag von Alexander Schunka in diesem Band. Zu den Auswanderern aus dem Defereggental und aus Dürrnberg vgl. Gerhard Brandtner, Die Vertreibung der Salzburger Protestanten und ihre Aufnahme in Preußen, in: Bernhard Jähnig/Silke Spieler (Hg.), Kirchen und Bekenntnisgruppen im Osten des Deutschen Reiches. Ihre Beziehungen zu Staat und Gesellschaft. Zehn Beiträge, Bonn 1991, S. 149-175, hier S. 152; Gabriele Emrich, Die Emigration der Salzburger Protestanten 1731-1732. Reichsrechtliche und konfessionspolitische Aspekte, Münster 2002, S. 13f. Vgl. auch Rudolf Leeb, Die große Salzburger Emigration von 1731/32 und ihre Vorgeschichte (Ausweisung der Deferegger 1684), in: Joachim Bahlcke (Hg.), Glaubensflüchtlinge. Ursachen, Formen und Auswirkungen frühneuzeitlicher Konfessionsmigration in Europa, Berlin 2008, S. 277-305; und Astrid von Schlachta, Die Emigration der Salzburger Kryptoprotestanten, in: Rudolf Leeb/Martin Scheutz/ Dietmar Weikl (Hg.), Geheimprotestantismus und evangelische Kirchen in der Habsburgermonarchie und im Erzstift Salzburg (17./18. Jahrhundert), Wien/München 2009, S. 63-92.

79 Vgl. Brandtner, Vertreibung, S. 157f.; Emrich, Emigration, S. 19-21; Schlachta, Emigration, S. 79-86. 
tät besaß ${ }^{80}$ Das preußische Einladungspatent erschien am 2. Februar $1732^{81}$, zu einem Zeitpunkt, als die Verhandlungen mit Salzburg wie auch mit den Vertretern der >Exulanten` bereits abgeschlossen und die ersten Züge auf dem Weg ins ferne Preußen waren. ${ }^{82}$ Etwa 12.000 bis 15.000 Salzburger gelangten wahrscheinlich nach Preußen, einige weitere zogen in andere Gebiete der Monarchie. ${ }^{83}$ Neben dem Peuplierungserfolg spielte sicher auch die Profilierung als protestantische Schutzmacht innerhalb des Reiches für Brandenburg-Preußen eine wichtige Rolle. »Was thut Gott dem Brandenburgischen Hause für Gnade! denn dieses gewiß von Gott kommt « - in diesen Worten Friedrich Wilhelms I. kommt deutlich die wirtschaftlich utilitaristische Grundtendenz der Salzburgeransiedlung in Preußen zum Ausdruck. $^{84}$

Nicht alle aus dem Fürstbistum ausgewanderten Protestanten gelangten nach Brandenburg-Preußen. Einige blieben im Herzogtum Württemberg, das auf dem Reiseweg lag. Herzog Eberhard Ludwig hatte nämlich ebenfalls Interesse an einer Ansiedlung dieser Leute und machte ihnen entsprechende Angebote. ${ }^{85}$ HessenKassel hatte bereits der Gesandtschaft, die sich vor der Auswanderung auf dem Weg nach Berlin befand, Angebote unterbreitet, wobei insbesondere Bergleute, von denen freilich kaum welche unter den Auswanderern waren, in Hessen bleiben sollten. Landgraf Friedrich, zugleich König von Schweden, wollte darüber hinaus Holzarbeiter für eine Ansiedlung in Schweden gewinnen. ${ }^{86}$ Schließlich überzeugte auch

80 Vgl. insbesondere Mack Walker, Der Salzburger Handel. Vertreibung und Errettung der Salzburger Protestanten im 18. Jahrhundert, Göttingen 1997, S. 80-82. Dazu wie auch zur Politik des Kaisers in dieser Angelegenheit Emrich, Emigration, S. 58-63; sowie Brandtner, Vertreibung, S. 160. 81 Aufnahmepatent für die Salzburger durch Kg. Friedrich Wilhelm I., Berlin, 2. Februar 1732, abgedruckt bei Beheim-Schwarzbach, Colonisationen, S. 201f. Vgl. zum Aufnahmepatent auch August Skalweit, Die ostpreußische Domänenverwaltung unter Friedrich Wilhelm I. und das Retablissement Litauens, Leipzig 1906, S. 271; Brandtner, Vertreibung, S. 160. Das Ausweisungsedikt Fürstbischof Firmians war am 31. Oktober 1731 ausgefertigt worden; vgl. Beheim-Schwarzbach, Colonisationen, 185f.; Brandtner, Vertreibung, S. 158f.; Emrich, Emigration, S. 29-34.

$82 \mathrm{Zu}$ den Verhandlungen und der Gesandtschaft der Salzburger Protestanten nach Berlin BeheimSchwarzbach, Colonisationen, S. 182; Brandtner, Vertreibung, S. 160.

83 Von 20.694 Personen für den Gesamtstaat Brandenburg-Preußen spricht Beheim-Schwarzbach, Colonisationen, S. 203; 15.508 seien nach Ostpreußen gelangt; ebd., S. 208. Zurückhaltendere Zahlenangaben bei Rainer Walz, Die Ansiedlung der Salzburger Emigranten in Ostpreußen, in: Klaus Militzer (Hg.), Probleme der Migration und Integration im Preußenland vom Mittelalter bis zum Anfang des 20. Jahrhunderts, Marburg 2005, S. 105-140, hier S. 114. Vgl. insgesamt auch Charlotte E. Haver, Salzburger Protestanten in Ostpreußen seit dem 18. Jahrhundert, in: Bade/Emmer/Lucassen/Oltmer (Hg.), Enzyklopädie Migration, S. 938-941.

84 Zitiert nach Beheim-Schwarzbach, Colonisationen, S. 203.

85 Diverse Verordnungen zur Aufnahme der Salzburger in Württemberg listen Achim Landwehr/Thomas Simon (Bearb.), Repertorium der Policeyordnungen der frühen Neuzeit Bd. 4: Baden und Württemberg, Frankfurt a.M. 2001, auf.

86 Beheim-Schwarzbach, Colonisationen, S. 182. 
der Kurfürst von Hannover einige der Salzburger und der in ihrem Gefolge emigrierenden Berchtesgadener Protestanten, sich in seinem Territorium anzusiedeln. Die Einwanderer ließen sich in einer Reihe von Ämtern und Städten nieder, so in Hannoversch Münden, Northeim, Göttingen, Hameln, Springe und Lauenstein. ${ }^{87}$ Zudem gingen etwa zweihundert Salzburger in die britische Kolonie Georgia. ${ }^{88}$

Noch unter König Friedrich Wilhelm I. begann auch die Ansiedlung böhmischer Emigranten in Brandenburg, und besonders in Berlin. Viele von ihnen kamen als Sekundärmigranten aus Sachsen, wo sie, sofern sie nicht als strikte Lutheraner galten, zunehmend unter Druck gerieten. Auch die auf dem Gut des sächsischen Geheimen Rats Nikolaus Ludwig Graf von Zinzendorf angesiedelte, stark von spiritualistischen Vorstellungen geprägte Gemeinde, die als Herrnhuter Brüdergemeine bekannt wurde, war davon betroffen. ${ }^{89}$ Überdies führten wirtschaftliche Probleme bei vielen in Sachsen und der Oberlausitz wohnhaften Einwanderern dazu, dass sich verschiedene Gruppen auf die Suche nach einer neuen Niederlassungsmöglichkeit begaben. Hinzu kam die weiterhin anhaltende Auswanderung aus Böhmen selbst. ${ }^{90}$ Unter Friedrich II. wuchs die Berliner Kolonie weiter an, und es wurden zusätzliche Ansiedlungen in Rixdorf, Nowawes bei Potsdam und in einigen anderen Orten geschaffen. ${ }^{91}$ Nach der Eroberung Schlesiens durch Preußen wurden auch hier zahlreiche Böhmen angesiedelt, darunter auch Mitglieder der Brüder-Unität. ${ }^{92}$

$\mathrm{Zu}$ Peuplierungszwecken angeworben wurden in einigen Fällen auch kleinere Gruppierungen wie die Mennoniten, die schon erwähnte Herrnhuter Brüdergemeine oder sogenannte >Inspirierte`, die - oft nur temporär geduldet - von Ausweisungen

87 Ausführlicher zur Niederlassung in Kurhannover Theodor Roscher, Böhmische und Salzburgische Exulanten im Hannoverland, in: Hannoversche Geschichtsblätter, 2. 1899, S. 157-159, 163f., 170-172; Viktor Loewe, Die Einwanderung der Berchtesgadener in Kurhannover, in: Zeitschrift des Historischen Vereins für Niedersachsen, 1902, S. 64-84; Fritz Klein, Die Einwanderung der `Berchtolsgadener Exulanten` in Kurhannover 1733, in: Hannoversche Geschichtsblätter, 34. 1980, S. 161-174.

88 Walker, Handel, S. 131; Horst Kenkel/Gerhard Florey, Salzburger in Amerika, in: Friederike Zaisberger (Hg.), Reformation. Emigration. Protestanten in Salzburg, Salzburg 1981, S. 133-136.

89 Vgl. Winter, Emigration, S. 92; Eva-Maria Graffigna, Böhmen in Berlin, in: Jersch-Wenzel/John (Hg.), Von Zuwanderern zu Einheimischen, S. 491-591, hier S. 506. Vgl. zu Zinzendorf und zur Brüdergemeine einführend Dietrich Meyer, Zinzendorf und die Herrnhuter Brüdergemeine 17002000, Göttingen 2000; ders., Herrnhuter Brüdergemeine in Europa seit der Frühen Neuzeit, in: Bade/Emmer/Lucassen/Oltmer (Hg.), Enzyklopädie Migration, S. 632-635; und Matthias Graf, Herrnhuter in Hessen, Frankfurt a.M. 2006, S. 18-76.

90 Vgl. Winter, Emigration, S. 86-130; Graffigna, Böhmen, S. 506-508.

91 Vgl. Neugebauer, Zentralprovinz, S. 129f.; Ulrich Schmelz, Zur Rolle der Ausländer beim Ausbau der Residenzstadt Potsdam (bis zum Jahre 1786), in: Hahn/Hübener/Schoeps (Hg.), Potsdam, S. 99114, hier S. 108-112; Graffigna, Böhmen, S. 532-536; Karin C. Jung, Die Böhmische Weberkolonie Nowawes 1751-1767 in Potsdam-Babelsberg. Bauliche und städtebauliche Entwicklung, Berlin 1997, S. 11-62.

92 Beheim-Schwarzbach, Colonisationen, S. 338-352; Winter, Emigration, S. 131-145. 
bedroht und auf der Suche nach neuen Heimstätten waren. Dies gilt etwa für Brandenburg-Preußen, wo nach dem Dreißigjährigen Krieg zusammen mit reformierten Niederländern auch einige Mennoniten angesiedelt und aus Polen einwandernde Mennoniten zumindest geduldet wurden. ${ }^{93}$ Auch die Herzöge von SchleswigHolstein-Gottorf, die Grafen von Isenburg-Büdingen oder die Grafen von Wied siedelten Mennoniten, Herrnhuter und Inspirierte in ihrem Herrschaftsgebiet an, und zwar besonders in Neustadtanlagen wie Friedrichstadt und Neuwied, die einen besonderen Ruf als religiöse Freistätten hatten. ${ }^{94}$

Üblicherweise erhielten die hier genannten Einwanderergruppen Privilegien, die ihren kirchlichen, rechtlichen und wirtschaftlichen Status festlegten und zugleich als Anreiz für eine Ansiedlung konzipiert waren. Dementsprechend mussten sie so gefasst werden, dass sie auf potenzielle Einwanderer attraktiv wirkten. Ein typisches Element solcher - oft schon früher erprobten - Privilegien war die Steuerfreiheit für eine festgelegte Anzahl von Jahren. Am intensivsten untersucht wurden in der Forschung die Privilegien für die Hugenotten. Schon in den 1660er Jahren erhielten sie in der Kurpfalz bis zu neun Jahre Steuerbefreiung. Solche Steuerfreiheiten sowie die Befreiung von Einfuhrzöllen bei der Einwanderung waren dann auch bei der Hugenotteneinwanderung seit 1685 allgemein üblich. Dabei fällt auf, dass oft die Edikte der kleineren Territorien bei den Steuerfreijahren besonders großzügig waren. Während Brandenburg-Preußen nämlich zunächst nur maximal zehn Jahre bot, versprach Landgraf Karl von Hessen-Kassel im Höchstfall bereits fünfzehn Jahre. Braunschweig-Lüneburg-Calenberg überbot diese Zusagen noch, indem zwanzig oder sogar 25 Jahre vorgesehen waren. ${ }^{95}$ Darüber hinaus wurden die kostenlose Zuteilung von Bauland und Baumaterialien sowie freie Unterbringung für eine Übergangszeit zugesagt. Im kirchlichen Bereich erhielten die Hugenotten das Recht

$93 \mathrm{Zu}$ den mit den reformierten Niederländern in die Kurmark eingewanderten Mennoniten vgl. Asche, Neusiedler, S. 433; ansonsten auch Beheim-Schwarzbach, Colonisationen, S. 147-153.

$94 \mathrm{Zu}$ Neuwied vgl. Wilfried Ströhm, Die Herrnhuter Brüdergemeine im städtischen Gefüge von Neuwied. Eine Analyse ihrer sozialökonomischen Entwicklung, Boppard a.R. 1988; Stefan Volk, Peuplierung und religiöse Toleranz. Neuwied von der Mitte des 17. bis zur Mitte des 18. Jahrhunderts, in: Rheinische Vierteljahrsblätter, 55. 1991, S. 205-231; zu Ansiedlungsorten in SchleswigHolstein Robert Dollinger, Geschichte der Mennoniten in Schleswig-Holstein, Hamburg und Lübeck, Neumünster 1930. Zur Ansiedlung von Herrnhutern auf dem Herrnhaag bei Büdingen vgl. Graf, Herrnhuter; und Klaus-Peter Decker, Die Herrnhuter in der Grafschaft Ysenburg-Büdingen. Eine Gegenelite als `Staat im Staate`, in: Markus A. Denzel/Matthias Asche/Matthias Stickler (Hg.), Religiöse und konfessionelle Minderheiten als wirtschaftliche und geistige Eliten, St. Katharinen 2009, S. 119-159.

95 Art. 5 und 6 des Edikts Kf. Friedrich Wilhelms, Potsdam, 29. Oktober 1685, abgedruckt bei Mengin (Bearb.), Recht, S. 190-192; Art. 3 des Edikts Ldf. Karls, Kassel, 12. Dezember 1685, gedruckt bei Mempel (Bearb.), Gewissensfreiheit, S. 51-56; Art. 6 und 8 des Edikts Hz. Ernst Augusts, Hannover, 21. November 1685, abgedruckt bei Klingebiel (Bearb.), Hugenotten, S. 53-55. Vgl. auch Niggemann, Immigrationspolitik, S. 68. 
auf freie Religionsausübung sowie eigene französisch-reformierte Geistliche zugesprochen, wobei dieses Recht in lutherischen Territorien wie Brandenburg-Bayreuth auf einige zentrale Ansiedlungsorte beschränkt sein konnte. ${ }^{96}$ Deutliche Unterschiede gab es in der Verwaltung der französisch-reformierten Kirchen. Während in lutherischen Territorien wie Braunschweig-Lüneburg und Brandenburg-Bayreuth/ Ansbach die presbyterial-synodale Kirchenverwaltung in der Folge schwerer gemeindeinterner Konflikte vom Landesherren zugelassen wurde, fehlte das synodale Element in Hessen-Kassel und Brandenburg-Preußen. ${ }^{97}$ Die nähere Untersuchung der Vorgänge, die zu den verschiedenen Formen einer Kirchenverwaltung führten, hat gezeigt, dass sich die Hugenotten in den von reformierten Herrschern regierten Territorien offenbar selbst nicht entschieden genug für die Etablierung ihrer in Frankreich entwickelten Kirchenverfassung einsetzten - vielleicht auch weil sie die reformierte Landesherrschaft als Garanten ihrer Religionsfreiheit ansahen. ${ }^{98}$

In einigen Territorien wie Brandenburg-Bayreuth und Hessen-Kassel wurde den hugenottischen Handwerkern die Möglichkeit eingeräumt, außerhalb der Zünfte tätig zu werden. Brandenburg-Preußen hingegen ordnete die kostenlose Aufnahme in die heimischen Zünfte an - eine Entwicklung, die mittelfristig freilich auch in anderen Territorien festgestellt werden kann. ${ }^{99}$ Eine Besonderheit des brandenbur-

96 Zum Artikel 11 des Potsdamer Edikts Grieshammer, Studien, S. 47; Kohnke, Edikt, S. 258; Birnstiel, Hugenotten, S. 123; Asche, Neusiedler, S. 421. Zu Hessen-Kassel Walter Mogk, Voraussetzungen für die Einwanderung von Hugenotten und Waldensern nach Hessen-Kassel, in: Jochen Desel/Walter Mogk (Hg.), Die Hugenotten und Waldenser in Hessen-Kassel, Kassel 1978, S. 13-41, hier S. 25f.; Kadell, Hugenotten, S. 324. Zu den Einschränkungen in Brandenburg-Bayreuth Artikel 2 und 4 des Edikts, Bayreuth, 27. November 1685, gedruckt bei Schanz, Geschichte (Abt. 2), S. 6-8. Vgl. Niggemann, Immigrationspolitik, S. 422f.

97 Vgl. etwa Walter Mogk, Kirchengeschichtliche Aspekte zur Situation der französisch-reformierten Gemeinden im Hessen-Kasselschen Refuge, in: Desel/Mogk (Hg.), Hugenotten, S. 395-435; Asche, Neusiedler, S. 453f., 521; Gresch, Hugenotten, S. 87; Dölemeyer, Hugenotten, S. 46, 82; Jochen Desel, "Sie achten auf ihre Kirchenzucht, weil sie ihre Prediger schätzen«. Gemeinde und Gottesdienst im deutschen Refuge, in: Sabine Beneke/Hans Ottomeyer (Hg), Zuwanderungsland Deutschland. Die Hugenotten, Berlin/Wolfratshausen 2005, S. 17-24, hier S. 19; Matthias Asche, Hugenotten und Waldenser im frühmodernen deutschen Territorialstaat zwischen korporativer Autonomie und obrigkeitlicher Aufsicht, in: Helmut Neuhaus (Hg.), Selbstverwaltung in der Geschichte Europas in Mittelalter und Neuzeit. Tagung der Vereinigung für Verfassungsgeschichte in Hofgeismar vom 10. bis 12. März 2008, Berlin 2010, S. 63-94; Susanne Lachenicht, Hugenotten in Europa und Nordamerika. Migration und Integration in der Frühen Neuzeit, Frankfurt a.M. 2010, S. 189-191.

98 Vgl. Niggemann, Immigrationspolitik, S. 501-511; und ders., Huguenot Attitudes to Church Administration in Brandenburg-Prussia and Hesse-Kassel, in: Proceedings of the Huguenot Society of Great Britain and Ireland, 29. 2008, S. 93-104.

99 Das erste Edikt Mgf. Christian Ernsts von Brandenburg-Bayreuth enthielt noch die Zunftaufnahme, erst 1687 wurden die Hugenotten davon freigestellt; Art. 16 der Deklaration Mgf. Christian Ernsts, Bayreuth, 15. August 1687, abgedruckt in Corpus Constitutionum BrandenburgicoCulmbacensium, 3 Bde., Bayreuth 1746-1748, hier Bd. 2/2, Sp. 634. Zu den Bestimmungen in Hes- 
gischen Aufnahmeedikts war die Zusage einer eigenen französischen Schiedsgerichtsbarkeit. Hier wie auch in einigen anderen Territorien entstand im Laufe der Zeit eine staatliche Sonderverwaltung für die französischen Kolonien und eine französische Gerichtsbarkeit, wobei allerdings die in den größeren Städten angesiedelten Hugenotten deutlich bevorzugt wurden. ${ }^{100}$ Ziel dieser Edikte war neben der Regelung der rechtlichen Verhältnisse bei der Einwanderung und Niederlassung vor allem die Gewinnung von Neusiedlern, weshalb den Hugenotten bei der Abfassung der Edikte oft erhebliches Entgegenkommen gezeigt wurde. Gelegentlich waren solche Edikte überdies mit werbenden Landesbeschreibungen versehen. ${ }^{101}$

Es ging also eindeutig darum, die Hugenotten zur Ansiedlung im jeweiligen Land zu bewegen. Doch nicht nur bei der Ortswahl dürften diese Edikte von Bedeutung gewesen sein. Vielmehr ist davon auszugehen, dass bereits bei der Entscheidung, überhaupt die Heimat zu verlassen, Kenntnisse über mögliche Zielorte und die dort zu erwartenden Ansiedlungsbedingungen eine wesentliche Rolle spielten. ${ }^{102}$ Die Tatsache, dass das Potsdamer Edikt gezielt auch in Frankreich verbreitet wurde $^{103}$, wird dementsprechend mit dazu beigetragen haben, dass Protestanten aus Frankreich sich auf den Weg nach Brandenburg machten. Darüber hinaus wurden die gedruckten Aufnahmeerlasse auch an den Sammelpunkten der Emigranten etwa in Frankfurt am Main, in der Schweiz oder in den Niederlanden - verteilt. Fürstliche Agenten sprachen zudem gezielt einflussreiche Personen wie Manufakturisten oder Prediger an, um möglichst ganze Gruppen von Einwanderern zu gewinnen. ${ }^{104}$ Charakteristisch für die Hugenottenmigration ist der ausgeprägte Konkur-

sen-Kassel und Brandenburg-Preußen: Art. 8 des Edikts Lgf. Karls, gedruckt bei Mempel (Bearb.), Gewissensfreiheit, S. 53; Artikel 7 des Potsdamer Edikts, abgedruckt bei Mengin (Bearb.), Recht, S. 192f. Vgl. dazu auch Niggemann, Immigrationspolitik, S. 298-301, sowie zur weiteren Entwicklung ebd., S. 336-340.

100 Zum Gerichtswesen Artikel 10 des Potsdamer Edikts, gedruckt bei Mengin (Bearb.), Recht, S. 192f. Vgl. dazu und zur weiteren Entwicklung Grieshammer, Studien, S. 61-73; Jürgen Wilke, Rechtsstellung und Rechtsprechung der Hugenotten in Brandenburg-Preußen (1685-1809), in: Thadden/Magdelaine (Hg.), Hugenotten, S. 100-114, hier S. 102-106; David, Colonies des réfugiés, S. 115, 127f.; ders., Colonies françaises, S. 70, 76; Birnstiel/Reinke, Hugenotten, S. 82-85; Asche, Neusiedler, S. 510-513.

101 So etwa das Hessen-Kasselsche Edikt vom 12. Dezember 1685, abgedruckt bei Mempel (Bearb.), Gewissensfreiheit, S. 55f.; werbende Hinweise auch in Art. 3 des >Potsdamer Edikts`, abgedruckt bei Mengin (Bearb.), Recht, S. 188f.

102 Vgl. Schunka, Glaubensflucht, S. 563f.

103 Vgl. v.a. Kohnke, Edikt, S. 254-257; dies., Vorgeschichte, S. 18f.

104 Dazu Michelle Magdelaine, Frankfurt am Main: Drehscheibe des Refuge, in: Thadden/Magdelaine (Hg.), Hugenotten, S. 26-37; Dölemeyer, Hugenotten, S. 37f., 94. Für Einzelbeispiele vgl. Kohnke, Edikt, S. 263f.; Klingebiel, Weserfranzosen, S. 34f.; Michael Peters, Joseph Auguste du Cros als Agent des Markgrafen Christian Ernst von Brandenburg-Bayreuth. Ein Beitrag zur Vorgeschichte der Hugenotten-Kolonisation in Franken, in: Erlanger Bausteine zur fränkischen Heimatforschung, 34. 1986, S. 163-173, hier S. 168-170. 
renzkampf deutscher Territorialherren um die Hugenotten, und zwar besonders um diejenigen, die entweder Vermögen mitbrachten, über spezielle Fertigkeiten verfügten oder als Kaufleute und Manufakturisten den Aufbau von Gewerbebetrieben versprachen. Dieser Konkurrenzkampf äußerte sich nicht nur darin, dass sich die Fürsten mit Privilegienangeboten gegenseitig zu überbieten versuchten, sondern dass es auch immer wieder zu Abwerbungen kam, die regelmäßig zu Verstimmungen zwischen den Territorien führten. So warb das Herzogtum und spätere Kurfürstentum Braunschweig-Lüneburg-Calenberg (Hannover) erfolgreich Hugenotten aus Erlangen ab. ${ }^{105}$ Kursachsen wiederum versuchte seit 1694 mehrfach gezielt, Franzosen aus dem kurbrandenburgischen Halle nach Leipzig zu locken. ${ }^{106}$

Die Hugenotteneinwanderung bildete in vielen Territorien das Muster, nach dem auch andere Neusiedler privilegiert wurden. Auch in dem schon genannten Gröninger Privileg für die in Magdeburg angesiedelte >Mannheimer Kolonie` waren die persönliche Freiheit der Kolonisten, ihre Freiheit von Einquartierungen für fünfzehn Jahre, die Zuteilung von Ackerland für die Bauern, Vergünstigungen beim Hausbau, Handwerksrechte, Religionsfreiheit und generell alle Privilegien, wie sie auch die französische Kolonie genoss, zugesagt. Insbesondere durften die >Pfälzer wie die Hugenotten in Magdeburg einen eigenen Magistrat mit eigener Gerichtsbarkeit bilden. ${ }^{107}$

Die gleichen Rechte wie anderen Kolonisten sicherte das Einladungspatent König Friedrich Wilhelms I. vom Februar 1732 auch den Salzburgern zu, wobei insbesondere auf das preußische Einwanderungsedikt von 1724 Bezug genommen wurde. Demnach erhielten die Einwanderer freies Acker- und Weideland, Baumaterial, Vieh und Ackergerät sowie Saatgut für ein Jahr. Außerdem wurden sie wie üblich für einige Jahre von allen Abgaben befreit. ${ }^{108}$ Fünfjährige Steuerfreiheit, freies Bürgerund Zunftrecht, fünfjährige Freiheit vom Militärdienst sowie die Erlaubnis zur öffentlichen Religionsausübung wurden unter König Friedrich Wilhelm I. auch den böhmischen Neusiedlern zugestanden, während die unter Friedrich II. auf dem Land angesiedelten Böhmen etwas schlechter gestellt waren. Diese mussten, wenn

105 Vgl. Klingebiel, Weserfranzosen, S. 36f.; ders. (Bearb.), Hugenotten, S. 20f.; und Niggemann, Immigrationspolitik, S. 150f.

106 Vgl. insbesondere Katharina Middell, Hugenotten in Kursachsen. Einwanderung und Integration, in: Braun/Lachenicht (Hg.), Hugenotten, S. 51-70; Schunka, Gäste, S. 66-69.

107 Edikt Kf. Friedrichs III., Gröningen, 25. Mai 1689, gedruckt bei Mylius, Corpus Constitutionum Marchicarum, Bd. 6 (Anhang), Sp. 66-72. Vgl. auch Fischer, Pfälzer Kolonie, S. 17-32.

108 Vgl. Rudolph Stadelmann, Friedrich Wilhelm I. in seiner Thätigkeit für die Landescultur Preußens, Leipzig 1878, S. 34-41; Walker, Handel, S. 84f.; Walz, Ansiedlung, passim. »Wiederholtes Patent, daß noch mehrere Handwercker von allerhand Profeßionen, wie auch 400 Familien arbeitsamer Leute [...] nach Preussen verlanget werden«, Berlin, 11. Februar 1724, abgedruckt bei Mylius, Corpus Constitutionum Marchicarum, Bd. 6, Sp. 65-70. 
auch in geringem Ausmaß, Dienste leisten. ${ }^{109}$ Auch die kleineren religiösen Gruppen, die reichsrechtlich nicht anerkannt waren, erhielten in verschiedenen Territorien in gewissem Umfang das Recht auf Religionsausübung, zumindest in Form des sexercitium privatum` oder der >devotio domestica`, die ihnen also Hausandachten und Privatgottesdienste im kleinen Kreis erlaubte. Darüber hinaus partizipierten sie an den Steuerfreijahren der übrigen Neubürger. ${ }^{110}$

Eine gewisse Ausnahme bildeten lediglich die Juden, die nur bedingt von den Einwandererprivilegien, die für christliche Gruppen galten, profitieren konnten. Meist erhielten sie nur als Einzelpersonen eine Ansiedlungserlaubnis. Weitaus seltener wurden ihnen, wie bei der 1671 erfolgten Aufnahme in Brandenburg, als Gruppe eigene Ansiedlungsbedingungen zugestanden, die jedoch erhebliche Restriktionen enthielten. In Kurbrandenburg wurde ihnen zwar eine gewisse Eigenständigkeit in der Gerichtsbarkeit sowie das Recht zur privaten Religionsausübung zugesagt, doch durften sie keine Synagogen errichten. Gerade im Vergleich zu den später privilegierten Hugenotten fallen die Restriktionen bei den Ansiedlungsbedingungen für die Juden auf. ${ }^{11}$

In gewisser Hinsicht gehören auch die >Transmigrationen ${ }^{112}$ in den Kontext der gelenkten Ansiedlung von >Konfessionsmigranten`, auch wenn es sich hier um eine zwangsweise innere Bevölkerungsumsiedlung handelt. Um nämlich einerseits das Ziel einer konfessionellen Homogenisierung der Kernlande zu erreichen und gleichzeitig die Schäden, die merkantilistischen Theorien zufolge durch Abwanderung entstanden, vorzubeugen, gingen die habsburgischen Territorien in der Regierungszeit Karls VI. und dann verstärkt unter Maria Theresia dazu über, Protestanten aus Kärnten und der Steiermark systematisch zu deportieren und in erst jüngst von den Osmanen eroberten Gegenden Ungarns und Siebenbürgens neu anzusiedeln. ${ }^{113}$ Die-

109 Beheim-Schwarzbach, Colonisationen, S. 250-255, 378-387; Graffigna, Böhmen, S. 514-523, 532-536; Neugebauer, Zentralprovinz, S. 129f.; Schmelz, Rolle, S. 108-112; Jung, Weberkolonie. Zu Berlin außerdem Hans J. Reichhardt, Die Böhmen in Berlin 1732-1982, Berlin 1982.

$110 \mathrm{Zu}$ den Privilegien in Neuwied vgl. Volk, Peuplierung, passim; zu Friedrichsstadt den Privilegienerlaß des Hz. von Schleswig, abgedruckt in Corpus Statutorium Slesvicensium Bd. 3, S. 587f.; und zu den Mennoniten in Brandenburg-Preußen (insbesondere Westpreußen) Stefi Jersch-Wenzel, Mennoniten in Westpreußen seit dem 16. Jahrhundert, in: Bade/Emmer/Lucassen/Oltmer (Hg.), Enzyklopädie Migration, S. 789-792.

111 Edikt Kf. Friedrich Wilhelms, Potsdam, 21. Mai 1671, gedruckt bei Mylius, Corpus Constitutionum Marchicarum, Bd. 5/5, Sp. 121-126. Vgl. Jersch-Wenzel, Juden, S. 33-39; Scheiger, Juden, S. 167f.; Asche, Neusiedler, S. 96-98.

112 Siehe hierzu auch den Artikel von Alexander Schunka in diesem Band.

113 Vgl. z.B. Konrad Schünemann, Österreichs Bevölkerungspolitik unter Maria Theresia, Berlin 1935, S. 95-106; Peter F. Barton, Evangelisch in Österreich. Ein Überblick über die Geschichte der Evangelischen in Österreich, Wien 1987, S. 111-114; Erich Buchinger, Die `Landler in Siebenbürgen. Vorgeschichte, Durchführung und Ergebnis einer Zwangsumsiedlung im 18. Jahrhundert, München 1980; sowie Mathias Beer, Österreichische Protestanten (`Landler`) in Siebenbürgen seit dem 18. 
se Maßnahmen der Zwangsumsiedlung entsprachen durchaus der Logik des Merkantilismus und zeugen davon, dass auch die katholischen Habsburger keineswegs, wie bisweilen behauptet, eine "anticolonisatorische « Politik betrieben. ${ }^{114}$

Resümierend lässt sich festhalten, dass gerade die größeren Gruppen von `Glaubensflüchtlingen` begehrte Objekte einer aktiven Bevölkerungspolitik waren. Protestantische Territorien bemühten sich daher intensiv um ihre Anwerbung, wobei den Hugenotten sicher eine besondere Aufmerksamkeit zuteil wurde. Fast immer erhielten religiös verfolgte Einwanderer das Recht zur freien Ausübung ihrer Religion, und darüber hinaus zahlreiche weitere Privilegien wie Steuerfreiheiten oder eine eigene Gerichtsbarkeit. Diese Privilegien waren zum Teil das Ergebnis von Verhandlungen mit Vertretern der Einwanderer selbst und sollten in jedem Fall als Anreiz zur Niederlassung wirken. Benachteiligt waren sicher Juden und kleinere religiöse Gemeinschaften. Letztere erhielten jedoch in einigen Territorien oder an bestimmten Orten religiösen Freistätten. Nicht zu unterschätzen ist sicher über den Aspekt der >Peuplierung ‘ hinaus auch die propagandistische Wirkung, die etwa die Aufnahme einer großen Zahl von Hugenotten und Salzburgern für Länder wie Brandenburg-Preußen hatte.

\section{Landesausbau und 'Peuplierung,}

Die Frühe Neuzeit war auch eine Phase des forcierten Landesausbaus. Sofern es bei diesen Meliorationen nicht um Einzelinitiativen der ansässigen Bevölkerung ging, mit dem Ziel, ihre Wirtschaftsgrundlagen auszuweiten ${ }^{115}$, so handelte es sich meist um großangelegte staatliche Maßnahmen, die mit der Ansiedlung von Einwanderern eng verbunden waren beziehungsweise sich wechselseitig bedingten. Dahinter stand der Wunsch sowohl nach Bevölkerungsvermehrung als auch nach der Nutzung brachliegender Ressourcen zwecks Erhöhung der Staatseinnahmen.

Jahrhundert, in: Bade/Emmer/Lucassen/Oltmer (Hg.), Enzyklopädie Migration, S. 818-820; Stephan Steiner, Transmigration. Ansichten einer Zwangsgemeinschaft, in: Leeb/Scheutz/Weikl (Hg.), Geheimprotestantismus, S. 331-360; ders., Rückkehr unerwünscht. Deportationen in der Habsburgermonarchie der Frühen Neuzeit und ihr europäischer Kontext, Wien 2014, S. 243-298.

114 Zitat von Beheim-Schwarzbach, Colonisationen, S. 222. Dass freilich die Kolonisation Ungarns nicht im Mittelpunkt der >Transmigrationen`stand, betont Buchinger, Landler, S. 54-59.

115 Hans-Jürgen Nitz weist dabei besonders auf die Auswirkungen steigender Kornpreise vom 16. bis zur Mitte des 17. Jahrhunderts und dann erneut gegen Ende des 18. Jahrhunderts hin: HansJürgen Nitz, Transformation of Old and Formation of New Structures in the Rural Landscape of Northern Central Europe during the 16th to 18th Centuries under the Impact of the Early Modern Commercial Economy, in: ders., Historische Kolonisation und Plansiedlung in Deutschland. Ausgewählte Arbeiten, Bd. 1, hg.v. Günther Beck, Berlin 1994, S. 317-336, hier v.a. S. 324-328. 
Der Übergang von den Repeuplierungsmaßnahmen nach dem Dreißigjährigen Krieg und einer darüber hinausgehenden systematischen Ansiedlung von Menschen im ländlichen Umfeld ist fließend. Verschiedentlich gingen schon die unmittelbaren Wiederbesiedlungsversuche mit der Erprobung neuer Anbaumethoden und der Urbarmachung bis dahin ungenutzten Landes einher. In Brandenburg bauten niederländische Kolonisten bereits seit 1651 unter der Leitung der Kurfürstin Louise Henriette eine Musterwirtschaft im Amt Oranienburg auf. ${ }^{116}$ Mit einigen friesischen beziehungsweise nordniederländischen Kolonisten wurden zur gleichen Zeit Verträge zur Anlage von Dörfern und zur Trockenlegung von Land in der Altmark und andernorts abgeschlossen. ${ }^{117}$ Das weitreichende, mit radikalen Reformideen (Abschaffung der Leibeigenschaft und aller Frondienste) einhergehende Projekt der Domänenbewirtschaftung durch die Brüder Lamy wurde hingegen nicht durchgeführt. ${ }^{118}$

Trotz einiger Fehlschläge in der Frühphase setzten die Kurfürsten und Könige von Brandenburg-Preußen in den Folgejahrzehnten Maßstäbe bei der ländlichen Kolonisation. Seit 1683 gab es Bemühungen, in der Milchwirtschaft und Viehzucht erfahrene Schweizer Bauern in die Mark zu ziehen. 1685 konnten dann tatsächlich die ersten vierzehn Familien aus dem Berner Land in neu errichteten Dörfern bei Potsdam angesiedelt werden. ${ }^{119}$ Diese frühen Schweizer Kolonisten erhielten noch Privilegien, die ihnen die reformierte Religionsausübung, eigene Pfarrer, eine presbyteriale Kirchenverwaltung sowie in materieller Hinsicht Steuerfreiheit für dreißig Jahre zusicherten. Überdies waren die Schweizer und alle ihre Nachkommen von der Leibeigenschaft befreit. Eine Besonderheit bestand darin, dass der Magistrat der Stadt Bern quasi als >Garantieinstanz` eingesetzt wurde und somit im Falle von Privilegienverletzungen seitens der brandenburgischen Regierung zugunsten seiner ehemaligen Untertanen intervenieren konnte. ${ }^{120}$ Seit 1690 wurden Kolonisten aus den Kantonen Bern und Zürich schwerpunktmäßig im Land Ruppin und bei Potsdam angesetzt, wo zahlreiche Bauernstellen neu geschaffen werden konnten. Überwiegend handelte es sich um sehr kinderreiche Familien, die aufgrund ihrer

116 Knapp dazu Otto Glaser, Die Niederländer in der Brandenburg-Preußischen Kulturarbeit, Berlin 1939, S. 26f.; Opgenoorth, Friedrich Wilhelm, Bd. 1, S. 230f.; ausführlich Asche, Neusiedler, S. 351360; und Ulrike Hammer, Kurfürstin Luise Henriette. Eine Oranierin als Mittlerin zwischen den Niederlanden und Brandenburg-Preußen, Münster 2001, S. 84-89.

117 Opgenoorth, Friedrich Wilhelm, Bd. 1, S. 173f.; Asche, Neusiedler, S. 264.

118 Vgl. Grieshammer, Studien, S. 21-23; Opgenoorth, Friedrich Wilhelm, Bd. 1, S. 175f.; Asche, Neusiedler, S. 411 und 426-431.

119 Asche, Neusiedler, S. 218 mit Anm. 820, 434f.; ders., Schweizer Protestanten, S. 971f.; Franz, Krieg, S. 100; Henning Heese, Einleitende Bemerkungen zur Entstehung und Entwicklung der Schweizer Kolonie im Golmischen Bruch bei Potsdam, in: ders. (Hg.), 300 Jahre Schweizer Kolonie am Golmischen Bruch bei Potsdam 1685-1985, St. Augustin-Hangelar 1985, S. 5-43.

120 Vgl. insbesondere Asche, Neusiedler, S. 462f. Abdruck des Privilegienvorschlags bei Kiefner (Bearb.), Privilegien, S. 1306f.; vgl. auch Heese, Bemerkungen, S. 7-16. 
Armut aus der Schweiz auswanderten oder gar von den dortigen Almosenkammern zur Auswanderung gedrängt wurden. Sie erhielten nun keine Privilegien mehr, sondern Ansiedlungsverträge, die freilich im Wesentlichen den Privilegien der früheren Kolonisten ähnelten. ${ }^{121}$

1686 begann dann in der Folge des Potsdamer Edikts die Wiederbesiedlung zahlreicher wüstgefallener Dörfer in der Uckermark und im Land Ruppin mit Hugenotten und wallonischstämmigen >Pfälzern ‘. ${ }^{122}$ Hugenotten und Waldenser wurden auch in Hessen-Kassel, Hessen-Darmstadt, Württemberg, Baden-Durlach und Brandenburg-Bayreuth in ländlichen Kolonien angesiedelt, wo sie neben dem Textilgewerbe vor allem im Ackerbau tätig waren. In Hessen-Kassel konnten auf diese Weise zahlreiche spätmittelalterliche Wüstungen neu besiedelt werden. ${ }^{123}$

Auch im 18. Jahrhundert brachten Krieg und Seuchenzüge Verheerungen und große Bevölkerungsverluste mit sich. 1709 dezimierte die Pest die Bevölkerung in Preußisch-Litauen. ${ }^{124}$ Das >Retablissement`, das meist allein König Friedrich Wilhelm I. angerechnet wird, begann bereits unter Friedrich I. In der ersten Phase stand neben den Versuchen, die geflüchtete Landbevölkerung zur Rückkehr zu bewegen, die Anwerbung neuer Siedler aus der Schweiz, aus Holstein, Schweden, Pommern, Hannover, Anhalt, Sachsen und Nassau-Siegen im Mittelpunkt. ${ }^{125}$ Spätestens ab 1723 kann von durchschlagenderen Erfolgen die Rede sein, sodass trotz der 1726/27 über Preußen hereinbrechenden Hungerkrise, die auch das >Retablissement` zu gefähr-

121 Vgl. Asche, Neusiedler, S. 218-221 und 462-484; ganz knapp auch Franz, Krieg, S. 100f.; und Neugebauer, Zentralprovinz, S. 70f.

122 Vgl. Margarete Pick, Die französischen Kolonien in der Uckermark, Prenzlau 1935; Enders, Uckermark, S. 410-415; Asche, Neusiedler, S. 302-347.

123 Zu Hessen-Kassel Kadell, Hugenotten, S. 86-175, 457-542; Lothar Zögner, Hugenottendörfer in Nordhessen. Planung, Aufbau und Entwicklung von siebzehn französischen Emigrantenkolonien. Eine Studie zur historisch-geographischen Landeskunde, Marburg 1966; Sigrid Althaus, Hugenottendörfer um Marburg und Frankenberg, Marburg 1989; sowie die Beiträge bei Desel/Mogk (Hg.), Hugenotten. Zu den ländlichen Kolonien in Brandenburg-Bayreuth vgl. Schanz, Geschichte, S. 16f.; Hintermeier, Selbstverwaltungsaufgaben, S. 46f.; Johannes E. Bischoff, ২Hugenotten-Orte ken neben Erlangen, in: Friederich (Hg.), 300 Jahre Hugenottenstadt, S. 53-58; Niggemann, Hugenotten in Brandenburg-Bayreuth, S. 108; ders., Immigrationspolitik, S. 232f. und 239f. Zu HessenDarmstadt, Baden-Durlach und Württemberg Dölemeyer, Hugenotten, S. 108-112, 142-145; Gresch, Hugenotten, S. 89-91, 113f. Zu Württemberg auch Asche, Hugenotten und Waldenser.

124 Vgl. zur Situation Ostpreußens Stadelmann, Friedrich Wilhelm I., S. 34f.; Skalweit, Domänenverwaltung, S. 10f., 245f.; Fritz Terveen, Gesamtstaat und Retablissement. Der Wiederaufbau des nördlichen Ostpreußen unter Friedrich Wilhelm I. 1714-1740, Göttingen 1954, S. 17-19; Brandtner, Vertreibung, S. 161f.; Walker, Handel, S. 75f.; Walz, Ansiedlung, S. 111f.

$125 \mathrm{Zu}$ den verschiedenen Kolonisationsversuchen seit 1710 vgl. Skalweit, Domänenverwaltung, S. 244-262; Terveen, Gesamtstaat, S. 19-63; Henning, Handbuch, Bd. 1, S. 778-780; Brandtner, Vertreibung, S. 162f.; Walz, Ansiedlung, S. 112f.; und speziell zur Schweizer Kolonie: Gerd Wunder, Die Schweizer Kolonisten in Ostpreußen 1710-1730 als Beispiel für Koloniebauern, in: Günther Franz (Hg.), Bauernschaft und Bauernstand 1500-1970, Limburg a.d. Lahn 1975, S. 183-195. 
den drohte, wohl bis 1730 ein Großteil der Höfe wieder besetzt werden konnte. ${ }^{126}$ Einen erneuten Anlauf, die Wiederbesiedlung Preußisch-Litauens voranzutreiben, stellten die gescheiterten Versuche dar, Waldenser aus dem Piemont und Jansenisten aus Frankreich für die Ansiedlung in Ostpreußen zu gewinnen. ${ }^{127}$ Erfolgreicher war hingegen die Anwerbung der Salzburger Emigranten. Von vornherein waren die zumeist bäuerlichen Migranten für das Herzogtum Preußen vorgesehen. Die schätzungsweise 15.000 Neusiedler wurden im wesentlichen auf die Ämter Insterburg, Ragnit, Tilsit und Memel sowie vereinzelt auch auf Städte wie Gumbinnen verteilt, wo sie mit Höfen und Landparzellen ausgestattet wurden. ${ }^{128}$

Gerade die Regierungszeit Friedrichs II. war geprägt von ländlichen Kolonisationsanstrengungen, die der König bereits in seinem >Politischen Testament von 1752 reflektierte und mit den noch immer zu konstatierenden Folgen des Dreißigjährigen Krieges begründete. ${ }^{129}$ Nach dem Siebenjährigen Krieg, der diese Peuplierungsbemühungen unterbrochen, teilweise sogar durch erneute Verluste zurückgeworfen hatte, wurden die Anwerbungen neuer Siedler fortgesetzt. Während - größtenteils unter direkter Aufsicht des Königs - in der Kurmark vor allem deutsche Siedler aus preußischen oder benachbarten Territorien, jedoch auch aus Süddeutschland zum Einsatz kamen, wurden im stark kriegszerstörten Schlesien und anderen östlichen Landesteilen vor allem polnische Kolonisten, daneben aber auch Österreicher, Böhmen und sogar Griechen angesetzt. ${ }^{130}$ Insgesamt wurden mit Hilfe gezielter Werbungsmaßnahmen wohl etwa 900 Kolonistendörfer gegründet. ${ }^{131} \mathrm{Zu}$ den bäuerlichen und kleinbäuerlichen Stellen kam die Schaffung ländlicher Gewerbeansiedlungen, so etwa die Spinner- und Weberdörfer, in denen das Material für die

126 Beheim-Schwarzbach, Colonisationen, S. 162-165; Stadelmann, Friedrich Wilhelm I., S. 39; Skalweit, Domänenverwaltung, S. 261f.; Wunder, Kolonisten, S. 191; Brandtner, Vertreibung, S. 163; sowie zur Krise Terveen, Gesamtstaat, S. 63-70.

127 Dazu Skalweit, Domänenverwaltung, S. 270; Terveen, Gesamtstaat, S. 71.

128 Zur Ansiedlung Stadelmann, Friedrich Wilhelm I., S. 39-41; Skalweit, Domänenverwaltung, S. 271-275; Terveen, Gesamtstaat, S. 70-75; Henning, Handbuch, Bd. 1, S. 779; Brandtner, Vertreibung, S. 164-167; Walker, Handel, S. 86-96; Haver, Salzburger Protestanten, S. 940.

129 »La Guerre de 30 anns, Cette Calamité affreuse, cete Desolation qui ruina toute La Marche, La Pomeranie et Le Magdeburg avoit Si bien Aneanti ces provinces que trois regnes dont deux furent entierement pasifiques, ne purent Les retablir«; politisches Testament Friedrichs II. von 1752, ediert bei Richard Dietrich (Bearb.), Die politischen Testamente der Hohenzollern, Köln/Wien 1986, S. 254-461, hier S. 282.

130 Vgl. zum Retablissement nach dem Siebenjährigen Krieg Johannes Kunisch, Friedrich der Große. Der König und seine Zeit, München 2004, S. 465-476; Asche, Neusiedler, S. 397-399.

131 Vgl. ausführlich dazu Beheim-Schwarzbach, Colonisationen, S. 265-441; Rudolph Stadelmann, Preußens Könige in ihrer Thätigkeit für die Landescultur, Teil 2: Friedrich der Große, Leipzig 1882, S. 14-38; Daniel Häberle, Auswanderung und Koloniegründungen der Pfälzer im 18. Jahrhundert. Zur zweihundertjährigen Erinnerung an die Massenauswanderung der Pfälzer (1709) und an den pfälzischen Bauerngeneral Nikolaus Herchheimer, den Helden von Oriskany (6. August 1777), Kaiserslautern 1909, S. 126-128; Neugebauer, Zentralprovinz, S. 130-134. 
Textilmanufakturen vorbereitet werden sollte. ${ }^{132}$ Ein wesentliches Privileg der Neusiedler unter Friedrich II. war die `Enrollierungsfreiheit`, das heißt die Freiheit vom Kriegsdienst bis in die dritte Generation der Siedler. Hinzu kamen Bekenntnisfreiheit und die Freiheit von der Leibeigenschaft. ${ }^{133}$

Bevölkerungsvermehrung, Ausgleich für Verluste durch die Flucht aus der Leibeigenschaft sowie eine Intensivierung der Flächennutzung waren sicher auch vorrangige Motive bei der Büdneransiedlung in Mecklenburg-Schwerin. Hier wurden im Laufe des 18. Jahrhunderts Kolonisten auf Kleinstellen gesetzt. ${ }^{134}$ Weniger bekannt ist - wohl auch aufgrund der forschungsgeschichtlich begründbaren Dominanz der protestantischen Staaten im Bild der Migrationsgeschichte -, dass auch in den östlichen Teilen der Habsburgermonarchie systematische Kolonisationsmaßnahmen durchgeführt wurden. Nachdem mit dem `Einrichtungswerk des Königreichs Hungarn` schon unter Leopold I. Vorschläge zur gezielten Ansiedlung von (auch protestantischen) Kolonisten in den im Zuge der Türkenkriege zurückeroberten Regionen Mittel- und Südungarns (vor allem die Batschka und das Banat) vorlagen $^{135}$, bemühten sich Karl VI. und Maria Theresia neben den protestantischen >Transmigranten` aus den Kernlanden der Monarchie vor allem um katholische Siedler. Erst Joseph II. ging dazu über, auch lutherische und reformierte >Donauschwaben` zur Ansiedlung einzuladen. Eigens zu diesem Zweck gegründete >Impopulationskommissionen k kümmerten sich um die Anwerbung und die Lenkung des Kolonistenstroms. ${ }^{136}$ Den Kolonisten wurde persönliche Freiheit und Freizügigkeit

132 Hansjörg Tröger, Die kurmärkischen Spinnerdörfer. Ein Beitrag zur Wirtschafts- und Siedlungspolitik Friedrichs des Großen. Nach den Akten des Geheimen Preußischen Staatsarchivs dargestellt, Diss. Leipzig 1936; Asche, Neusiedler, S. 391; Carsten Liesenberg, Die Kolonisation des Oderbruchs. Planung, Ablauf und Ergebnisse eines absolutistischen Besiedlungskonzeptes aus baulicher Sicht, Diss. Weimar 2003, S. 92-100.

133 Vgl. etwa Tröger, Spinnerdörfer, S. 22f.

134 Vgl. René Wiese, Peuplierung in Mecklenburg. Leistungen und Grenzen der Büdneransiedlung im 18. Jahrhundert, in: Matthias Manke/Ernst Münch (Hg.), Verfassung und Lebenswirklichkeit. Der Landesgrundgesetzliche Erbvergleich von 1755 in seiner Zeit, Lübeck 2006, S. 261-278.

135 Das >Einrichtungswerk liegt jetzt ediert und mit einer instruktiven Einleitung versehen vor: János Kalmár/János J. Varga (Hg.), Einrichtungswerk des Königreichs Hungarn (1688-1690), Stuttgart 2010, hier besonders S. 32f., 43 und 130-136.

136 Vgl. zur Situation in den ehemals osmanischen Gebieten Buchinger, Landler, S. 48-50; Márta Fata, Einwanderung und Ansiedlung der Deutschen (1686-1790), in: Günter Schödl (Hg.), Land an der Donau, Berlin 1995, S. 89-196, hier S. 91-97. Zur Wiederbesiedlung Barton, Evangelisch in Österreich, S. 113; Häberle, Auswanderung, S. 161-181; Schünemann, Bevölkerungspolitik; Imre Wellmann, Die erste Epoche der Neubesiedlung Ungarns nach der Türkenzeit (1711-1761), in: Acta Historica, 26. 1980, S. 241-304, hier S. 259-274; Gustav Otruba, Die Wirtschaftspolitik Maria Theresias, Wien 1963, S. 170-178; Konrad G. Gündisch, Die deutsche Siedlung in Südosteuropa. Ein Überblick, in: Die Donauschwaben. Deutsche Siedlung in Südosteuropa, hg.v. Innenministerium Baden-Württemberg, 2. Aufl. Sigmaringen 1989, S. 11-22, hier S. 15-17; Fata, Einwanderung, S. 146172; und dies., >Donauschwaben` in Südosteuropa seit der Frühen Neuzeit, in: Bade/Emmer/Lucas- 
garantiert. Sie wurden zudem mit Land und Baumaterial sowie mit Saatkorn ausgestattet, dazu kamen mehrjährige Steuerfreiheiten. ${ }^{137}$ Nach der Emigration von fast 20.000 Protestanten bemühte sich übrigens auch der Fürstbischof von Salzburg systematisch um die Wiederbesetzung der verlassenen Hofstellen - ein Aspekt der Geschichte der Salzburger Emigration, der bislang noch wenig beachtet worden ist. Gezielt wurden Verzeichnisse der zum Verkauf stehenden Höfe nach Tirol, Bayern, Schwaben und ins Oberrheingebiet gesandt, wobei bewusst um katholische Neusiedler geworben wurde. ${ }^{138}$

Das 18. Jahrhundert stand freilich auch im Zeichen der Neulandgewinnung. Seit 1718 nahm Brandenburg-Preußen unter König Friedrich Wilhelm I. umfangreiche Meliorationsarbeiten in den Bruchgebieten an Havel und Rhin in Angriff. Überdies wurden die bereits unter Kurfürst Joachim Friedrich zu Anfang des 17. Jahrhunderts in ersten Ansätzen begonnenen Arbeiten am Netze- und Dragebruch unter Friedrich Wilhelm I. wieder aufgegriffen. Mit Beginn der Meliorationen wurden Siedlungswillige durch öffentliche Ausschreibungen angeworben. Etwa tausend Arbeiter, darunter zahlreiche Soldaten, konnten zu diesem Zweck gewonnen und nach erfolgter Neulandgewinnung mit Kolonistenstellen versorgt werden. ${ }^{139}$ Als Kolonisator der Bruchlandschaften im Oder-, Netze- und Warthegebiet machte sich jedoch dann vor allem König Friedrich II. einen Namen. Während seiner Regierungszeit wurde insbesondere im ländlichen Bereich systematisch kolonisiert. Schon 1746 richtete sich das Interesse vor allem auf die noch unkultivierten Bruchlandschaften an der Oder. Mit der Trockenlegung dieser Flusslandschaften wurde in großem Umfang neues Siedelland gewonnen, das an Pächter gegen die Verpflichtung vergeben wurde, Kolonisten anzusetzen. 1.200 Familien konnten auf diesem Wege in 43 neuen Dörfern angesiedelt werden. ${ }^{140}$ Nach dem Siebenjährigen Krieg wurden die Meliora-

sen/Oltmer (Hg.), Enzyklopädie Migration, S. 535-540. Eine umfassende Darstellung der Migrationspolitik Josephs II. bietet jetzt dies., Migration. Ein Ansiedlungspatent Maria Theresias für Einwanderer aus Vorderösterreich vom 21. Juni 1755 ist abgedruckt bei Günther Franz (Bearb.), Quellen zur Geschichte des deutschen Bauernstandes in der Neuzeit, München/Wien 1963, S. 228-231.

137 Vgl. v.a. Fata, Einwanderung, S. 155f., 163-166, 169; Schünemann, Bevölkerungspolitik, S. 250252; außerdem Abdruck eines Werbungstextes von 1767 ebd., S. 280-282.

138 Vgl. dazu Josef Brettenthaler, Die Wiederbesiedlung, in: Zaisberger (Hg.), Reformation, S. 172179.

139 Stadelmann, Friedrich Wilhelm I., S. 62-72; Gerd Heinrich, Friedrich der Große und die preußische Wasserstraßenpolitik. Wasserbaukunst und Bruchland-Meliorationen des 18. Jahrhunderts, in: Helmut Neuhaus (Hg.), Verfassung und Verwaltung. Festschrift Kurt G.A. Jeserich, Köln 1994, S. 103-123, hier S. 107f.; Asche, Neusiedler, S. 383f.

140 Vgl. Stadelmann, Könige, Teil 2, S. 44-50; Theodor Schieder, Friedrich der Große. Ein Königtum der Widersprüche, Frankfurt a.M. 1983, S. 336f.; Heinrich, Friedrich der Große, S. 113f.; Neugebauer, Zentralprovinz, S. 131f.; Asche, Neusiedler, S. 387-389; und detailliert zum Gesamtvorgang der Oderbruch-Melioration und der anschließenden Kolonisation Liesenberg, Kolonisation, S. 35102. 
tions- und Drainagearbeiten in den Bruchgebieten an Rhin und Dosse sowie an Netze und Drage fortgesetzt. Nach dem Erwerb Westpreußens und des Netzedistrikts (1772) kamen die Trockenlegungen in den Warthebrüchen hinzu. Auch hier konnten zahlreiche neue Kolonisten angesetzt werden. ${ }^{141}$

Überdies trieb Friedrich II. im seit 1744 preußischen Ostfriesland die - vereinzelt bereits seit 1633/34 zum Beispiel um Papenburg begonnene - Moorkolonisation voran. Auf der Grundlage des Urbarmachungsedikts vom 22. Juli 1765 wurden zwischen 1768 und 17901.131 Kolonistenstellen geschaffen, die sich freilich mittelfristig als zu klein erwiesen, zumal die durch Brandkultur fruchtbar gemachten Böden schnell erschöpft waren. ${ }^{142}$ Solche Hochmoorkolonisationen gab es über Ostfriedland hinaus im Emsland (Bourtanger Moor), im Oldenburger Land, in Kurhannover (unter anderem im Teufelsmoor ab 1751) sowie im Eider- und Treene-Gebiet im Herzogtum Schleswig-Holstein-Gottorf. ${ }^{143}$ Dass es bei der Besiedlung der Moore neben dem Bestreben der Ressourcenausschöpfung auch um politische Zielsetzungen gehen konnte, zeigt das Beispiel des Bourtanger Moors im Grenzgebiet zwischen dem Erzstift Münster und den Niederlanden, wo Neusiedler auch zur Sicherung des 1784/85 vereinbarten Grenzverlaufs angesetzt wurden. ${ }^{144}$ In engem Zusammenhang mit der Moorkolonisation steht zumindest in Schleswig-Holstein auch die Besiedlung der Heidegebiete, für die in den Jahren 1759 bis 1763 immerhin etwa 4.000

141 Vgl. Beheim-Schwarzbach, Colonisationen, S. 409-441; Stadelmann, Könige, Teil 2, S. 50-57; Walther Maas, Preußische Siedlungen in Westpreußen und dem Netzedistrikt 1772-1848, in: Deutsche Ostsiedlung in Mittelalter und Neuzeit, Köln/Wien 1971, S. 197-218; Neugebauer, Zentralprovinz, S. 132f.; Asche, Neusiedler, 398. Zu weiteren Meliorationen vgl. Stadelmann, Könige, Teil 2, S. 57-65.

142 Zur Moorkultivierung in Ostfriesland vgl. Heinrich Koppelmann, Die friderizianische Kolonisation in Ostfriesland, Diss. Münster 1922, S. 47-96; Heinz-Günther Borck, Die Besiedlung und Kultivierung der Emslandmoore bis zur Gründung der Emsland $\mathrm{GmbH}$, in: Niedersächsisches Jahrbuch für Landesgeschichte, 45. 1973, S. 1-30, hier S. 4-7; Hans-Jürgen Nitz, Moorkolonien. Zum Landesausbau im 18. und 19. Jahrhundert westlich der Weser, in: ders., Historische Kolonisation, S. 337358, hier S. 342; Harm Wiemann/Reinhard Bruhns, Ostfriesische Geschichte, Teil III, Leer 1951, S. 14-17.

143 Zum Eider-Treenegebiet vgl. Jürgen Brockstedt, Regionale Mobilität in Schleswig-Holstein im 18. und 19. Jahrhundert, in: ders. (Hg.), Regionale Mobilität in Schleswig-Holstein 1600-1900. Theorie, Fallstudien, Quellenkunde, Bibliographie, Neumünster 1979, S. 63-88, hier S. 69f.; und Irmgard Gooß, Die Moorkolonien im Eidergebiet. Kulturelle Angleichung eines Ödlandes an die umgebende Geest, Kiel 1940. Zur Moorkolonisation in Kurhannover Müller-Scheeßel, Findorff; in Oldenburg Franz Böcker, Die innere Kolonisation im Herzogtum Oldenburg, Oldenburg 1914, S. 13-19; und im Münsterland, Böcker, Kolonisation, S. 9-11; Borck, Besiedlung, 9-12; Nitz, Moorkolonien, S. 343357; und zusammenfassend Nitz, Moorkolonien, S. 338f., 342f.; ders., Smallholder Colonization in the Heathlands of North-West-Germany during the 18th and 19th Centuries, in: ders., Historische Kolonisation, S. 359-366.

144 So bereits Böcker, Kolonisation, S. 11; außerdem Nitz, Moorkolonien, S. 344f. Borck, Besiedlung, S. 9, zufolge ging es sogar ausschließlich um diese politischen Zielsetzungen. 
Siedler aus Baden, Hessen und der Pfalz systematisch angeworben wurden. ${ }^{145}$ Freilich bleiben diese Zahlen bei weitem hinter der Kolonisationstätigkeit Friedrichs II. von Preußen zurück, der wohl allein für die Kurmark Brandenburg 100.000 neue Siedler anwarb, die vor allem aus dem Südwesten Deutschlands, aber auch aus der Schweiz, aus Österreich, Böhmen, Polen und anderen Gegenden stammten. ${ }^{146}$

In den Zusammenhang der Neulandgewinnung gehören auch die umfangreichen Eindeichungen an den Küsten der Nordsee von den Niederlanden bis nach Schleswig-Holstein, aber auch in Ostengland. ${ }^{147}$ Große Anstrengungen unternahm der dänische König ab der Mitte des 17. Jahrhunderts in Schleswig-Holstein, wo durch Eindeichungen Ackerland gewonnen und geschützt wurde. ${ }^{148}$ Mit dem System der soktroyierten Köge` (Eindeichungen durch Privatpersonen aufgrund einer landesherrlichen Konzession) wurden im frühen 17. Jahrhundert die Voraussetzungen für eine systematische landesherrliche Besiedlung der Köge geschaffen. ${ }^{149}$ Die Deichbauarbeit betrieben oft niederländische Spezialisten, die neugewonnenen Parzellen wurden dann an diese Arbeiter vergeben oder aber an die Investoren, die diese gewinnbringend verpachteten. ${ }^{150}$ Solche Maßnahmen konnten auch verheerenden Flutkatastrophen folgen, wie etwa der Burchardi-Flut vom 11. Dezember 1634, als große Teile der Insel Nordstrand völlig verwüstet worden waren. ${ }^{151}$ Die

145 Brockstedt, Mobilität, S. 69.

146 Vgl. für das Oderbruch Liesenberg, Kolonisation, S. 85f.; zur Kurmark Beheim-Schwarzbach, Colonisationen, S. 365f.; Asche, Neusiedler, S. 398. Von einer Gesamtheit für das ganze Königreich von etwa 300.000 Kolonisten sprechen Beheim-Schwarzbach, Colonisationen, S. 441; und Henning, Handbuch, Bd. 1, S. 780. Ausführlich zur Anwerbung von Pfälzer Kolonisten für Pommern, die Kurmark, das Oderbruch und andere Gebiete Häberle, Auswanderung, S. 128-139.

$147 \mathrm{Zu}$ Ostengland vgl. Christopher G. Clay, Economic Expansion and Social Change. England, 1500-1700, 2 Bde., Cambridge 1984, hier Bd. 1, S. 110; Joan Thirsk, Farming Regions of England, in: dies. (Hg.), The Agrarian History of England and Wales, Bd. 4, Cambridge 1967, S. 1-112, hier S. 3840; Henry C. Darby, The Draining of the Fens, 2. Aufl. Cambridge 1956.

148 Von jeher spielten der Deichbau und das System des Deichschutzes hier eine wesentliche Rolle; vgl. etwa die zahlreichen Bestimmungen dazu in den einschlägigen Gesetzestexten des Herzogtums Schleswig: Corpus Statutorum Slesvicensium, oder: Sammlung der in dem Herzogthum Schleswig geltenden Land- und Stadt-Rechte, nebst den für diese Gegenden erlassenen neueren Verfügungen Bd. 1, [hg.v. C.L. Freiherr von Brockdorff/F.L. von Eggers], Schleswig 1794.

149 Vgl. Marie Luisa Allemeyer, »Kein Land ohne Deich...!« Lebenswelten einer Küstengesellschaft in der Frühen Neuzeit, Göttingen 2006, S. 136-156.

150 Allemeyer, Kein Land ohne Deich, S. 140-154. Zu den aus den Eindeichungen resultierenden Wanderungen auch Brockstedt, Mobilität, S. 69; und zur oft hohen Mobilität der Deicharbeiter Rolf Uphoff, Die Deicher, Oldenburg 1995, S. 93f. Als Beispiel eines Kontrakts mit niederländischen Spezialisten vgl. »Fürstl. Octroy für die Nordstrandische Participanten« erlassen durch Hg. Friedrich, Gottorf, 8. Juli 1652, gedruckt in Corpus Statutorum Slesvicensium, Bd. 1, S. 560-579.

151 Vgl. Fritz Karff, Nordstrand. Geschichte einer nordfriesischen Insel, Flensburg 1968, S. 193-205; und Manfred Jakubowski-Tiessen, »Erschröckliche und unerhörte Wasserflut«. Wahrnehmungen und Deutungen der Flutkatastrophe von 1634, in: ders./Hartmut Lehmann (Hg.), Um Himmels 
>Partizipanten erhielten von Herzog Friedrich von Holstein-Gottorf das volle Recht am anwachsenden Land, das vor den Deichen angespült wurde, sowie die Fischerei-, Jagd- und Mühlenrechte. Der Herzog bewilligte zudem neben der lutherischen Konfession das Religionsausübungsrecht für katholische und reformierte Investoren und ihre Haushalte. Im Falle der Insel Nordstrand wurde sogar eine eigenständige kommunale Gerichtsbarkeit festgelegt. ${ }^{152}$ Ein besonderes Privileg, das freilich auch zu Konflikten mit der ansässigen Bevölkerung führte, war die Befreiung von den Deichlasten, die somit von den übrigen Anwohnern mit übernommen werden mussten. ${ }^{153}$ Vergleichbare Bemühungen der Landesherren um eine systematischere Nutzung und Besiedlung der Marschregionen sind auch für die ostfriesische und oldenburgische Küste nachweisbar. ${ }^{154}$ Insgesamt muss freilich für die Moor- und Deichkolonisation festgehalten werden, dass es sich zu einem guten Teil um binnenkolonisatorische Maßnahmen handelte, im Zuge derer Fernwanderungen eher eine untergeordnete Rolle spielten und der Großteil der Neusiedler aus der unmittelbaren Umgebung kam, im Falle der wirtschaftlich problematischen und durch die Brandkultur schnell erschöpften Moorregionen vor allem aus den unterbäuerlichen Schichten. ${ }^{155}$

Die hier dargestellten Fälle systematischer Peuplierungsbemühungen auf dem Land - oft verbunden mit Bestrebungen des Landesausbaus - beziehen sich ausnahmslos auf die Territorialstaaten im Heiligen Römischen Reich Deutscher Nation. Es gab jedoch auch auf der Ebene der Grundherrschaften gelegentlich solche - freilich selten intensiv erforschte - Ansätze. Ein Beispiel wurde im Zusammenhang mit

Willen. Religion in Katastrophenzeiten, Göttingen 2003, S. 179-200. Zu den Wiederherstellungsmaßnahmen Allemeyer, Kein Land ohne Deich, S. 97-99 und 141 mit Anm. 267.

152 Vgl. das herzogliche »Octroy«, Gottorf, 8. Juli 1652, abgedruckt in Corpus Statutorum Slesvicensium Bd. 1, S. 560-579. Auch dazu Allemeyer, Kein Land ohne Deich, S. 141.

153 Vgl. Allemeyer, Kein Land ohne Deich, S. 237-249.

154 Insbesondere zur im 16. Jahrhundert beginnenden Frühphase Dietrich Saalfeld, Ländliche Wirtschafts- und Sozialgeschichte vom Beginn des 16. bis zur Mitte des 17. Jahrhunderts, in: Christine van den Heuvel/Manfred von Boetticher (Hg.), Geschichte Niedersachsens, Bd. 3/1: Politik, Wirtschaft und Gesellschaft von der Reformation bis zum Beginn des 19. Jahrhunderts, Hannover 1998, S. 637-688, hier S. 664-666; desweiteren Koppelmann, Kolonisation, S. 9-46; Friedrich-Wilhelm Schaer, Die Grafschaften Oldenburg und Delmenhorst vom späten 16. Jahrhundert bis zum Ende der Dänenzeit, in: Albrecht Eckhardt (Hg.), Geschichte des Landes Oldenburg. Ein Handbuch, Oldenburg 1987, S. 173-228, hier S. 177, 193f., 222-224; und Gebhard Löning, Ostfriesische Geschichte ,Teil II, Leer 1951, S. 68f.; Nitz, Transformation, S. 328; sowie Friedrich-Wilhelm Schaer, Zur wirtschaftlichen und sozialen Lage der Deicharbeiter an der oldenburgisch-ostfriesischen Küste in der vorindustriellen Gesellschaft, in: Niedersächsisches Jahrbuch für Landesgeschichte, 45. 1973, S. 115-144, der sich freilich hauptsächlich auf Lohnarbeiter konzentriert (Bemerkungen zur Ansiedlung von Deicharbeitern ebd., S. 124f.).

155 Müller-Scheeßel, Findorff, S. 45 und 56-58; Nitz, Moorkolonien, S. 341 und 345. Zu den Problemen, die durch die Umsiedlung der ehemals hofgebundenen unterbäuerlichen Schichten für die alten Höfe am Moorrand entstanden, ebd., S. 345f. 
der Hugenottenansiedlung bereits kurz gestreift: Graf Otto von Schwerin, Geheimer Rat in der Regierung Kurfürst Friedrich Wilhelms von Brandenburg-Preußen, initiierte in Brandenburg die Einwanderung französischer Protestanten, indem er durch seinen in Paris weilenden Sohn Siedler für sein Gut bei Altlandsberg anwerben ließ. ${ }^{156} \mathrm{Zu}$ nennen ist überdies die Anwerbung niederländischer Kolonisten auf den Gütern der brandenburgischen Oberjägermeister aus der Familie von Hertefeld an der Havel zwischen Liebenwalde und Grüneberg (`Neuholland $).{ }^{157}$ Auch die Ansiedlung von Hugenotten im fränkischen Wilhelmsdorf durch Isaac Buirette von Oehlefeld können, wenngleich sie im engen Zusammenhang mit der Einwanderungspolitik Markgraf Christian Ernsts von Brandenburg-Bayreuth zu sehen sind, hierzu gerechnet werden. ${ }^{158}$ Ein anderes Beispiel für Peuplierungsmaßnahmen im Rahmen eines landsässigen Rittergutes ist das im Herzogtum Coburg gelegene Hassenberg, wo in der zweiten Hälfte des 18. Jahrhunderts gezielt auf eine Erweiterung der Dörfer hingearbeitet wurde. ${ }^{159}$ Hinzu kommen die privat durchgeführten Kolonisationen des grundbesitzenden Adels in Ungarn. ${ }^{160}$

Hinzuweisen ist freilich auch auf die Tatsache, dass viele der ländlichen Kolonien von den Obrigkeiten zunehmend kritisch gesehen wurden. So beklagten sich Hessen-Kasselsche Beamte darüber, dass sich die französischen Kolonien - insbesondere diejenigen im Oberfürstentum - nach jahrelanger Unterstützung mit Vieh und Saatkorn noch immer nicht selbst ernähren konnten. Die Schuld dafür wurde häufig bei den Neusiedlern selbst gesucht, die sich angeblich dem Müßiggang hingaben. ${ }^{161}$ Ähnliches lässt sich auch über Brandenburg sagen: Derselbe König Friedrich Wilhelm I., der sich so intensiv um die Repeuplierung der ländlichen Gegenden Ostpreußens bemühte, hatte für ländliche Hugenottensiedlungen nichts übrig. ${ }^{162}$

156 Zur Ansiedlung in Altlandsberg Muret, Geschichte, S. 5f.; Manoury, Geschichte, S. 1; Birnstiel, Hugenotten, S. $115 f$.

157 Vgl. Asche, Neusiedler, 363-370; Jan Peters, Neuholland von den Anfängen bis zur Mitte des 18. Jahrhunderts, in: ders./Hartmut Harnisch/Lieselott Enders (Hg.), Märkische Bauerntagebücher des 18. und 19. Jahrhunderts. Selbstzeugnisse von Milchviehbauern aus Neuholland, Weimar 1989, S. $18-80$.

158 Schanz, Geschichte, S. 44-46; Rudolf Endres, Staat und Gesellschaft. Zweiter Teil: 1500-1800, in: Handbuch der Bayerischen Geschichte, Bd. 3/1, 3. Aufl. München 1997, S. 702-782, hier S. $765 f$.

159 Vgl. Thomas Gunzelmann, Hassenberg - ein Beispiel ritterschaftlicher Peuplierung im Coburger Land, in: Jahrbuch der Coburger Landesstiftung, 35. 1990, S. 279-294.

160 Schünemann, Bevölkerungspolitik, S. 212-225, 243-250; Wellmann, Epoche, S. 251-258; Fata, Einwanderung, S. 114-140. Für ähnliche Vorgänge in Österreich auch Regina Pörtner, Migration und Herrschaftsverdichtung: Ökonomische Voraussetzungen konfessionell bedingter Untertanenmobilität in den Ländern der Habsburgermonarchie 1680-1780, in: Bahlcke (Hg.), Glaubensflüchtlinge, S. 365-369.

161 Vgl. Zögner, Hugenottendörfer, S. 113; Kadell, Hugenotten, S. 163f. und 475-478; Niggemann, Immigrationspolitik, S. 241-243.

162 Vgl. Muret, Geschichte, S. 58; und Asche, Neusiedler, S. 340f. und 529-552. 
Und auch den Schweizer Kolonisten wurde vorgehalten, sie seien faul und täten zu wenig, um sich aus eigener Kraft zu ernähren. ${ }^{163}$ Geradezu paradox mutet zudem die unter Friedrich Wilhelm I. durchgeführte Ausweisung der Mennoniten an, die zeitgleich mit der Salzburger Ansiedlung stattfand. Begründet wurde diese Maßnahme vor allem mit der Verweigerung des Militärdienstes durch diese dem strikten Pazifismus verpflichtete Gruppe. ${ }^{164}$ Solche Vorgänge waren insgesamt keine Seltenheit und verweisen auf den Utilitarismus der Einwanderungspolitik, in deren Logik es lag, Bevölkerungsgruppen nach nützlichen und weniger nützlichen zu kategorisieren. Auch Landgraf Karl von Hessen-Kassel befahl im Zusammenhang mit der Unterbringung der Hugenotten in Kassel zu untersuchen, ob sich »nicht unnütz gesinde in der statt« befinde, welches »umb desto mehr raum vor die frantzoßen zugewinnen, hinauszuschaffen wehre ${ }^{165}$

Neulandgewinnung, Urbarmachung bislang ungenutzter Flächen war ein wichtiges Ziel landesherrlicher Politik in der Frühen Neuzeit, wobei eine Intensivierung der Bemühungen während des 18. Jahrhunderts festzustellen ist. Insbesondere Brandenburg-Preußen unternahm erhebliche Anstrengungen im Bereich der Bruchlandmeliorationen und der Moorkultivierung. Stets wurden solche Landgewinnungsmaßnahmen zum Ausgangspunkt von Kolonisationsbemühungen. Um das neugewonnene Land $\mathrm{zu}$ bestellen, wurden Menschen aus dem Inland wie auch aus dem Ausland mit zum Teil umfangreichen Privilegien ins Land gelockt und angesiedelt. Doch auch Kriegsverheerungen oder die Folgen der Pest führten im 18. Jahrhundert zu umfangreichen ländlichen Wiederbesiedlungsmaßnahmen, wie das wohl prominenteste Beispiel, die Ansiedlung der Salzburger Exulanten in Preußen zeigt.

\section{Städtische Neusiedler, Neustädte und Residenz- ausbau}

Besondere Aufmerksamkeit richteten die Merkantilisten stets auf das städtische Umfeld, insbesondere auf Handel und Gewerbe. Auch hier gilt, was schon bei der ländlichen Kolonisation festgestellt wurde: >Peuplierung` und Gewerbeförderung waren in der Regel eng miteinander verflochten. Die Ansiedlung von Menschen diente der Bevölkerungsvermehrung, war aber gleichzeitig auch eine Maßnahme zur Förderung der Wirtschaft, insbesondere zur Weiterentwicklung neuer Betriebsformen und zur Herstellung bislang nur im Ausland produzierter Güter. Zugleich schuf erst eine systematische Gewerbeförderung die Möglichkeit, Einwanderer in

163 Asche, Neusiedler, S. 241 mit Anm. 882.

164 Dazu Beheim-Schwarzbach, Colonisationen, S. 168f.; Walker, Handel, S. 85f.

165 Zitiert bei Niggemann, Immigrationspolitik, S. 154. 
Lohn und Brot $\mathrm{zu}$ bringen. Besonders interessiert waren die von merkantilistischen Theorien beeinflussten Landesherren an der Niederlassung von Manufakturen. Manufakturen als zentralisierte Großbetriebe galten als Heilmittel für die Wirtschaft, zumal viele Fürsten im Rahmen einer Bildungsreise die Gelegenheit gehabt hatten, solche Großbetriebe in Frankreich und den Niederlanden zu bewundern. ${ }^{166}$ Abgesehen von der Möglichkeit, hier sowohl Massenwaren - etwa für den Militärbedarf als auch Luxusgüter für den Hof produzieren zu lassen, konnten in den Manufakturen auch zahlreiche Arbeiter beschäftigt werden. ${ }^{167}$ Bisweilen war die Einstellung einer bestimmten Zahl von Arbeitern sogar Bedingung für die Erteilung einer Konzession. ${ }^{168}$

Große Manufakturen, insbesondere im Bereich der Textilherstellung, entstanden etwa im Zuge der Hugenotteneinwanderung in Berlin, Magdeburg, Halle, Erlangen und Kassel. Auch unter den Schweizer Einwanderern befanden sich Handwerker und Manufakturisten, die in Berlin-Cölln, Potsdam, Neustadt-Eberswalde und Prenzlau angesiedelt wurden. ${ }^{169}$ Bei der Anlage dieser Großbetriebe spielten landesherrliche Zuschüsse und Kredite eine zentrale Rolle. Über die finanziellen Zuwendungen hinaus erhielten die Manufakturisten in der Regel auch Gebäude oder zumindest Baumaterial. Vielfach wurden ihnen sogar Produktionsanlagen wie Lohmühlen aus landesherrlichen Mitteln erbaut. ${ }^{170}$ Hinzu kamen umfangreiche, oft

166 Dass bei vielen fürstlichen Bildungsreisen auch die Besichtigung von Gewerbebetrieben auf dem Programm stand, betont Eva Bender, Die Prinzenreise. Bildungsaufenthalt und Kavalierstour im höfischen Kontext gegen Ende des 17. Jahrhunderts, Berlin 2011, S. 134, 141-148, 295 u.ö.

167 Zur Betriebsform der Manufaktur und zu ihrer Bedeutung für die Wirtschaftspolitik vgl. z.B. Kellenbenz, Wirtschaftsgeschichte, Bd. 1, S. 312, 330f.; Gömmel, Entwicklung, S. 49f.; Henning, Handbuch, Bd. 1, S. 765f., 823; Wilfried Reininghaus, Gewerbe in der frühen Neuzeit, München 1990, S. 4f.

168 Dies lässt sich etwa im Zusammenhang mit dem Aufbau von Manufakturen durch eingewanderte Hugenotten in Brandenburg-Preußen beobachten; vgl. etwa die Konzession für die >Große Manufaktur in Magdeburg, abgedruckt bei Tollin, Geschichte, Bd. 2, S. 477-479; außerdem Ingrid Mittenzwei, Die Hugenotten in der gewerblichen Wirtschaft Brandenburg-Preußens, in: dies. (Hg.), Hugenotten, S. 112-168, hier S. 118; Otto Hintze, Die Preußische Seidenindustrie im 18. Jahrhundert und ihre Begründung durch Friedrich den Großen, Berlin 1892, S. 83, Jersch-Wenzel, Juden, S. 80; und Niggemann, Immigrationspolitik, S. 295.

169 Asche, Neusiedler, S. 245f.

170 Beispiele für finanzielle $\mathrm{Zu}$ - und Vorschüsse sowie für den Bau von Gewerbeeinrichtungen bei Beheim-Schwarzbach, Colonisationen, S. 58; Tollin, Geschichte Bd. 2, S. 411f.; Schanz, Geschichte, S. 24f. mit Anm. 6; Preetz, Hugenotten-Kolonien, S. 77; Hintze, Seidenindustrie, S. 83; JerschWenzel, Juden, S. 79f.; Peter Landgrebe, Minoritätengruppe und wirtschaftliche Bedeutung. Zum Einfluß der Hugenotten auf die deutsche Wirtschaftsentwicklung, Sickte 1977, S. 184 und 197 mit Anm. 1; Alfred Giebel, Die landgräfliche Wolltuchmanufaktur in Treysa, in: Zeitschrift des Vereins für hessische Geschichte und Landeskunde, 65/66. 1954, S. 106-119, hier S. 106-108; Kadell, Hugenotten, S. 555-557; Birke Grießhammer, Die Strumpffabrikation - eine Fehlinvestition?, in: Friederich (Hg.), Hugenottenstadt, S. 160-167, hier S. 163; Dietmar Willoweit, Gewerbeprivileg und ınatürliche` Gewerbefreiheit. Strukturen des preußischen Gewerberechts im 18. Jahrhundert, in: Karl O. 
über die allgemeinen Einwandererprivilegien hinausgehende Steuer- und Zollvergünstigungen. ${ }^{171}$ Dennoch erwiesen sich viele dieser Betriebe als unwirtschaftlich, was auch an den unterentwickelten Absatzstrukturen lag. Streitigkeiten und langwierige Prozesse der Manufakturisten untereinander waren - besonders auffällig im Falle der Hugenotten - die Folge. ${ }^{172}$

In der Praxis blieben größere Manufakturbetriebe in fast allen deutschen Territorien die Ausnahme. Auch unter den Hugenotten, die nach Deutschland kamen, befanden sich nur wenige, die solche Betriebe eröffneten. Die Mehrzahl der in den Städten angesiedelten Hugenotten betätigte sich im Rahmen des traditionellen Kleinhandwerks, wo sie sich spätestens nach Ablauf der in den Einwandererprivilegien festgelegten Freijahre in aller Regel den ortsüblichen zünftigen Strukturen anpassen mussten. ${ }^{173}$

Scherner/Dietmar Willoweit (Hg.), Vom Gewerbe zum Unternehmen. Studien zum Recht der gewerblichen Wirtschaft im 18. und 19. Jahrhundert, Darmstadt 1982, S. 60-111, hier S. 77; Andreas Jakob, Die Neustadt Erlangen. Planung und Entstehung, Erlangen 1986, S. 109-112; Birnstiel/Reinke, Hugenotten, S. 114f. und 121-123.

171 Teilweise sind diese schon in den allgemeinen Privilegien zugunsten der Manufakturisten differenziert: So sehr deutlich im Privilegienedikt Mgf. Christian Ernsts von Brandenburg-Bayreuth (Art. 9, 11), Bayreuth, 27. November 1685, abgedruckt bei Schanz, Geschichte (Abt. 2), S. 6-8; sowie Privilegienedikt Mgf. Christian Ernsts (Art. 13), Bayreuth, 15. August 1687, abgedruckt bei Mempel (Bearb.), Gewissensfreiheit, S. 68. Vgl. Schanz, Geschichte, S. 12; Ebrard, Christian Ernst, S. 21; Endres, Staat, S. 765. Ähnlich auch das Edikt Lgf. Karls von Hessen-Kassel (Art. 3), Kassel, 12. Dezember 1685, abgedruckt bei Mempel (Bearb.), Gewissensfreiheit, S. 52. Vgl. dazu Schmidmann, Kolonien, S. 24; Mogk, Voraussetzungen, S. 26; Kadell, Hugenotten, S. 301, 323f. Darüber hinaus erhielten Manufakturisten oft individuelle Privilegien; vgl. etwa Mittenzwei, Hugenotten, S. 119; und Klingebiel, Weserfranzosen, S. 83. Insgesamt dazu auch Niggemann, Immigrationspolitik, S. 290-296.

172 Vgl. zur Einschätzung des wirtschaftlichen Erfolgs Jersch-Wenzel, Juden, S. 82; Rudolf von Thadden, Die Hugenotten: eine innovatorische Schubkraft in der Geschichte BrandenburgPreußens? Ein Diskussionsbeitrag, in: Mittenzwei (Hg.), Hugenotten, S. 100-111, hier S. 104; Mittenzwei, Hugenotten, S. 119f.; Kadell, Hugenotten, S. 543; Henning, Handbuch, Bd. 1, S. 824; und Niggemann, Immigrationspolitik, S. 304-308. Zu den Konflikten der hugenottischen Manufakturisten untereinander ebd., S. 315-318; und ders., Kirchliches Leben und Konflikterfahrung. Zur Konstituierung von französischen Réfugiés-Gemeinden im Herzogtum Magdeburg (1685-1700), in: Joachim Bahlcke/Rainer Bendel (Hg.), Migration und kirchliche Praxis. Das religiöse Leben frühneuzeitlicher Glaubensflüchtlinge in alltagsgeschichtlicher Perspektive, Köln 2008, S. 223-247, hier S. 236-247.

173 Hierzu ausführlich Niggemann, Immigrationspolitik, S. 320-354; ders., Hugenotten als wirtschaftliche Elite. Wahrnehmung und Selbstwahrnehmung in den immigrationspolitischen Auseinandersetzungen in Deutschland und England, 1680-1700, in: Denzel/Asche/Stickler (Hg.), Minderheiten, S. 319-345, hier S. 343f.; ders., Craft Guilds and Immigration: Huguenots in German and English Cities, in: Bert de Munck/Anne Winter (Hg.), Gated Communities? Regulating Migration in Early Modern Cities, Farnham 2012, S. 45-60. 
Der Regelfall der städtischen Kolonisation war die Ansetzung der Einwanderer in den bestehenden Städten. Insbesondere in den stark kriegsverwüsteten Städten wurden den Einwanderern bestimmte, über die jeweilige Stadt verstreute wüste Hausstellen oder Instand zu setzende Häuser eingeräumt. Pläne wie etwa im Fall der Waldenseransiedlung in der altmärkischen Stadt Stendal, Teile der Bevölkerung innerhalb der Stadt umzusiedeln, um ein geschlossenes Einwandererviertel zu schaffen, wurden kaum jemals verwirklicht. ${ }^{174}$ Es gab jedoch in der Frühen Neuzeit auch das Phänomen der Exulantenstädte: Stadtneugründungen, die entweder im Zuge einer Einwanderung erfolgten oder aber zum Auslöser gezielter Anwerbungspolitik wurden. ${ }^{175}$ Wie fast alle städtischen Neugründungen im Europa der Frühen Neuzeit wurden diese Städte meist als Planstädte angelegt, oft mit dem Anspruch verbunden, Visionen von der idealen Stadt, wie sie in großer Zahl seit der Renaissance (zum Beispiel von Albrecht Dürer) verbreitet worden waren, zu verwirklichen. ${ }^{176}$ Dies war etwa bei der Neustadt Hanau der Fall, die ab 1597 für aus Frankfurt abwandernde niederländische und wallonische Reformierte erbaut worden war. ${ }^{177}$ Die Gründung von Mannheim im Jahr 1606 gehört ebenfalls in diesen Zusammenhang, denn auch hier wurde vor allem für niederländische und wallonische Einwanderer eine neue Stadt gebaut, die freilich mit ihrer Zitadelle Friedrichsburg auch eine starke militärische Komponente besaß. ${ }^{178}$ Schließlich lässt sich auch Friedrichstadt an der Eider als Beispiel anführen. Hier waren es neben sieben weiteren Religionsgemeinschaften (darunter Mennoniten und Katholiken) insbesondere

174 Vgl. zu den Plänen in Stendal Tollin, Geschichte, Bd. 2, S. 82f. und 85.

175 Zum Typus der Exulantenstadt Heinz Stoob, Über frühneuzeitliche Städtetypen, in: ders., Forschungen zum Städtewesen in Europa, Bd. 1: Räume, Formen und Schichten der mitteleuropäischen Städte. Eine Aufsatzfolge, Köln/Wien 1970, S. 246-284, hier S. 264-276; vgl. auch Walter Grossmann, Städtisches Wachstum und religiöse Toleranzpolitik am Beispiel Neuwied, in: Archiv für Kulturgeschichte, 62/63. 1980/81, S. 207-232, hier S. 208; und Ulrich Rosseaux, Städte in der Frühen Neuzeit, Darmstadt 2006, S. 39-42.

$176 \mathrm{Zu}$ den Idealstadtvorstellungen der Frühen Neuzeit vgl. etwa Ruth Eaton, Die ideale Stadt. Von der Antike bis zur Gegenwart, Berlin 2001, S. 40-71; Sascha Winter, Idealstadt, in: Friedrich Jaeger (Hg.), Enzyklopädie der Neuzeit, Bd. 5, Stuttgart 2007, Sp. 767-769.

177 Zur Neustadt Hanau ausführlich Heinrich Bott, Gründung und Anfänge der Neustadt Hanau 1696-1620, Bd. 1: Die Gründung der Neustadt Hanau 1596-1601. Darstellung und ausgewählte Quellen, Marburg 1970. Knapp auch Stoob, Städtetypen, S. 208-210; Dölemeyer, Hugenotten, S. 131f.; und Rosseaux, Städte, S. $40 f$.

$178 \mathrm{Zu}$ Mannheim Armand Baumann, Zur Geschichte Mannheims und der Pfalz. Pläne und Bilder aus der Sammlung des Mannheimer Altertums-Vereins, Mannheim 1897; Friedmann, AltMannheim, S. 7f.; Klaus Merten, Residenzstädte in Baden-Württemberg im 17. und 18. Jahrhundert, in: Michael Maaß/Klaus W. Berger (Hg.), »Klar und lichtvoll wie eine Regel«. Planstädte der Neuzeit vom 16. bis zum 18. Jahrhundert, Karlsruhe 1990, S. 221-230, hier S. 222. 
niederländische Remonstranten, die von Herzog Friedrich III. von Gottorf Privilegien für den Bau einer neuen Stadt erhielten. ${ }^{179}$

In anderen Fällen gingen die Entscheidung zum Bau einer neuen Stadt und deren Planung einer systematischen Anwerbung von Neubürgern voraus. Dies lässt sich etwa für Freudenstadt feststellen: Hier stand die Entscheidung zur Neugründung im Zusammenhang mit der wirtschaftlichen Erschließung des Schwarzwaldes und mit den politischen Ambitionen des Herzogs von Württemberg im Elsass. Erst nach der Fertigstellung der Pläne und im Kontext des Gründungsaktes 1599 folgten gezielt Werbungen unter den Protestanten in Österreich. ${ }^{180}$ Glückstadt in Holstein ist ein anderes Beispiel. Auch hier rundete die Gründung einer Stadt die wirtschaftliche Erschließung des Landes, in diesem Fall eines seit 1615 eingedeichten Gebietes ab, die zugleich als politische und militärische Operationsbasis König Christians IV. von Dänemark dienen sollte. ${ }^{181}$ Zugleich mit den Planungsarbeiten warb der König um "gute und vermögende leute, so das newe angefangene städtlein [...] aufbauen mügen « ${ }^{182}$ In der Folgezeit siedelten sich Arbeiter und Soldaten aus der näheren Umgebung, aber auch portugiesische Juden sowie Remonstranten und Mennoniten aus den Niederlanden in der Stadt an. ${ }^{183}$

Nach dem Dreißigjährigen Krieg wurden weitere Neustädte gegründet, die im engen Zusammenhang mit der Ansiedlung von Einwanderern standen und denen dieselben Prinzipien zugrunde lagen. Kurfürst Johann Georg von Sachsen gründete 1654 für böhmische Einwanderer, die bereits in ihrer Heimat als Bergleute tätig waren, die Bergbaustadt Johanngeorgenstadt - außer dem kleineren Neusalza in der Oberlausitz die einzige städtische Neugründung für böhmische `Exulanten` in Sachsen. ${ }^{184}$ Weitaus bekannter als Exulantenstadt dürfte hingegen die Neustadt Erlangen sein, die von Markgraf Christian Ernst von Brandenburg-Bayreuth im Zuge der $\mathrm{Hu}$ genotteneinwanderung gegründet wurde. Nachdem zunächst eine Ansiedlung der Franzosen in Neustadt an der Aisch oder Baiersdorf erwogen worden war, fiel im Sommer 1686 die Entscheidung, südlich der Altstadt Erlangen eine völlig neue Stadt

179 Carl A. Carstensen, Die Gründung und anfängliche Entwicklung von Friedrichstadt an der Eider, Diss. Kiel 1913.

180 Überblick in: Planstadt Kurstadt Freudenstadt. Chronik einer Tourismusstadt, hg.v. Stadtarchiv Freudenstadt, Karlsruhe 1999.

$181 \mathrm{Zu}$ den Motiven Christians IV. vgl. Gerhard Köhn, Die Bevölkerung der Residenz, Festung und Exulantenstadt Glückstadt von der Gründung 1616 bis zum Endausbau 1652, Neumünster 1974, S. 24-26.

182 Aus einem Werbungsschreiben Kg. Christians IV. von Dänemark aus dem Jahr 1616, hier zitiert nach Köhn, Bevölkerung, S. 22.

183 Köhn, Bevölkerung, S. 22f. und 45-63.

184 Frank Teller, Bergbau und Bergstadt Johanngeorgenstadt (1654-1945), Johanngeorgenstadt 2001, S. 8-12; Alexander Schunka, »St. Johanngeorgenstadt zu kurfürstlicher Durchlaucht unsterblichen Nachruhm«. Stadtgründung und städtische Traditionsbildung in der Frühen Neuzeit, in: Neues Archiv für Sächsische Geschichte, 74/75. 2003/2004, S. 175-205; Rosseaux, Städte, S. 40. 
zu errichten. Schon die geometrisch gestaltete Gesamtanlage bringt die Ambitionen der Regierung und das Streben nach Prestige deutlich zum Ausdruck. Dieser Aspekt wurde 1708 durch die Erhebung der Stadt zur Nebenresidenz und bereits in den Jahren 1700 bis 1704 durch den Bau des Schlosses zusätzlich betont, was der Stadt freilich einen von der ursprünglichen Planung abweichenden Charakter gab. ${ }^{185}$

Auch der Bau der Kasseler Oberneustadt erhielt den entscheidenden Anstoß durch die Einwanderung der Hugenotten. Ähnlich wie in Erlangen entstand vor den Toren der Altstadt eine planmäßig ausgebaute barocke Vorstadt nach den Plänen des hugenottischen Architekten Charles du Ry. ${ }^{186}$ Typisch für beide Anlagen ist, dass sich hier ästhetische Vorstellungen mit dem Ziel einer Gewerbe- und Manufaktursiedlung verbanden. In Erlangen etwa wurde eigens ein großes Manufakturhaus eingeplant. ${ }^{187}$ In Kassel entwickelte sich die Oberneustadt zum Wohnort vor allem der kleineren Gewerbetreibenden und der Manufakturarbeiter. ${ }^{188}$ Weitere Beispiele für solche >Hugenottenstädte`, die freilich architektur- und stadtgeschichtlich keinen eigenen Typus bilden ${ }^{189}$, sind etwa Neu-Isenburg oder Karlshafen (beide 1699). ${ }^{190}$ Für alle diese Städte wurde über den Kreis der Hugenotten hinaus in der Folgezeit um weitere Neubürger geworben, etwa für Kassel, wo man Weber und Spinner aus Schlesien ansiedelte. ${ }^{191}$

185 Vgl. zur Planung und zum Bau der Neustadt Erlangen insbesondere Jakob, Neustadt; ders., Die Baugeschichte der Erlanger Neustadt, in: Friederich (Hg.), Hugenottenstadt, S. 192-203. Zur Erhebung zur Residenz und Amtshauptmannschaft sowie zum Schloßbau vgl. Hintermeier, Selbstverwaltungsaufgaben, S. 124; Jakob, Neustadt, S. 66-73.

186 Zur Gründung der Oberneustadt vgl. Alfred Heussner, Die französische Colonie in Cassel, Magdeburg 1903, S. 12f.; Hugo Brunner, Geschichte der Residenzstadt Cassel, Kassel 1913 Ndr. Frankfurt a.M. 1978, S. 203f.; Alfred Giebel, Réfugiés in der Residenzstadt Kassel, in: Desel/Mogk (Hg.), Hugenotten, S. 47-103, hier S. 49; Kadell, Hugenotten, S. 177; Winfried Bergmeyer, Landgraf Karl von Hessen-Kassel als Bauherr. Funktionen von Architektur zwischen Vision und Wirklichkeit, Münster 1999, S. 184; Dölemeyer, Hugenotten, S. 104.

187 Zum Erlanger Manufakturhaus Jakob, Neustadt, S. 109.

188 Zur Sozialstruktur der Kasseler Oberneustadt vgl. Kadell, Hugenotten, S. 185f., demzufolge der französische Anteil an der Bevölkerung »immer verhältnismäßig gering « geblieben sei.

189 So in aller Deutlichkeit Andreas Jakob, Die barocke Stadtanlage von Karlshafen und ihre europäischen Wurzeln, in: Jahrbuch der hessischen kirchengeschichtlichen Vereinigung, 51. 2000, S. 341, hier S. 5-8; und ders., Die Legende von den >Hugenottenstädten<. Deutsche Planstädte des 16. und 17. Jahrhunderts, in: Maaß/Berger (Hg.), »Klar und lichtvoll wie eine Regel«, S. 181-198. Vorsichtiger in diesem Sinne auch Willi Stubenvoll, Die deutschen Hugenottenstädte, Frankfurt a.M. 1990, S. 192-198.

190 Zum heutigen Bad Karlshafen, das zunächst Sieburg genannt wurde, vgl. Jakob, Stadtanlage; und den Sammelband von Gerd Fenner (Hg.), Landgraf Karl und die Gründung von Karlshafen 1699-1999, Kassel 1999; Dölemeyer, Hugenotten, S. 104. Zu Neu-Isenburg vgl. den Sammelband von Heidi Fogel/Matthias Loesch (Hg.), »Aus Liebe und Mitleiden gegen die Verfolgten«. Beiträge zur Gründungsgeschichte Neu-Isenburgs, Neu-Isenburg 1999; Dölemeyer, Hugenotten, S. 128f.; und Wolfgang Pülm, Neu-Isenburg. Die Entwicklung der Hugenottenstadt, 2. Aufl. Frankfurt a.M. 1999. 191 Vgl. dazu Schmidmann, Kolonie, S. 146; Kadell, Hugenotten, S. 186. 
In anderen Fällen ging der Gründungsakt ohnehin der Anwerbung von Einwohnern voraus. Dies gilt ganz besonders für die neu entstehenden Residenzstädte, wie etwa Neuwied (1662), das zugleich als günstig am Rhein gelegenes Handelsund Gewerbezentrum der kriegszerstörten Grafschaft Wied positive Impulse geben sollte. ${ }^{192}$ Ab 1660 begann auch der Ausbau Potsdams als Zweitresidenz des Kurfürsten Friedrich Wilhelm von Brandenburg. Insbesondere unter König Friedrich II. folgte dann die weitere Ausgestaltung durch den Bau des Schlosses Sanssouci und des Neuen Palais. Zuvor schon war Potsdam unter Friedrich Wilhelm I. zu einem wichtigen Garnisonsstandort geworden. ${ }^{193}$ Auch mit dem Ausbau Berlins wurde in der Zeit Kurfürst Friedrich Wilhelms begonnen, zuerst mit der Befestigung und Privilegierung des Friedrichswerders (1662), dann mit dem Bau der Dorotheenstadt (seit 1673) und der Friedrichsstadt (seit 1688). ${ }^{194}$ Wie bei der schon erwähnten Kasseler Oberneustadt handelte es sich hier um planmäßig angelegte Vorstädte, in denen zahlreiche Einwanderer angesiedelt wurden.

Völlig neue Residenzstädte wurden außer dem schon erwähnten Neuwied mit der Gründung von Ludwigsburg durch Herzog Eberhard Ludwig von Württemberg (seit 1709) oder der `Fächerstadt \Karlsruhe durch Markgraf Karl von Baden-Durlach (seit 1715) geschaffen. ${ }^{195}$ Vor allem wirtschaftlichen Zielen diente der seit 1610 durch die Herzöge von Berg betriebene Ausbau der Stadt Mülheim am Rhein zu einer Gewerbestadt mit eigenem Hafen. Das rechtsrheinische Mülheim wurde bewusst in Konkurrenz zur in Sichtweite liegenden Reichsstadt Köln mit weitgehenden religiösen Freiheiten versehen und lockte daher zahlreiche aus Köln ausgewiesene Reformierte an, die insbesondere in der Textilproduktion tätig waren. ${ }^{196}$ Als reine Manu-

192 Zur Gründungsgeschichte von Neuwied vgl. Grossmann, Wachstum; Ströhm, Herrnhuter Brüdergemeine, S. 39-47; und Volk, Peuplierung.

193 Vgl. Julius Haeckel, Politische und wirtschaftliche Entwickelung im Zeitalter des Absolutismus, in: ders. (Hg.), Geschichte der Stadt Potsdam, Potsdam 1912, S. 31-118; Kunisch, Funktion, S. 73-76; Peter-Michael Hahn, Geschichte Potsdams von den Anfängen bis zur Gegenwart, München 2003, S. 19-82.

194 Erika Schachinger, Die Berliner Vorstadt Friedrichswerder 1658-1708, Köln 1993; dies., Die Dorotheenstadt 1673-1708. Eine Berliner Vorstadt, Köln 2001; Asche, Neusiedler, S. 107. Zur Niederlassung der Hugenotten in den Neustädten Wilke, Kolonie, S. 359-361.

195 Zu Ludwigsburg Merten, Residenzstädte, S. 224-227. Zu Karlsruhe Karl G. Fecht, Geschichte der Haupt- und Residenzstadt Karlsruhe, Karlsruhe 1887; Gottfried Leiber, Städtebau in Karlsruhe - Von der Gründung bis zum Ende der Ära Weinbrenner, in: Leben in der Fächerstadt, Karlsruhe 1991, S. 23-47, hier S. 23-36; Merten, Residenzstädte, S. 225-227; Christina Wagner, Von der Stadtgründung zur großherzoglich badischen Haupt- und Residenzstadt 1715-1806, in: Susanne Asche u.a. (Hg.), Karlsruhe. Die Stadtgeschichte, Karlsruhe 1998, S. 65-189, hier S. 66-115.

196 Zur Lage der Reformierten in Köln Leonhard Ennen, Die reformirte Gemeinde in der Stadt Köln am Ende des sechzehnten Jahrhunderts, in: Monatsschrift für rheinisch-westfälische Geschichtsforschung und Alterthumskunde, 1. 1875, S. 397-438, 493-528. Zur Anfangsphase des Mülheimer Projekts und zum erfolgreichen Widerstand Kölns gegen den Festungsbau Hans-Wolfgang Bergerhausen, Die Stadt Köln und die Reichsversammlungen im konfessionellen Zeitalter. Ein Beitrag zur 
faktur- und Gewerbesiedlung wurde seit 1767 auch das Höchster Neustadtprojekt durch Kurfürst Emmerich Joseph von Mainz betrieben. ${ }^{197}$

Stets war mit der Gründung auch die Werbung um ansiedlungswillige Neubürger verbunden. Oft waren es größere Gruppen, die gezielt angeworben wurden. Neben den Hugenotten, die sich in größerer Zahl etwa in den Berliner Vorstädten niederließen, waren dies wie etwa in Neuwied ${ }^{198}$ Mennoniten, Inspirierte, Herrnhuter und Juden oder wie in Potsdam ${ }^{199}$ Hugenotten, Böhmen, Schweizer, Sachsen, Pfälzer und Niederländer, von denen letztere ein eigenes Viertel erbauten. In Berlin kamen nach den Hugenotten zahlreiche weitere Einwanderergruppen hinzu, die ein ganz erhebliches Stadtwachstum förderten. Typisch war in allen diesen Fällen das Zugeständnis der mehr oder weniger freien Religionsausübung, die im Falle der reichsrechtlich nicht anerkannten Gruppen freilich auf Hausandachten beschränkt werden konnte. In vielen Fällen waren die Neustädte vom Zunftbann befreit oder erhielten eigene Zünfte. Im Falle größerer Einwanderergruppen wie den Hugenotten wurde vielfach auch eine eigene Gerichtsbarkeit und Stadtverwaltung für die Neustadt geschaffen, die dann nach dem Ortsprinzip für alle Bewohner galt. Beispiele hierfür sind etwa Erlangen, Kassel-Oberneustadt, Neuwied oder Karlsruhe. ${ }^{200}$

Darüber hinaus ist stets $\mathrm{zu}$ bedenken, dass gerade die größeren Residenzstädte wie Berlin, Dresden, München und Wien auch ohne aktive Einwanderungspolitik einen erheblichen Bevölkerungszuwachs zu verzeichnen hatten. Der Hof und der anwachsende Beamtenapparat zogen zahlreiche Menschen in die Hauptstadt. Hinzu kamen allerlei Zulieferer, die den Hof mit Luxusgütern und Lebensmitteln versorgten. ${ }^{201} \mathrm{Im}$ Gegensatz zu Berlin und - im geringeren Ausmaß - Dresden sind aktive

korporativen reichsständischen Politik 1555-1616, Köln 1990, 298-305; Joachim Deeters, Pläne und Ansichten zum Ausbau Mülheims in den Jahren 1588 bis 1615, in: Rechtsrheinisches Köln. Jahrbuch für Geschichte und Landeskunde, 19. 1993, S. 1-46.

197 Vgl. dazu Rudolf Schäfer, Förderung von >Handel und Wandel in Kurmainz im 18. Jahrhundert, Frankfurt a.M./Höchst 1968, S. 10-14.

198 Grossmann, Wachstum; Volk, Peuplierung; Ströhm, Herrnhuter Brüdergemeine, S. 47-51, und speziell zu den Herrnhutern ebd., passim.

199 Haeckel, Entwickelung, S. 67-69; Schmelz, Rolle; Silke Kamp, Die verspätete Kolonie. Hugenotten in Potsdam 1685-1809, Berlin 2011.

200 Vgl. für Kassel-Oberneustadt das Stadtprivileg, 17. Februar 1690, gedruckt in Sammlung fürstlich-hessischer Landesordnungen, Bd. 3, S. 348f. Dazu Kadell, Hugenotten, S. 180-182, 187-189, 383f. Zu Erlangen vgl. Hintermeier, Selbstverwaltungsaufgaben, S. 54, 68f., 96f., 124; Rudolf Endres, Selbstverwaltung und Rechtsstellung der Hugenotten in Erlangen (1685-1708), in: Peter Johanek (Hg.), Sondergemeinden und Sonderbezirke in der Stadt der Vormoderne, Köln 2004, S. 173-196, hier S. 185f. Karlsruher Stadtprivilegien von Mgf. Karl von Baden-Durlach, Karlsburg, 24. September 1715, abgedruckt bei Fecht, Geschichte, S. I-IV. Vgl. auch ebd., S. 107-115; Wagner, Stadtgründung, S. 72f. Für Neuwied vgl. Ströhm, Herrnhuter Brüdergemeine, S. 43-47; und Volk, Peuplierung, passim.

201 Vgl. Rosseaux, Städte, S. 31-35; Stoob, Städtetypen (1970), S. $276 f$. 
Anwerbungen von Neubürgern aus den großen Residenzstädten Wien und München kaum bekannt. In München fällt lediglich die Ansetzung zahlreicher neuer Klöster durch den Kurfürsten im Bereich der wachsenden Stadt auf. ${ }^{202}$

Wiederbesiedlung nach Kriegsverlusten, aber auch die Hebung von Handel und Gewerbe - so lässt sich resümieren - waren die wichtigsten Ziele städtischer Kolonisationsmaßnahmen. Kleinere und größere Neusiedlergruppen wurden zumeist in bestehenden Städten zugesiedelt, wobei sie - wie im Fall der Hugenotten oder auch der in Magdeburg angesiedelten >Pfälzer` - bisweilen sogar eigene Stadtverwaltungen und ein eigenes Gerichtswesen erhielten. Doch auch Neustadtgründungen waren in der Frühen Neuzeit keine Seltenheit. Neustädte, meist als geometrische Planstadtanlagen konzipiert, wurden entweder speziell für bestimmte Einwanderergruppen errichtet oder sie gingen der Anwerbung von Neubürgern voraus. Im letzteren Fall handelte es sich oft um Residenzstädte oder andere aus politischen Gründen errichtete Anlagen, für deren Besiedlung gezielt um Einwanderer geworben wurde.

\section{Die Privilegienpolitik und ihre Hintergründe}

Der staatliche Gestaltungsanspruch durch Migrationssteuerung im Kontext der hier vorgestellten Beispiele ist nicht zu übersehen. Die Ansätze, die sich vereinzelt bereits im 16., dann aber vor allem im 17. Jahrhundert erkennen lassen, verstärkten sich im 18. Jahrhundert noch. Im Mittelpunkt standen unverkennbar das wirtschaftliche und bevölkerungspolitische Interesse und damit zusammenhängend die Frage nach der Nützlichkeit von gezielter Einwanderungspolitik. Zu diskutieren ist, inwieweit mit Hilfe der Einwanderungspolitik auch Konfessionspolitik betrieben wurde. Die hier vorgeführten Beispiele haben bereits deutlich gemacht, dass keineswegs immer bevorzugt Angehörige der Glaubensgemeinschaft des Landesherrn angesiedelt wurden. Im Zuge eines von merkantilistischen Vorstellungen beherrschten Wirtschaftsdenkens, das ergänzt wurde durch den Utilitarismus der Aufklärung, waren die Landesherren zunehmend bereit, die konfessionelle Geschlossenheit ihrer Territorien zugunsten ihrer wirtschaftlich-fiskalischen Interessen aufzugeben. Am deutlichsten wird dies sicher bei Friedrich II. von Preußen, dessen bekannte Randglosse (»Alle Religionen seindt gleich und guht, wann nur die leute, so sie profesiren erliche leute seindt, und wen Türken und Heiden kähmen und wolten das

202 Vgl. Manfred Peter Heimers, Die Strukturen einer barocken Residenzstadt. München zwischen Dreißigjährigem Krieg und dem Vorabend der Französischen Revolution, in: Richard Bauer (Hg.), Geschichte der Stadt München, München 1992, S. 211-243, hier S. 222f. 
Land pöpliren, so wollen wier sie Mosqueen und Kirchen bauen ${ }^{203}$ ) in aller Deutlichkeit das agnostische Denken und die konfessionelle Offenheit des Königs offenbart.

Es wird überdies argumentiert, dass gerade ein Fürst wie der Kurfürst von Brandenburg, der als Reformierter ja einer Majorität lutherischer Untertanen gegenüberstand, bestrebt gewesen sei, durch die Ansiedlung reformierter Zuwanderer (Niederländer, Schweizer, Hugenotten) seine eigene Position zu stärken, nicht zuletzt deshalb, weil sich die ständische Opposition auch an konfessionellen Gegensätzen entzündete. ${ }^{204}$ Diese Deutung ist zumindest für die Regierungszeit Kurfürst Friedrich Wilhelms und Kurfürst beziehungsweise König Friedrich III./I. formuliert worden, während die Retablissementpolitik Friedrich Wilhelms I., erst recht aber die Peuplierungspolitik Friedrichs II. offenkundig nicht mehr auf eine Bevorzugung reformierter Einwanderergruppen ausgerichtet war. Doch auch für die frühere Phase sollte der konfessionspolitische Aspekt wohl nicht überbetont werden. Zwar waren die Haupteinwanderergruppen tatsächlich reformiert, doch dürfte sich ihr Einfluss auf die lutherische Bevölkerung und damit auch die Stärkung der landesherrlichen Position in engen Grenzen gehalten haben, weil sie eben in rechtlich segregierten und oft auch örtlich abgegrenzten Gemeinden angesiedelt wurden. Hinzu kam im Falle der Hugenotten, der Niederländer und der französisch-sprechenden Schweizer die sprachliche Isolation. Diese begrenzten Einflussmöglichkeiten dürften auch der Regierung bekannt gewesen sein, sodass der bevölkerungs- und wirtschaftspolitische Zug der Privilegierung wohl deutlich im Vordergrund stand, ohne dass man darüber konfessionelle Solidarität mit den glaubensverwandten >Konfessionsmigranten $\triangleleft$ ausschließen sollte. Inwieweit gerade im brandenburgischen Fall die Übernahme der Rolle der Kurpfalz als protestantische Schutzmacht im Reich symbolisch durch die Aufnahme von protestantischen Migranten zum Ausdruck gebracht werden sollte, wäre noch zu klären.

Ähnliches ist auch zu den in den letzten Jahren verstärkt vorgebrachten ständepolitischen Implikationen der Einwanderungs- und Privilegienpolitik zu sagen. Demnach sei nicht nur in Brandenburg-Preußen die Privilegierung von Einwande-

203 Marginalie zur Zuzugserlaubnis für einen katholischen Kaufmann von 1740, hier zitiert nach Michael Höhle, Friedrich der Große und die Katholiken, in: Michael Drechsler (Hg.), Preußens Toleranz. Zur Integration von Minderheiten in Geschichte und Gegenwart, Berlin 2002, S. 54-60, hier S. 56.

204 Vgl. zu diesem Aspekt Peter M. Hahn, Calvinismus und Staatsbildung. Brandenburg-Preußen im 17. Jahrhundert, in: Meinrad Schaab (Hg.), Territorialstaat und Calvinismus, Stuttgart 1993, S. 239-269, hier S. 268; Thomas Klingebiel, Deutschland als Aufnahmeland. Vom Glaubenskampf zur absolutistischen Kirchenreform, in: Thadden/Magdelaine (Hg.), Hugenotten, S. 85-99, hier S. 97; Frédéric Hartweg, Die Hugenotten in Berlin. Eine Geschichte, die vor 300 Jahren begann, in: ders./Stefi Jersch-Wenzel (Hg.), Die Hugenotten und das Refuge. Deutschland und Europa. Beiträge zu einer Tagung, Berlin 1990, S. 1-56, hier S. 15; Elsner, Pfälzer, S. 69; Dölemeyer, Hugenotten, S. 86; Asche, Neusiedler, S. 132-137, 637-639. 
rern als Instrument sowohl gegen die ständische Opposition als auch gegen ein politisch erstarkendes Bürgertum verwendet worden. Mit privilegierten Einwanderern hätten sich die Landesherren demnach eine Klientel verschafft, die dazu beitragen sollte, die Macht gerade der städtischen Zünfte und der mit diesen verflochtenen Stadtmagistrate aufbrechen zu helfen. Ähnliches habe bei der Ansiedlung ländlicher Einwanderer gegolten: Bäuerliche Rechte seien zunehmend beschnitten worden, wobei auch hier der Privilegierung von Einwanderern eine Schlüsselrolle zugekommen sei. ${ }^{205}$

Auch wenn größere, stark privilegierte Einwanderergruppen tatsächlich eine enge Bindung an den Landesherrn entwickelten, wird hier sicher der politische Wille, gegen die altständischen Korporationen vorzugehen, überschätzt, zumal gerade Konfliktsituationen deutlich machen, dass Entscheidungen der Regierungen keineswegs regelmäßig zum Nachteil einheimischer Korporationen ausfielen. Eine neue, vielleicht insgesamt plausiblere Deutung der Einwandererprivilegien der Frühen Neuzeit ergibt sich, wenn man die Privilegienedikte nicht allein von der Intention der aufnehmenden Landesfürsten her $\mathrm{zu}$ verstehen versucht, sondern wenn man sie als komplexen, multilateralen Aushandlungsvorgang betrachtet, in den die Interessen und Motive unterschiedlicher, an den formellen wie auch informellen Aushandlungsprozessen Beteiligter einflossen. Dann lässt sich die Privilegienpolitik auf die Formel bringen, dass der Umfang der Privilegierung ganz wesentlich davon abhing, wie wünschenswert die Ansiedlung eines bestimmten Personenkreises dem aufnehmenden Fürsten erschien. Je dringender die Niederlassung erwünscht war und je mehr Angebote von anderer Seite es gab, desto besser war die Verhandlungsposition der Kolonisten. Überspitzt kann man also sagen, dass der Umfang der Privilegierung sich nach Angebot und Nachfrage richtete, wobei das

205 Insgesamt zu dieser Argumentation, die zweifellos ihren Schwerpunkt bei der Hugenottenansiedlung in Brandenburg-Preußen hat, z.B. Grieshammer, Studien, S. 39f.; Landgrebe, Minoritätengruppe, S. 130-138; Klingebiel, Deutschland, S. 99; Heinz Duchhardt, Einleitung des Herausgebers, in: ders. (Hg.), Der Exodus der Hugenotten. Die Aufhebung des Edikts von Nantes 1685 als europäisches Ereignis, Köln/Wien 1985, S. 1-7, hier S. 5; Eckart Birnstiel, Die Aufnahme hugenottischer Glaubensflüchtlinge in Brandenburg-Preußen. Ein Akt der Toleranz?, in: Andreas Flick/Albert de Lange (Hg.), Von Berlin bis Konstantinopel. Eine Aufsatzsammlung zur Geschichte der Hugenotten und Waldenser, Bad Karlshafen 2001, S. 9-33, hier S. 19f.; Michael Maurer, Mit Ausländern Staat machen? Glaubensflüchtlinge im Absolutismus, in: Essener Unikate, 6/7. 1995, S. 74-85; Thadden, Hugenotten, S. 105f.; Andreas Reinke, Die Kehrseite der Privilegierung. Proteste und Widerstände gegen die hugenottische Niederlassung in den deutschen Territorialstaaten, in: Comparativ. Leipziger Beiträge zur Universalgeschichte und vergleichenden Gesellschaftsforschung, 7. 1997, S. 39-52, hier S. 41, 49f., 53-55; ders., »Man fügt ihnen unendlich Schmach zu«. Proteste und Widerstände gegen die Hugenotten in den deutschen Staaten, in: Beneke/Ottomeyer $(\mathrm{Hg})$, Zuwanderungsland, S. 65-72, hier S. 66, 69f., 72; Matthias Dahlke, "Aus gerechtem Mitleiden«? Zu den Motiven des Großen Kurfürsten zum Edikt von Potsdam, in: Hugenotten, 69. 2005, S. 107-129, hier S. 117-120, Asche, Neusiedler, S. 450, 458. 
Religionsausübungsrecht, steuerliche Vorteile und Starthilfen geradezu notwendige Elemente der Kolonistenanwerbung waren. Bei den Hugenotten wird dies ganz deutlich. ${ }^{206}$ In einer weitaus schwächeren Position befanden sich etwa Juden und Mennoniten, die zumeist zufrieden sein konnten, wenn sich überhaupt ein Aufnahmeland fand, in dem sie sich niederlassen und in Frieden leben konnten.

In der praktischen Durchführung blieben die Regierungen immer auf die Mitarbeit lokaler Instanzen und auf die Akzeptanz in der Bevölkerung angewiesen. Dass Widerstände seitens der Bevölkerung beziehungsweise seitens einheimischer Korporationen nicht eskalierten, ist sicher auch darauf zurückzuführen, dass Reibungsflächen durch separierte Ansiedlungen oder durch die rechtliche Segregation größerer Einwanderergruppen wie der Hugenotten stark minimiert wurden. Zudem reagierten die Regierungen auf Widerstände oft nachgiebig und bemühten sich, Toleranzgrenzen bei der Bevölkerung nicht zu überdehnen. Für die Regierungen bedeutete dies eine Gratwanderung zwischen den eigenen Peuplierungsinteressen und damit den Ansprüchen möglicher Kolonisten auf der einen und den Interessen der ansässigen Bevölkerung auf der anderen Seite. Die Ausformung der Ansiedlungsbedingungen bewegte sich zwischen diesen Polen und stellt sich auch als Prozess des Ausprobierens dar.

206 Vgl. dazu Niggemann, Immigrationspolitik, S. 80-100, 536-539 und passim; ders., Hugenotten in Brandenburg-Bayreuth, S. 123f. 